\title{
Convergence or Divergence in the EMU?
}

Author: $\quad$ Marcus Wortmann

Thesis Committee: Prof. Dr. Renate Ohr

Prof. Dr. Gerhard Rübel

Prof. Dr. Robert Schwager

Dissertation

in order to acquire the doctoral degree

from the Faculty of Economic Sciences

at Georg-August-Universität Göttingen

Göttingen, 2018 



\section{Danksagung}

Für die Unterstützung, die ich von vielen Menschen während der Erstellung meiner Dissertation erhalten habe, möchte ich mich an dieser Stelle herzlich bedanken. Zunächst gilt mein besonderer Dank Frau Prof. Dr. Renate Ohr, die mir die Möglichkeit gab, an ihrem Lehrstuhl zu arbeiten und eine Doktorarbeit zu verfassen. Dabei konnte ich mich in den vergangenen fünf Jahren und selbst während ihres Ruhestands jederzeit voll und ganz auf ihre umfassende Betreuung verlassen. Für die zahllosen fachlichen und persönlichen Gespräche sowie die überaus vertrauensvolle Zusammenarbeit an ihrem Lehrstuhl bin ich sehr dankbar. Insgesamt werde ich immer gerne auf diese lehrreiche und schöne Zeit in Göttingen zurückblicken.

Auch bei Herrn Prof. Dr. Gerhard Rübel und Herrn Prof. Dr. Robert Schwager bedanke ich mich herzlich für die konstruktive Betreuung und die Bereitschaft zur Teilnahme an meiner Prüfungskommission. Zum Gelingen einzelner Kapitel dieser Arbeit haben zudem meine KoAutoren Markus Stahl, Dr. Markus Ahlborn sowie Prof. Dr. Tino Berger erheblich beigetragen, denen ich für die vertrauensvolle und freundschaftliche Zusammenarbeit einen ganz besonderen Dank aussprechen möchte. Auch meine Kollegen, insbesondere Julia Richter, Christin Stückrath, Oliver Saffran und Jonas Geppert, haben mir jederzeit verlässlich mit Rat und Tat zur Seite gestanden und für eine angenehme und humorvolle Arbeitsatmosphäre an den Lehrstühlen gesorgt. Für seine vielen fachlichen und persönlichen Ratschläge gilt mein herzlicher Dank ebenso Dr. Jörg König.

Schließlich wäre diese Dissertation ohne den bedingungslosen Rückhalt meiner Freundin, meiner Familie und meiner engsten Freunde sicherlich nicht entstanden. Dafür bedanke ich mich bei allen und insbesondere bei meinen Eltern Annette und Michael sowie bei meinem Bruder Martin von Herzen, die mich stets bei meinen Vorhaben und Herausforderungen auf vielfältigste Weise unterstützt haben. Mein größter Dank gilt dabei meiner Freundin Vanessa, die mich während der langen Zeit, in der ich häufig getrennt von ihr in Göttingen gearbeitet habe, uneingeschränkt bestärkt, mir den Rücken frei gehalten und sich in herausragender Weise um unseren Sohn Mika gekümmert hat. Die gemeinsame Zeit an den Wochenenden und die Liebe, die die beiden mir entgegengebracht haben, waren für mich von unschätzbarem Wert. In Dankbarkeit und Anerkennung widme ich ihnen diese Arbeit. 



\section{Contents}

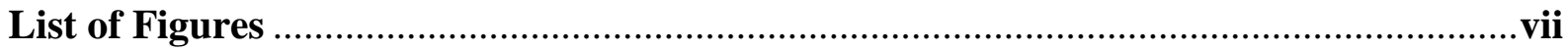



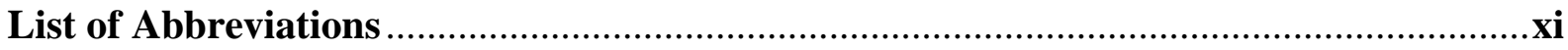

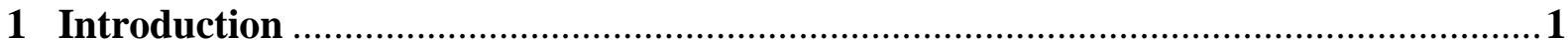

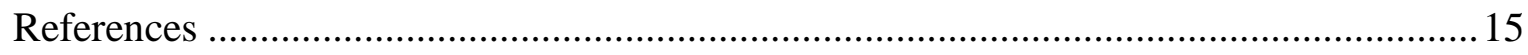

2 One Size Fits Some: A Reassessment of EMU's Core-periphery Framework ............21

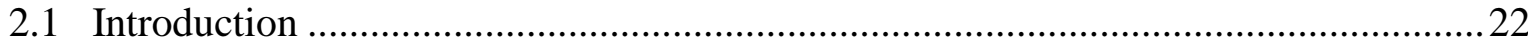

2.2 Macroeconomic Imbalance Procedure ………………………………………….......2

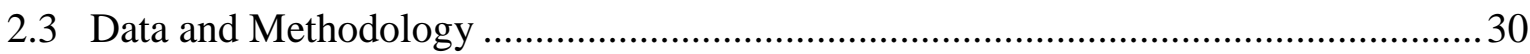



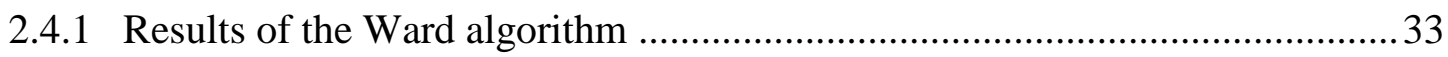

2.4.2 Results of the Fuzzy C-means algorithm ......................................................... 37

2.4.3 Indicators defining the core and the periphery ……………………………....... 39

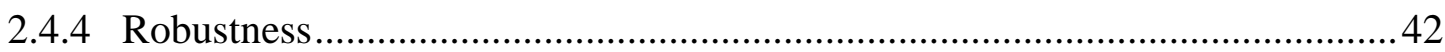

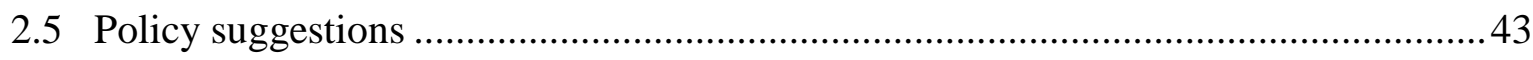

2.5.1 Suitability for EMU membership ............................................................... 43

2.5.2 Achieving greater homogeneity in the EMU ……………………………..... 45



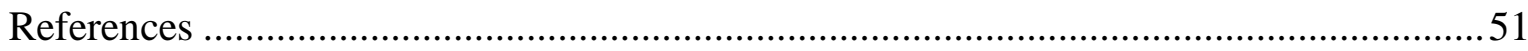

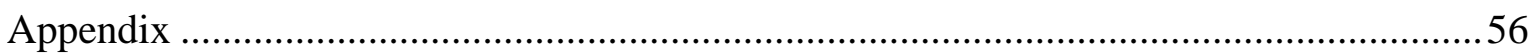

3 The core-periphery pattern of European business cycles: A fuzzy clustering

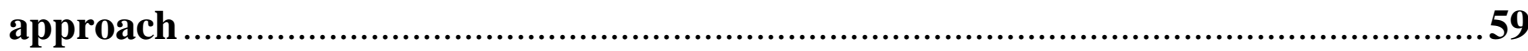

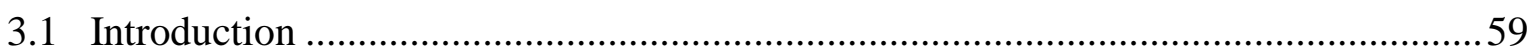



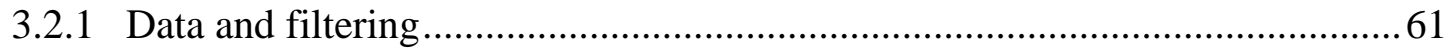



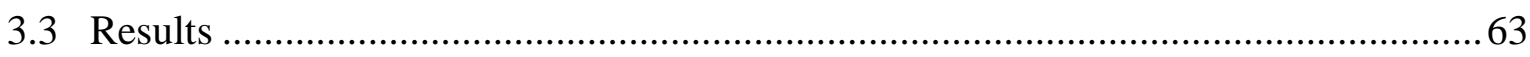

3.3.1 Business cycle clusters in Europe, 1996-2015 ……………………………....63

3.3.2 The relationship between core and peripheral business cycles ..........................65

3.3.3 The core and periphery before and after the crisis ............................................67 67 


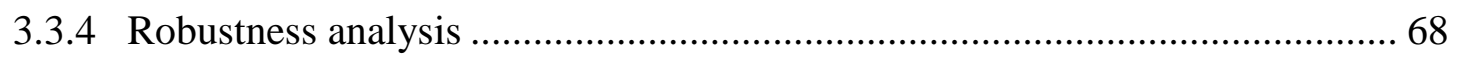

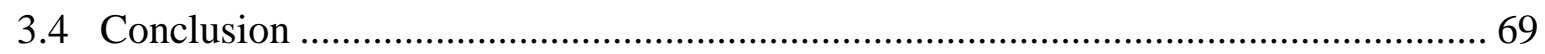

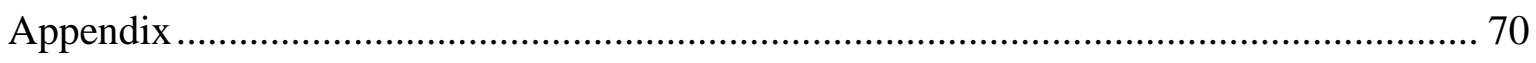



4 Global vs. group-specific business cycles: The importance of defining the groups .... 75

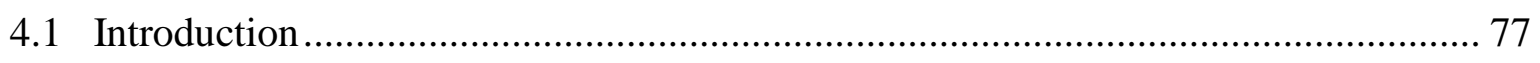

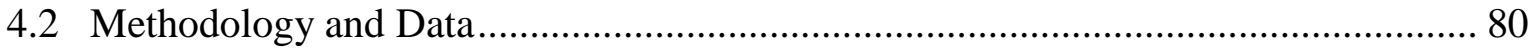

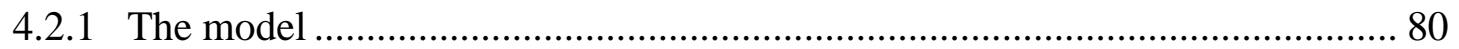

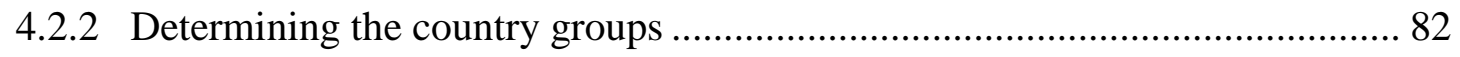

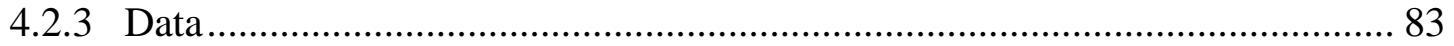

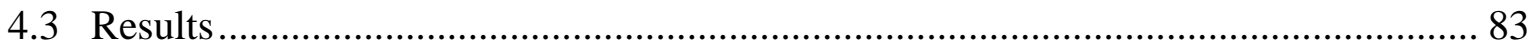

4.3.1 The country group pattern of international business cycles ......................... 83

4.3.2 The importance of the group specification in DFM ..................................... 85

4.3.3 Changing country group pattern and implications for the 'decoupling' trend 87

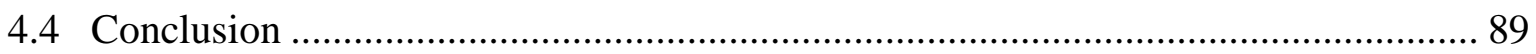

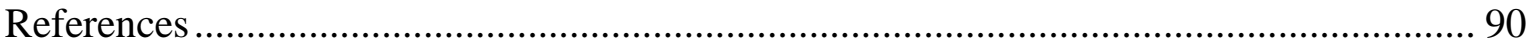



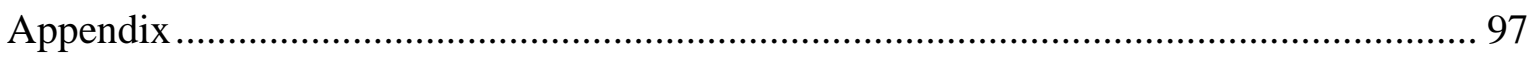

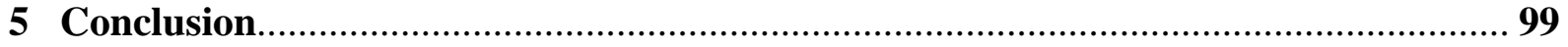




\section{List of Figures}

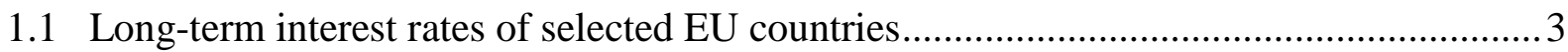

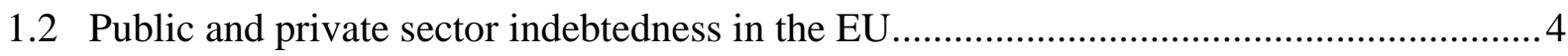

1.3 Real GDP growth rates of selected EU countries .....................................................4

1.4 Current account balances and unit labor costs of selected EU countries ........................5



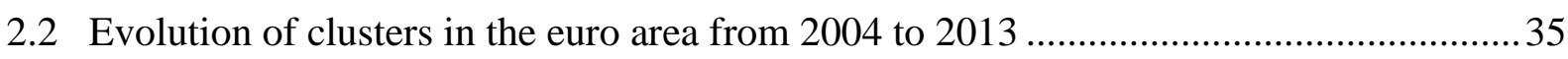

2.3 Country groups according to the first two principal components ................................. 43

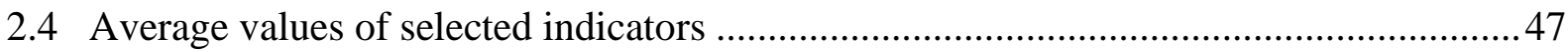

2.5 Appendix 1: Dendrogram of the cluster analysis for the EU in 2013 ............................56

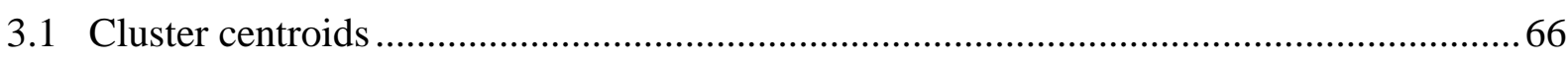

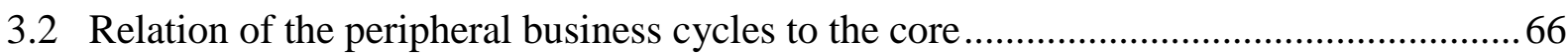

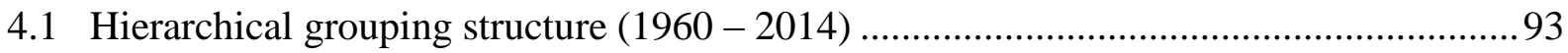



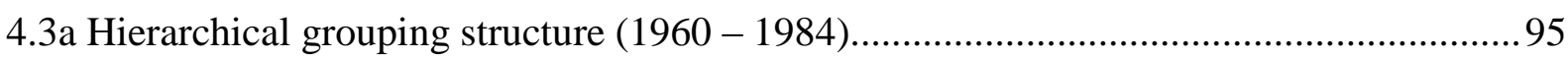

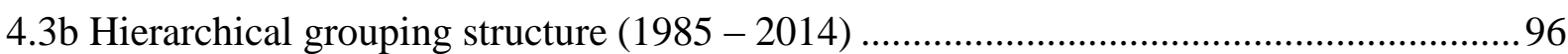





\section{List of Tables}

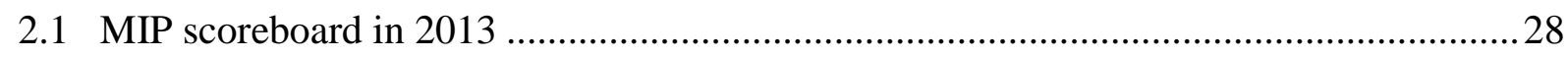

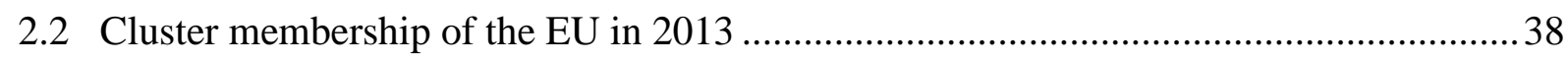

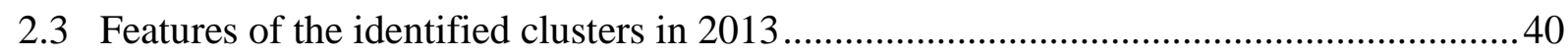

2.4 Appendix 2: Correlation matrix and cumulative variances ..........................................57

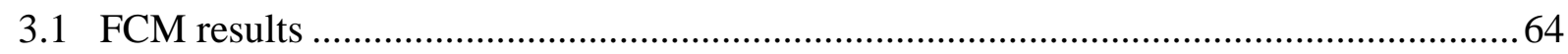

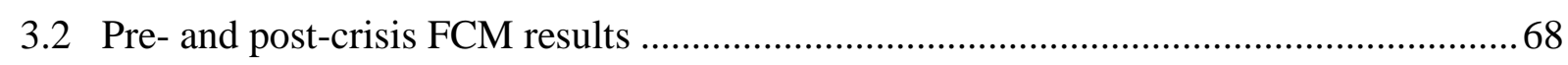

3.3 Appendix Table A1: FCM results, output gaps extracted using the Hodrick-Prescott

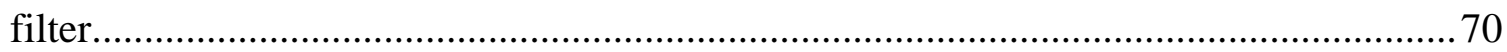

3.4 Appendix Table A2: FCM results, including the USA, Japan and Korea ....................... 71

3.5 Appendix Table A3: Results for hierarchical clustering using weighted average



3.6 Appendix Table A4: FCM results based on the Manhattan distance norm..................... 72

3.7 Appendix Table A5: Pre- and post-crisis FCM results, excluding 20 08/20 09.............. 72

4.1 Variance decompositions using different country groupings for the full sample period (1960 - 2014)

4.2 Variance decompositions using different country groupings for sub periods 1960 -

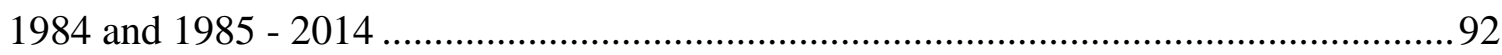

4.3 Appendix Table A1: List of countries and attribution to groups ................................... 97

4.4 Appendix Table A2: Optimal number of clusters within all periods ..............................98 



\section{List of Abbreviations}

\begin{tabular}{|c|c|}
\hline CEEC & Central and Eastern European country \\
\hline $\mathbf{C F}$ & Christiano Fitzgerald (filter) \\
\hline CME & Coordinated market economy \\
\hline DE & Developing economy \\
\hline DFM & Dynamic factor model \\
\hline EA & Euro area \\
\hline ECB & European Central Bank \\
\hline EM & Emerging market \\
\hline EMU & (European) Economic and Monetary Union \\
\hline $\mathbf{E U}$ & European Union \\
\hline FCM & Fuzzy c-means \\
\hline GDP & Gross domestic product \\
\hline GIIPS & Greece, Ireland, Italy, Portugal, Spain \\
\hline GIPS & Greece, Ireland, Portugal and Spain \\
\hline HICP & Harmonized Index of Consumer Prices \\
\hline HP & Hodrick Prescott (filter) \\
\hline IE & Industrialized economy \\
\hline MIP & Macroeconomic Imbalance Procedure \\
\hline OCA & Optimum currency area \\
\hline OECD & Organisation for economic co-operation and development \\
\hline PCA & Principal Components Analysis \\
\hline SGP & Stability and growth pact \\
\hline UK & United Kingdom \\
\hline USA & United States of America \\
\hline
\end{tabular}





\section{Chapter 1}

\section{Introduction}

The past decade has dramatically shaped the European economic landscape. After the global financial and economic crisis of 2008/09 hit the continent, the southern European periphery exemplified by Greece experienced a strongly diverging economic development. As capital inflows from the North dried up, the highly indebted southern euro countries running large current account deficits provoked fears of contagious sovereign defaults. The EU responded to the subsequently escalating 'euro crisis' with a series of institutional adjustments including the hitherto unwanted bail-out opportunities for individual member states. While these reforms were meant to strengthen supra-national capacities and cohesion, in 2016, UK citizens rather decided to exit the EU as the first country in history and being one of its economically powerful member states in the North. However, the corresponding heated debates about 'Grexit' and 'Brexit' on opposite sides of Europe also reflected the rising overall skepticism about the benefits from economic and monetary integration. Similar discussions across EU member states in fact created the impression that the European unification sooner or later might drift apart.

Against this backdrop, the question of economic convergence or divergence within the European Economic and Monetary Union (EMU) came back into political and academic focus. It is of key importance, as in the absence of economic homogeneity, particularly between the so-called 'core' and the 'peripheral' countries, any supranational policy will most likely continue to favor some countries at the expense of others, thereby giving rise to political disruption and nationalist tendencies. The present dissertation is an attempt to highlight some of the underlying group-dynamic con- and divergences in macroeconomic developments within the EMU in order to provide data-based guidance for national and European policy makers. To understand the root causes of the current situation and the choice of economic indicators, however, some historical developments have to be set in context first.

Over the past quarter century, the EU has substantially extended both its membership and the policy fields, over which it is responsible. From the original EU-12 when the Maastricht Treaty came into force in 1993, the Union expanded into the North in 1995 and over the 12 mainly Central and Eastern European countries (CEECs) in 2004 and 2007. Finally, Croatia has been welcomed as its newest and $28^{\text {th }}$ member state in 2013. At the same time, more and more 
formerly national competences have been shifted towards the supranational level, with the establishment of the EMU being the most prominent and far-reaching unification so far including the single monetary policy of 19 euro area (EA) members under the head of the European Central Bank (ECB). According to applied legislation, all EU member states should at some point in the future adopt the Euro as the common European currency ${ }^{1}$ so that a fully integrated internal market of about 500 million European citizens can unfold its full potential.

Although the aim of this unique integration project has ever been economic convergence and overall prosperity, ${ }^{2}$ the rapid simultaneous expansion and deepening processes have brought about substantial economic and political discrepancies, most evidently regarding the monetary integration of the southern and eastern European 'peripheries' and the 'core' countries in the North. ${ }^{3}$ While the prospects of a single monetary union had been heavily debated within the latter country group ${ }^{4}$ and beyond, ${ }^{5}$ among the southern weak currency countries, the belief in the benefits of a common currency prevailed. The hope was to profit from greater stability and lower interest rates that facilitate investing and overall catching-up to the core countries once national currencies were abandoned.

\section{Growing imbalances between the original EA-12}

In fact, when the Euro was introduced as the third step of EMU in 1999, the GIIPS countries had already benefitted from the associated decline in long-term interest rates (Figure 1). From

\footnotetext{
${ }^{1}$ Exceptions are Denmark and the UK, who negotiated an opt-out of the monetary integration. In fact, as has been done by Sweden, the otherwise mandatory euro introduction can also be postponed rather artificially by not fulfilling the conditions of membership set out in the Maastricht Treaty.

${ }^{2}$ These goals were proclaimed in the preambles of the Treaties on European Union and the Functioning of European Union.

${ }^{3}$ Although the present dissertation attempts to define each countries' belongingness to these groups more specifically, for reasons of simplicity, the remainder of this introduction refers to those selected EU member states that have been most commonly used in the literature to represent the core and the peripheries. Accordingly, Figures 1 to 4 display the development of Germany representing the supposed core countries in Central Europe. While the eastern periphery is represented by the EU-8 accession countries (Poland, Czech Republic, Slovakia, Slovenia, Hungary, Estonia, Latvia, and Lithuania) among the CEECs, the southern periphery is summarized together with Ireland as the GIIPS countries (Greece, Italy, Ireland, Portugal, and Spain) or GIPS without Italy. However, it should be noted that there is still remarkable heterogeneity within these groups, which is discussed more closely in the next chapters.

${ }^{4}$ While French and German political leaders promoted Europe's monetary integration for political reasons, British and Danish politicians decided against such a loss of national sovereignty. Nonetheless, many German economists publicly warned against the too early inception of the Euro for manifold economic reasons (see Ohr and Schäfer (1992) and Kösters et al. (1998) for two manifests against the EMU resolutions).

${ }^{5}$ Jonung and Drea (2010) offer an overview of American economists' views on the prospects of EMU.
} 
the high levels of the early 90s, those countries' long-run interest rates converged to the same low levels of the core countries, indicating that henceforth no individual country risks were seen for any EA member state. Remarkably, this was despite the no-bail-out legislation that had been put in place in the Maastricht Treaty, but did not possess the necessary credibility to ensure continuity of country-specific risk premia.

Figure 1: Long-term interest rates of selected EU countries



Notes: Eurostat data, monthly long-term government bond interest rates, own representation.

With decreasing costs of borrowing and rising private sector debt-to-GDP ratios (Figure 2), capital started to flow from the core countries mainly into the GIIPS countries' non-tradable sector, causing the demand-driven economic boom of the early 2000s visible in Figure 3. Although this was perceived in line with the expected real catching-up (Blanchard and Giavazzi 2002), in fact little had been invested to repay the borrowed capital in the future. Instead, the cheap credits were largely used to finance public and private sector consumption (Baldwin et al. 2015). At the same time, wages and prices increased to uncompetitive levels compared with the North that were not justified by an equivalent rise in productivity. While nominal unit labor costs climbed up accordingly, imports increased and exports were restrained in the South. As seen in Figure 4, this led to substantial competitiveness and current account imbalances between the core and the southern periphery, which could no longer be resolved by an exchange rate mechanism. ${ }^{6}$

\footnotetext{
${ }^{6}$ See, for instance, Jaumotte and Sodsriwiboon (2010), Chen et al. (2012), Frankel (2015), Kang and Shambaugh (2016), and Baldwin et al. (2015) who provide a conclusive view of many leading economists on the rising imbalances and their impacts within the EA.
} 
Figure 2: Public and private sector indebtedness in the EU

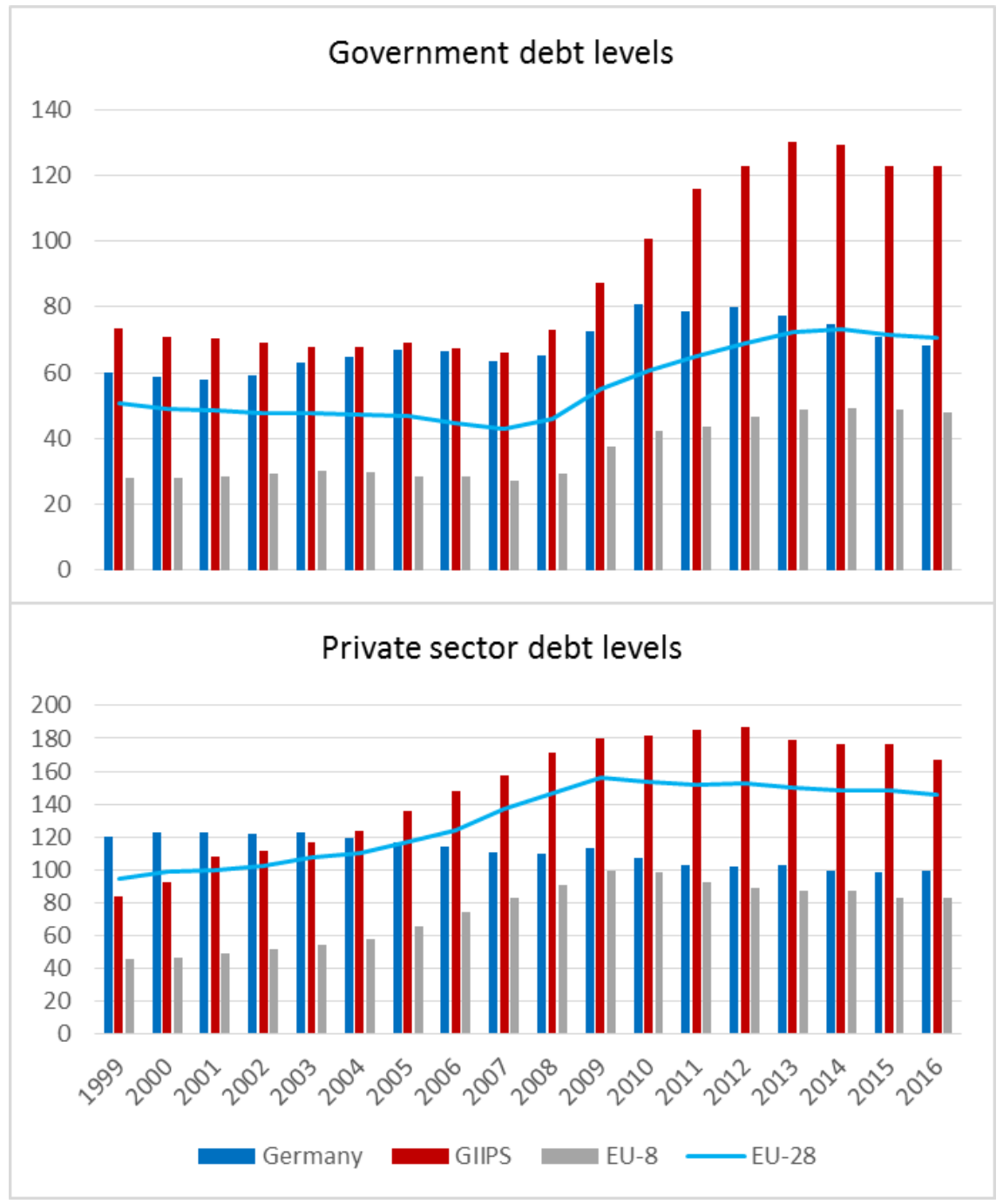

Notes: Eurostat data, consolidated government and private sector debt levels in percent of GDP, country group averages, own representation.

Figure 3: Real GDP growth rates of selected EU countries

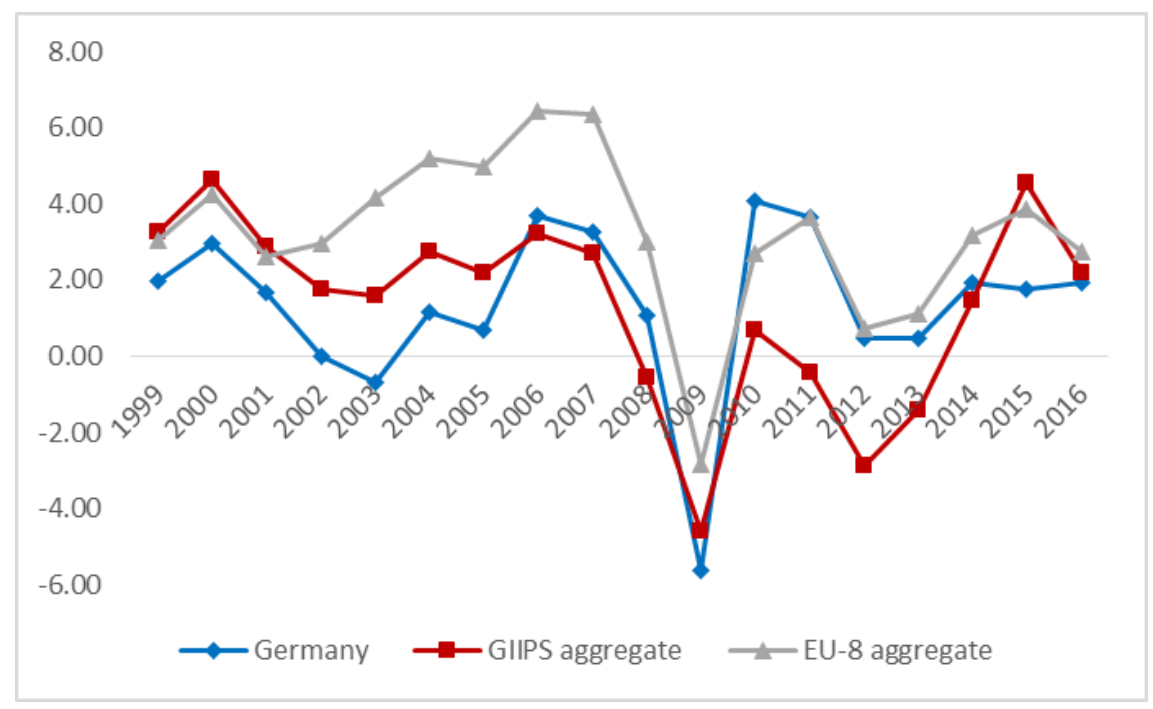

Notes: Eurostat data, annual real GDP growth rates, own representation. 
Figure 4: Current account balances and unit labor costs of selected EU countries

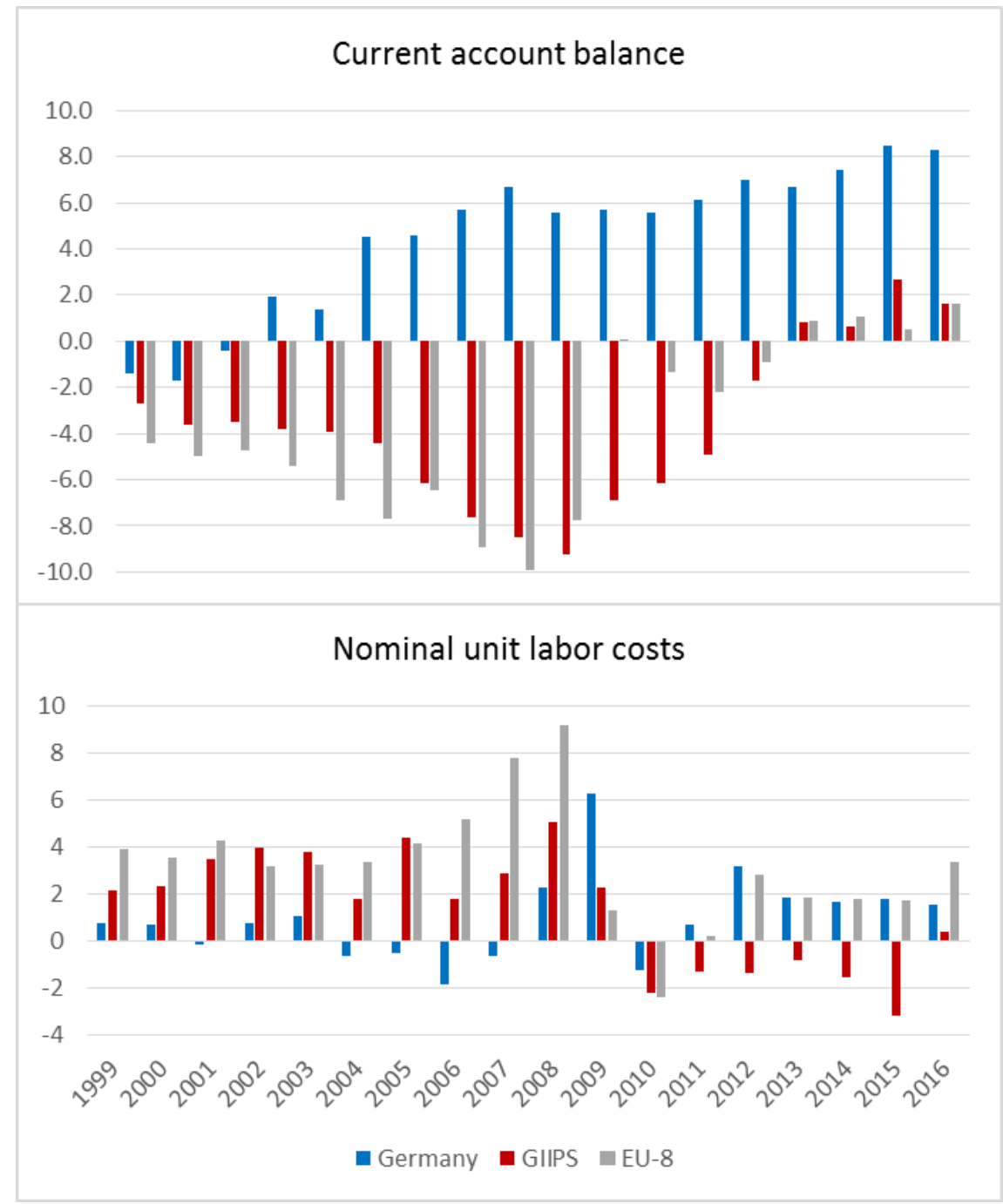

Notes: Eurostat data, annual current account balances in percent of GDP and annual growth rate of nominal unit labor costs, country group averages, own representation.

\section{The impact of the global financial and economic crisis $2008 / 09$ and the euro crisis}

With the outbreak of the global financial crisis in 2007, the situation worsened dramatically, as price bubbles especially in the Irish and Spanish real estate market burst and led to bank defaults and state rescue measures. Across European economies, extensive economic programs were put in place to fight the subsequent deep global recession of 2008/09 and avoid system-relevant bankruptcies, which drastically increased government debt levels from 2008 onwards. Figure 2 illustrates that not only did overall public indebtedness increase in every direction, but also the deviations between the core and the peripheries widened. After Greece had declared its real fiscal deficits in late 2009, the acute crisis of the EA then broke out as capital flows came to a sudden halt and investors started again to impose risk premia on countries that were considered 
to be on a similarly unsustainable path and prone to contagion (Baldwin et al. 2015). As seen in Figure 1, the interest rates on long-term government bonds spread again, pushing the recapitalization costs of the GIIPS countries to extremely high levels. Consequently, these countries were threatened by government default in an already recessionary and deflationary situation marked by low external competitiveness, heavily indebted banks, high unemployment, and no individual exchange rate policy at hand. What is often labelled the European government debt crisis (Lane 2012), can thus also be seen in a broader perspective as mutually reinforcing banking-, debt-, and growth crises fundamentally linked with the construction of the EA and the unfolding of earlier imbalances (Shambaugh 2012; Frankel 2015; Eichengreen 2015). This was reflected in the growth rates of real GDP as the GIIPS countries, in contrast to the core, experienced another prolonged downturn after the immediate slump of 2008/09 (Figure 3).

Hence, to reverse the lingering discrepancies in competitiveness and growth, structural reforms, internal devaluations (Tressel et al. 2014; Salvatore 2015), and austerity in the GIIPS countries (Feldstein 2015), but also other options like the Greece exit from the EA ('Grexit') or even a breakup of the EA (Eichengreen 2010) were intensively debated. On the other hand, the Eastern periphery did experience a quite similar development of high current account deficits, unit labor costs growth, private sector debt accumulation through large capital inflows, and sustained demand-driven growth over the first decade of the Euro (Figures 1 to 4). However, while maintaining individual exchange rates, these countries overcame the partly severe recession impacts remarkably fast. ${ }^{7}$

\section{Supra-national policy response and adjustment}

This 'euro crisis' put the ECB in front of immediate challenges in terms of financial stability and the survival of the Euro, as well as the permanent dilemma of finding an optimal 'one-sizefits-all' monetary policy for the whole EA, which has been divided into the struggling southern periphery and the faster recovering countries in the North and East (Figure 3). In 2012, while already conducting an expansive monetary policy in favor of the southern periphery, the ECB President Mario Draghi claimed to 'do whatever it takes to preserve the Euro.' In reaction to his pledge and the respectively announced 'outright monetary transactions' program, indeed, the spread in government bond yields started to decrease again without any real intervention

\footnotetext{
${ }^{7}$ Slovenia first introduced the Euro in 2007 and was followed by Slovakia in 2009, Estonia in 2011, Latvia in 2014 and finally Lithuania in 2015. Bakker and Klingen (2012) provide a comprehensive analysis of the pre- and post-crisis developments in the CEECs.
} 
(Figure 1). Nonetheless, as the standard mechanism had been exhausted at the zero lower bound, the ECB subsequently followed other central banks in adopting unconventional monetary policies for the EA. ${ }^{8}$ Additionally, the EU introduced a body of policy measures and new governance tools (financial aid packages, European Stability Mechanism, 'Six Pack' measures, European Semester, Macroeconomic Imbalance Procedure (MIP), Fiscal Compact, European banking union, Juncker Plan, among others) aimed at supporting the southern periphery as well as resolving the current and preventing future crises. ${ }^{9}$

The fiscal bail-outs and the unconventional monetary policy of recent years, however, have provoked a lot of criticism primarily on the side of the core countries. Besides the discussions about the central bank's capacity of avoiding high future inflation and asset price bubbles, as well as its general appropriateness for maintaining financial stability, ${ }^{10}$ it is feared that keeping interest rates low and opening bail-out opportunities could induce serious moral hazards undermining the will to reform (Feldstein 2015). In recent years, however, it can be seen from Figures 1 to 4 that the situation seems somewhat improved, as external imbalances between the core and the periphery appear to reverse, unit labor costs fell in the GIIPS and, even though late, growth returned along with decreasing debt-to-GDP ratios. Whether these adjustments are sustained and stem from adequate policies and the stipulated structural changes (Varga et al. 2013; ECB 2015b; European Commission 2016) or rather come from cyclical factors (Tressel and Wang 2013; Tressel et al. 2014) is debatable and should be differentiated by country. ${ }^{11}$

\section{Is the European integration project at risk?}

Among many other reasons, the recent crisis experience and the contentious response of the EU (dominated by 19 EA member states) may have been one factor that fueled the British skepticism against Brussels and Frankfurt and led to the 'Brexit'-decision in 2016. In fact, the prolonged economic malaise in Europe, which is perceived to have lasting impact for the living standard of whole generations, fostered negative attitudes against the EU and the Euro not only in Britain. It seems that it even paved the way to a new wave of nationalism, giving rise to

\footnotetext{
${ }^{8}$ See Joyce et al. (2012) for an introduction to unconventional monetary policy and ECB (2015a) and Driffill (2016) for a discussion of the ECB measures and their impacts.

${ }^{9}$ See the website of the European Commission (2018) for details and timeline of the reformed economic governance framework.

${ }^{10}$ See, e.g., Smets (2014), Borio and Zabai (2016), and Blot et al. (2017) who provide overviews of the vast literature.

${ }^{11}$ See Kang and Shambaugh (2016) who provide detailed discussions of the unwinding of external imbalances.
} 
populist parties in almost every member state that seek to end or even reverse the economic integration process (Baldwin et al. 2015). As resolving the crisis may require even closer integration, it remains to be seen if the necessary fortitude of European identities among the 'winners' from integration will outweigh the national tendencies of those who are supposedly not benefitting or worse. ${ }^{12}$ At least, the attractiveness of the Euro for candidate countries like Poland has suffered noticeably, as membership has been postponed indefinitely into the future. But, also within the current EA, diverse economic conditions and hence opinions over the proper reforms may foster imperfect crisis solutions and constitute once again new impediments to a smoothly operating future EMU. ${ }^{13}$

\section{Assessing and achieving convergence within EMU}

As summarized above, the question of convergence or divergence of macroeconomic parameters among a diverse set of $28 \mathrm{EU}$ countries is crucial for a smoothly operating monetary union and the future integration process as a whole. While the catching-up of lower-income peripheral member states certainly implies transitory divergence of some variables, the euro crisis highlighted clearly that a high degree of real and nominal homogeneity among the participating EA countries is important for both maintaining financial stability and finding a 'one size fits all' monetary policy for the core and the periphery. The purpose of this dissertation is therefore to empirically assess how the group-dynamic convergences and divergences in European macroeconomic developments affect the efficiency and stability of EMU. From a policy perspective, exploring the evolving homogeneities among individual countries and groups in the data is important for two main reasons. First, it provides the basis for pursuing adequate supra-national policies aimed at achieving convergence within and beyond the existing EA. And second, it can be used to evaluate any EU countries' suitability for staying inside or joining the EA in the future, unless one expects convergence as a consequence of membership anyway, a perception discussed further below. While the latter issue is - at least implicitly - considered in all of the subsequent research articles, the first paper discusses the necessary reforms in greater detail.

To this end, the dissertation is structured into three different albeit related approaches (Chapters 2 to 4 introduced further below) that employ empirical techniques, such as cluster analysis,

\footnotetext{
${ }^{12}$ See Fligstein et al. (2012) for a discussion of this issue.

${ }^{13}$ Jones et al. (2016) describe what can be seen as the "failing forward" of European integration.
} 
principal components analysis, correlation analysis, and factor models, which are capable of identifying commonalties in large multivariate datasets. A fundamental issue thereby is of course the choice of meaningful macroeconomic indicators that can be used to assess the wellfunctioning of a monetary union. The economic literature as well as the EU legislation provide many possible parameters that may be considered relevant in this context.

\section{Convergence of what parameters?}

From a theoretical point of view, the literature on optimum currency areas (OCA) provides manifold criteria concerning the potential costs and benefits of fixing the exchange rate or sharing a common currency. On the one hand, countries can benefit from reduced transaction costs and price transparency fostering competition, international trade, and investment activity. On the other hand, the macroeconomic costs arise from losing the monetary and exchange rate policy flexibility in the event of asymmetric shocks (Campos et al. 2017). The latter, in turn, is more or less disadvantageous depending on several alternative adjustment mechanisms. Whereas the traditional OCA contributions in this context suggest the flexibility of prices and wages (Friedman 1953), labor mobility (Mundell 1961), financial market integration (Ingram 1962), a high degree of openness (McKinnon 1963), the diversification of the economy (Kenen 1969), the similarity of inflation rates (Fleming 1971) and a fiscal transfer system (Kenen 1969) to be relevant pre-conditions for a beneficial common currency, Frankel and Rose (1997) stressed the endogeneity property of a monetary union (Mongelli (2005; 2008); Dellas and Tavlas (2009)). Through increasing intra-industry trade relations due to the economic and monetary integration itself, the participating countries' cyclic correlations would increase so that the costs of sharing a common currency would decrease endogenously over time. This hypothesis, however, stands in contrast to the theory of diverging business cycles emanating from the potential inter-industry specialization of economies that may be likewise triggered by the integration process (Krugman 1993).

Consequently, while the fulfillment of OCA criteria is ambiguous and subject to several endogeneities surrounding the interaction between integration, flexibility, and symmetry (De Grauwe and Mongelli 2005), the literature has focused on business cycle synchronization of (prospective) EA members as a univariate meta-criterion (Mongelli 2005). It should indicate whether countries are more or less hit by asymmetric shocks that require country-specific monetary policy responses. Hence, the simple logic behind this is that when business cycles are 
commoving the cost of sharing a common currency are expected to be low. ${ }^{14}$ This aspect has been dealt with in the third and fourth chapters of the dissertation.

In practice, the suitability of prospective Euro countries was thought to be ensured by the Maastricht convergence criteria. It was demanded of the candidates that, prior to entering the EA, the economy should achieve convergence of its long-run interest and inflation rates as well as stability of its exchange rate and fiscal stance (budget deficit of less than three percent of GDP and total government debt of less than 60 percent of GDP). The latter two fiscal criteria were also proclaimed in the stability and growth pact (SGP), which envisaged along with the no-bail-out legislation the monetary union-inherent moral hazards linked with the separation of fiscal and monetary policy (Frankel 2015) and the potential externalities of excessive debt accumulation (Beetsma and Uhlig 1999). However, the Maastricht criteria (as well as the $\mathrm{SGP}^{15}$ ) turned out to be insufficient regarding the well-functioning of EMU for several reasons. First, the criteria need to be fulfilled only once to enter the EA. Second, all criteria are nominal and therefore neglect the fundamental structural homogeneity among Euro countries. And third, they are not binding so that the final decision is political. Remarkably, this is despite the quite extensive economic literature that have evolved under the OCA notion.

Today, the well-functioning is supposed to be safeguarded by additionally monitoring the broader macroeconomic imbalances discussed above. As part of the 'Sixpack' reform measures of 2011, the EU introduced the MIP as a surveillance tool aimed at detecting and preventing national competitiveness losses as well as internal and external imbalances that could also undermine the smooth functioning of EMU (European Commission 2012). Since the scoreboard indicators, which today comprise 14 real and nominal parameters, have been developed in the light of the economic developments that caused the euro crisis, they provide an adequate starting point for highlighting group-dynamic con- and divergences.

\section{Operationalizing relevant criteria and highlighting con- and divergences}

Thus, by operationalizing these MIP criteria, the first article of the dissertation ('One Size Fits Some: A Reassessment of EMU's Core-periphery framework ${ }^{16}$, Chapter 2) aims at indicating

\footnotetext{
${ }^{14}$ De Haan et al. (2008), Kappler and Sachs (2013), and Campos et al. (2017) provide summary studies. ${ }^{15}$ See, for instance, Heipertz and Verdun (2004), Feldstein (2005), and Eichengreen (2005), who provide analyses of the rationale, flaws, and history of the SGP.

${ }^{16}$ The paper has been published in the Journal of Economic Integration, Vol. 31 (2), 2016, pp. 377-413 together with Markus Stahl.
} 
homogenous country groups in terms of external balances, competitiveness, indebtedness, and economic performance over the period 2004 to 2013. This is done in an unprejudiced manner using two cluster techniques and principal components analysis that provide data-based proof of the often-claimed core-periphery division in Europe. More specifically, the identified groups indeed consist of the GI(I)PS countries (plus Cyprus and Croatia), the CEECs, and the Central European core countries, respectively. When comparing the results with the existing EA, we find it striking that the current composition of the EA is inadequate based on the EU's own surveillance tool. While, on the one hand, the GI(I)PS countries are found to constitute a fairly distinct group requiring specific policy treatment, on the other hand, some of the non-EA members such as Denmark, Sweden, and the UK belong to the core group of countries that could by itself form an efficient and stable monetary union. Repeating the exercise at different points in time reveals that the GIPS countries were grouped together already before the global recession of 2008/09 and further diverged thereafter. However, it should be noted that for some countries, like Italy and Hungary, the distance to the core cluster appears less dramatic as indicated by the second fuzzy clustering approach, which sets a relative degree of belongingness to all clusters for all countries. Moreover, despite forming a quite distinct cluster too, the accession of CEECs seems generally less problematic, because peculiarity also stems from low debt levels and rising export market shares, which cannot be judged negatively. This in turn points to the limitations of multivariate clustering that are addressed by applying the principal components analysis to the MIP scoreboard of indicators. As noted before, using many potentially correlated country features may impede economic interpretation regarding monetary integration, as the distinctiveness of any identified group can be due to over-weighted or contradictory criteria (Artis and Zhang 2001). Another way of coping with these problems is the univariate assessment of cluster structures undertaken in Chapter 3.

The second article of this dissertation named 'The core-periphery pattern of European business cycles: A fuzzy clustering approach' ${ }^{17}$ (Chapter 3 ) specifically deals with the identification of business cycle clusters and group-specific business cycles in Europe between 1996 and 2015. As highlighted by the first article, a latent core-periphery pattern appears to undermine the efficiency and stability of the EA in its current composition. The literature, however, often uses this division only in terms of the cyclical co-movements of national GDP or industrial production time series, either presuming the respective cluster members or grouping them

\footnotetext{
${ }^{17}$ The paper has been published in the Journal of Macroeconomics, Vol. 55 (1), 2018, pp. 12-27 together with Markus Ahlborn.
} 
according their synchronicities with a reference cycle. This cycle has almost always been set without empirical verification, too. By applying a time series cluster analysis, we tackle both problems simultaneously and provide for the first time a comprehensive picture of clusters and group-specific cycles in the EU without imposing any other assumptions than varying the number of clusters to find the optimal solution.

Indeed, we find clear evidence of a core-periphery cyclical division along the lines of a Central European core group, a southern periphery, and an eastern periphery again, of which the latter can be further partitioned into the Baltics, the south-eastern transition countries, and Bulgaria and Romania. More specifically, the countries' fuzzy membership coefficients for all clusters indicate that while some non-EA countries among the CEECs (Hungary and to a lesser degree the Czech Republic, and Poland) as well as Denmark, Sweden, Switzerland, and the UK exhibit strong similarities with the core business cycle, the GIPS countries do not (anymore). By using time-varying synchronization measures with the core business cycle, we show that, whereas the southern periphery in fact diverged since the global recession of 2008/09, the eastern periphery converged.

It is important to bear in mind that the multiple group-specific European cycles of Chapter 3 have been imposed and do not exclude that there is also a particular 'European business cycle' like other potentially regional cycles around the world. The corresponding high degree of unionwide synchronization would of course be the best-case scenario for a single 'one size fits all' monetary policy. But empirical findings on this issue are mixed and should be interpreted with caution as evidence of such a European business cycle (e.g., Artis et al. 2004) may in fact as well be a result of limited sample sizes indicating global rather than European co-movement (Kose et al. 2003). Whereas Lumsdaine and Prasad (2003) and Mansour (2003) find a European cycle coexisting with a global business cycle, more recent studies like Canova et al. (2007) and Camacho et al. (2008) negate the existence of a specific European cycle.

Therefore, the third article ('Global vs. group-specific business cycles: The importance of defining the groups' ${ }^{18}$, Chapter 4) examines the question of whether distinct group-specific business cycles, such as the European business cycle, have emerged that may have become more important for domestic fluctuations than a global business cycle in a large-scale dataset of 106 countries and three macroeconomic variables (real output, real consumption, and real

\footnotetext{
${ }^{18}$ The paper has been submitted to the Journal of International Money and Finance together with Tino Berger.
} 
investment) covering the period of 1960 to 2014. Such regional factors may have gained importance for a number of reasons, including the profound increase in intra-regional trade and financial flows over the past decades that is increasingly of the intra-industry type. ${ }^{19}$

Within Europe, for example, a large and growing body of empirical literature finds that efforts of economic and monetary integration of the past decades indeed fostered trade (Micco et al. 2003; Baldwin 2006; Baldwin et al. 2008; Bun and Klaassen 2007; Berger and Nitsch 2008; Glick and Rose 2016; Glick 2017) and financial ties (Lane 2006; Spiegel 2009; Kalemli-Ozcan et al. 2010) significantly. However, quantifications range between 3 percent of an EA-related (Bun and Klaassen 2007) and up to 70 percent of an EU-related trade plus (Glick 2017) and should be interpreted in the context of both high independent European trade growth over the long-run and even more dynamic trade increases with countries outside the EA (Mongelli 2008). Empirical evidence generally suggests that economic and financial integration of countries rather increases business cycle synchronization (see, for instance, Imbs (2006), and Dées and Zorell (2012)). But, as many integration processes overlap and isolating particular impacts is a difficult task, it still seems unclear whether the observed increase in European business cycle co-movements is due to the establishment of a monetary union (Campos et al. 2017) or emanated from a more general synchronization process (Canova et al. 2012; Enders et al. 2013). In order to disentangle the relative importance of the global from group-specific, country-specific, and idiosyncratic determinants of national macroeconomic fluctuations, a dynamic factor model is estimated using Bayesian techniques. But essentially different from the previous literature, to which we compare our results, the underlying country groups are identified by a cluster analysis of the business cycle data rather than assumed according to the countries' geographic proximity or the time-invariant level of development.

By doing so, we find that the degree of similarity among all the industrialized economies is indeed high, but two subgroups are still well distinguishable at lower aggregation levels of the hierarchical clustering that have not been considered previously. Specifically, we identify one 'Central European' cluster comprising also Japan and one 'Anglo-Saxon' cluster containing besides Ireland, the UK, and some Northern European economies as well the USA, Canada, and Oceania. The fact that Ireland and the UK and later the Northern European countries as a 'Northern periphery' evolved somewhat differently from their continental partner countries clearly proves that, besides extensive regional European trade and financial integration, inter-

\footnotetext{
${ }^{19}$ See Hirata et al. (2013) who also provide an overview of the literature.
} 
regional linkages too played a significant role. This might be due to historically pronounced trade ties or linguistic reasons, as the broad Latin American cluster of South-, Middle-, and North American countries suggests. For Ireland and Finland, even higher similarity with countries outside than inside the EA may imply problems with the appropriateness of the ECB monetary policy that depend on the extent of dissimilarity between the Central European and the Anglo-Saxon cycles.

Imposing these data-based group-specific factors into the dynamic factor model shows that they play an increasingly important and much greater role than both the global factor and the prespecified purely regional or development-based counterparts, particularly in Europe. For the EU-12 economies, for example, the group-specific factors explain, on average, 48 percent of national output variability compared with only 20 and 26 percent that would be captured by the cross-regional and the industrialized economy factors, respectively. Over the second sub-period starting in the mid-1980s, this share even rose to 63 percent, suggesting cyclical convergence within the two country groups to has increased substantially. On the other hand, the global business cycle is found to be less important and even becoming negligible over the more recent time period for most of the countries. While for the average EU-12 country, output variability is still $12 \%$ explained by the global factor, for all countries this figure is just above $4 \%$, raising the question of whether the global factor common to multiple variables is diminishing. ${ }^{20}$ Overall, these findings underline the increasing importance of group-specific trade and financial linkages which can be influenced decisively by the abolishment of trade barriers and supra-national policies within the European integration process.

In sum, this dissertation attempts to complement the economic literature, where it falls short of providing conclusive empirical evidence of the group-dynamic macroeconomic developments in Europe. As such an assessment of the con- and divergences particularly between the core and the peripheral member states may be regarded as crucial for evaluating the prospects of EMU, the subsequent Chapters 2 to 4 provide the basis for the concluding Chapter 5 that formulates some policy implications for individual countries and groups within this framework.

\footnotetext{
${ }^{20}$ See Berger and Pozzi (2018) and Karadimitropoulou and León-Ledesma (2013) for recent evidence in this direction.
} 


\section{References}

Artis, Michael J., and Wenda Zhang. 2001. "Core and periphery in EMU: A cluster analysis." Economic Issues 6 (2): 39-59.

Artis, Mike, Hans-Martin Krolzig, and Juan Toro. 2004. "The European business cycle." Oxford Economic Papers 56: 1-44.

Baldwin, Richard. 2006. “The euro’s trade effects.” ECB Working Paper No. 594.

Baldwin, Richard, Virginia Di Nino, Lionel Fontagné, Roberto A. de Santis, and Daria Taglioni. 2008. Study on the Impact of the Euro on Trade and Foreign Direct Investment. European economy Economic papers 321.

Baldwin, Richard et al. 2015. "Rebooting the eurozone: Step 1 - Agreeing a crisis narrative." CEPR Policy Insight No. 85.

Bakker, Bas B., and Christoph Klingen. 2012. "How emerging Europe came through the 2008/09 crisis: an account by the staff of the IMF's European Department." Washington, D.C.: International Monetary Fund.

Beetsma, Roel, and Harald Uhlig. 1999. "An Analysis of the Stability and Growth Pact." Economic Journal 109 (458): 546-71.

Berger, Helge, and Volker Nitsch. 2008. "Zooming out: The trade effect of the euro in historical perspective." Journal of International Money and Finance 27 (8): 1244-60.

Berger, Tino, and Lorenzo Pozzi. 2018. "Is there really a global business cycle? A dynamic factor model with stochastic factor selection." forthcoming.

Blanchard, Olivier, and Francesco Giavazzi. 2002. "Current Account Deficits in the Euro Area: The End of the Feldstein-Horioka Puzzle?" Brookings Papers on Economic Activity 2002 (2): $147-86$.

Blot, Christophe, Paul Hubert, and Fabien Labondance. 2017. "Does Monetary Policy Generate Asset Price Bubbles?” OFCE Sciences Po Working Paper 2017-05.

Borio, Claudio, and Anna Zabei. 2016. "Unconventional monetary policies: a re-appraisal." Bank For International Settlements Working Paper 570.

Bun, Maurice J. G., and Franc J. G. M. Klaassen. 2007. "The Euro Effect on Trade is not as Large as Commonly Thought." Oxford Bull Econ \& Stats 69 (4): 473-96. 
Camacho, Maximo, Gabriel Perez-Quiros, and Lorena Saiz. 2008. "Do European business cycles look like one?" Journal of Economic Dynamics and Control 32 (7): 2165-90.

Campos, Nauro F., Jarko Fidrmuc, and Iikka Korhonen. 2017. Business Cycle Synchronisation in a Currency Union: Taking Stock of the Evidence. Bank of Finland research discussion papers 28.

Canova, Fabio, Matteo Ciccarelli, and Eva Ortega. 2007. "Similarities and convergence in G-7 cycles." Journal of Monetary Economics 54 (3): 850-78.

Canova, Fabio, Matteo Ciccarelli, and Eva Ortega. 2012. "Do institutional changes affect business cycles? Evidence from Europe." Journal of Economic Dynamics and Control 36 (10): $1520-33$.

Chen, Ruo, Gian M. Milesi-Ferretti, and Thierry Tressel. 2012. "External Imbalances in the Euro Area." IMF Working Paper 12/236.

De Grauwe, Paul, and Francesco P. Mongelli. 2005. "Endogeneities of Optimum Currency Areas: What Brings Countries Sharing a Single Currency Closer Together?.” ECB Working Paper Series No. 468.

De Haan, Jakob, Robert Inklaar, and Richard Jong-A-Pin. 2008. "Will Business Cycles in the Euro Area Converge? A Critical Survey of Empirical Research." Journal of Economic Surveys 22 (2): 234-73.

Dées, Stéphane, and Nico Zorell. 2012. "Business Cycle Synchronisation: Disentangling Trade and Financial Linkages." Open Economies Review 23 (4): 623-43.

Dellas, Harris, and George S. Tavlas. 2009. “An optimum-currency-area odyssey.” Journal of International Money and Finance 28 (7): 1117-37.

Driffill, John. 2016. "Unconventional Monetary Policy in the Euro Zone." Open Economies Review 27 (2): 387-404.

Eichengreen, Barry. 2005. "Europe, the euro and the ECB: Monetary success, fiscal failure." Journal of Policy Modeling 27 (4): 427-39.

Eichengreen, Barry. 2010. "The Breakup of the Euro Area." in: Alesina, Alberto and Francesco Giavazzi (eds.) Europe and the Euro. Chicago: University of Chicago Press, pp. 11-41.

Eichengreen, Barry. 2015. "How the euro crisis ends: Not with a bang but a whimper." Journal of Policy Modeling 37 (3): 415-22. 
Enders, Zeno, Philip Jung, and Gernot J. Müller. 2013. "Has the Euro changed the business cycle?" European Economic Review 59: 189-211.

European Central Bank. 2015a. "The transmission of the ECB's recent non-standard monetary policy measures.” ECB Economic Bulletin Issue 7.

European Central Bank. 2015b. "Progress with structural reforms across the euro area and their possible impacts.” ECB Economic Bulletin Issue 2.

European Commission. 2012. "Scoreboard of the surveillance of macroeconomic imbalances." European Economy Occasional Papers 92.

European Commission. 2016. "The Economic Impact of Selected Structural Reform Measures in Italy, France, Spain and Portugal.” European Economy Institutional Papers 023.

European Commission. 2018. "https://ec.europa.eu/info/business-economy-euro/economicand-fiscal-policy-coordination_en" accessed on 02/14/2018.

Feldstein, Martin. 2005. "The euro and the stability pact." Journal of Policy Modeling 27 (4): 421-26.

Feldstein, Martin. 2015. "Ending the euro crisis.” Journal of Policy Modeling 37 (3): 423-27.

Fleming, J. Marcus. 1971. “On Exchange Rate Unification.” Economic Journal 81: 467-88.

Fligstein, Neil, Alina Polyakaova, and Wayne Sandholtz. 2012. "European Integration, Nationalism and European Identity.” Journal of Common Market Studies 50 (10): 106-22.

Frankel, Jeffrey. 2015. “The euro crisis: Where to from here?" Journal of Policy Modeling 37 (3): 428-44.

Frankel, Jeffrey A. and Andrew K. Rose. 1997. "Is EMU more Justifiable Ex Post than Ex Ante?." European Economic Review 41 (3-5): 753-60.

Friedman, Milton. 1953. "Essays in Positive Economics.” Chicago: University of Chicago Press.

Glick, Reuven. 2017. "Currency Unions and Regional Trade Agreements: EMU and EU Effects on Trade.” Comparative Economic Studies 59 (2): 194-209.

Glick, Reuven, and Andrew K. Rose. 2016. "Currency unions and trade: A post-EMU reassessment." European Economic Review 87: 78-91. 
Heipertz, Martin, and Amy Verdun. 2004. "The dog that would never bite? What we can learn from the origins of the Stability and Growth Pact." Journal of European Public Policy 11 (5): 765-80.

Hirata, Hideaki, M. Ayhan Kose, and Christopher Mark Otrok. 2013. "Regionalization vs. Globalization.” IMF Working Paper 13/19.

Imbs, Jean. 2006. "The real effects of financial integration." Journal of International Economics 68 (2): 296-324.

Ingram, James C. 1962. "Regional Payments Mechanisms: The Case of Puerto Rico." Chapel Hill: University of North Carolina Press.

Jaumotte, Florence, and Piyaporn Sodsriwiboon. 2010. "Current Account Imbalances in the Southern Euro Area.” IMF Working Paper 10/139.

Jones, Erik, R. Daniel Kelemen, and Sophie Meunier. 2016. "Failing Forward? The Euro Crisis and the Incomplete Nature of European Integration." Comparative Political Studies 49 (7): $1010-34$.

Jonung, Lars, and Eoin Drea. 2010. "It Can't Happen, It's a Bad Idea, It Won't Last: U.S. Economists on the EMU and the Euro, 1989 2002." Econ Journal Watch 7: 4-52.

Joyce, Michael, David Miles, Andrew Scott, and Dimitri Vayanos. 2012. "Quantitative Easing and Unconventional Monetary Policy - an Introduction.” The Economic Journal 122 (564): F271-F288.

Kalemli-Ozcan, Sebnem, Elias Papaioannou, and José-Luis Peydró. 2010. "What lies beneath the euro's effect on financial integration? Currency risk, legal harmonization, or trade?" Journal of International Economics 81 (1): 75-88.

Kappler, Marcus, and Andreas Sachs. 2013. "Business Cycle Synchronisation and Economic Integration: New Evidence from the EU.” Heidelberg: Imprint: Physica.

Karadimitropoulou, Aikaterini, and Miguel León-Ledesma. 2013. "World, country, and sector factors in international business cycles." Journal of Economic Dynamics and Control 37 (12): 2913-27.

Kang, Joong S., and Jay C. Shambaugh. 2016. "The rise and fall of European current account deficits.” Economic Policy 31(85): 153-99.

Kenen, Peter. 1969. "The theory of optimum currency areas: An eclectic view." in: Mundell, Robert, and Alexander Swoboda (eds.) Monetary problems of the international economy. Chicago: University of Chicago Press, pp. 41-60. 
Kösters, Wim, Manfred M. Neumann, Renate Ohr, Roland Vaubel. 1998. "The Euro starts too early.” Frankfurter Allgemeine Zeitung (FAZ), February 9th 1998, Frankfurt.

Kose, M. Ayhan, Christopher Otrok, and Charles H. Whiteman. 2003. "International Business Cycles: World, Region, and Country-Specific Factors." American Economic Review 93 (4): 1216-39.

Krugman, Paul. 1993. "Lessons of Massachusetts for EMU," in: Torres, Francisco, and Francesco Giavazzi (eds.) Adjustment and Growth in the European Monetary Union. Cambridge University Press, pp. 241-61.

Lane, Philip R. 2006. "The Real Effects of European Monetary Union." Journal of Economic Perspectives 20 (4): 47-66.

Lumsdaine, Robin L., and Eswar S. Prasad. 2003. "Identifying the Common Component of International Economic Fluctuations: A New Approach. ” The Economic Journal 113: 10127.

Mansour, Joffrey Malek. 2003. "Do national business cycles have an international origin?" Empirical Economics 28 (2): 223-47.

McKinnon, Ronald. 1963. “Optimum currency areas.” The American Economic Review 53(4): 717-725.

Micco, Alejandro, Ernesto Hugo Stein, and Guillermo Luis Ordoñez. 2003. "The Currency Union Effect on Trade: Early Evidence from Emu.” Economic Policy 18 (37): 315-56.

Mongelli, Francesco P. 2008. "European Economic and Monetary Integration, and the Optimum Currency Area Theory." European economy Economic papers 302.

Mongelli, Francesco P. 2005. "What is European Economic and Monetary Union Telling us About the Properties of Optimum Currency Areas?" Journal of Common Market Studies 43 (3): 607-35.

Mundell, Robert A. 1961. "A theory of optimum currency areas." The American Economic Review 51 (4): 657-665.

Ohr, Renate and Wolf Schäfer. 1992. "The monetary resolutions of Maastricht: A danger for Europe." Frankfurter Allgemeine Zeitung (FAZ), June 11th 1992, Frankfurt.

Salvatore, Dominick. 2015. "Europe's euro and competitiveness crises." Journal of Policy Modeling 37 (3): 445-49. 
Shambaugh, Jay C. 2012. "The Euro's Three Crises." Brookings Papers on Economic Activity, Spring 2012: 157-211.

Smets, Frank. 2014. "Financial Stability and Monetary Policy: How Closely Interlinked?." International Journal of Central Banking 10 (2): 263-300.

Spiegel, Mark M. 2009. "Monetary and financial integration: Evidence from the EMU." Journal of the Japanese and International Economies 23 (2): 114-30.

Tressel, Thierry and Shengzu Wang. 2013. "Rebalancing in the euro area and cyclicality of current account adjustments.” IMF Working Paper 14/130.

Tressel, Thierry, Shengzu Wang, Joong S. Kang, and Jay C. Shambaugh. 2014. "Adjustment in euro area deficit countries: progress, challenges and policies." IMF Staff Discussion Note $14 / 7$.

Varga, Janos, Werner Roeger, and Jan in 't Veld. 2013. "Growth Effects of Structural Reforms in Southern Europe: The case of Greece, Italy, Spain and Portugal." European Economy Economic Papers 511. 
Journal of Economic Integration

\title{
One Size Fits Some : A Reassessment of EMU's Core-periphery Framework
}

\author{
Marcus Wortmann \\ Georg-August-University Göttingen, Göttingen, Germany \\ Markus Stahl \\ Georg-August-University Göttingen, Göttingen, Germany
}

\begin{abstract}
This study provides a new multivariate assessment of core-periphery structures within the European Union. By applying different cluster algorithms to the broad set of Macroeconomic Imbalance Procedure indicators, we detect a relatively stability-oriented and homogeneous group of European Union core countries that would be suitable for having a common currency. Unlike previous results, our analysis shows that countries such as the United Kingdom, Denmark, and Sweden would also fit well within such a hypothetical euro area. However, Greece, Ireland, Italy, Portugal, and Spain plus Cyprus and Croatia on the southern periphery, as well as most of the countries of the eastern enlargement are found to form very distinct clusters in terms of competitiveness, indebtedness, and economic performance. Our findings thus reveal that a single monetary policy can be appropriate only for some countries, even when measured using the official Macroeconomic Imbalance Procedure scoreboard specifically designed to monitor the smooth functioning of the Economic and Monetary Union.
\end{abstract}

\footnotetext{
* Corresponding Author: Marcus Wortmann; Georg-August-University Göttingen, Platz der Göttinger Sieben 3, 37073 Göttingen, Germany; Tel: +49 (0) 55139 7355, Fax: +49 (0) 55139 7093, E-mail: marcus.wortmann@wiwi.unigoettingen.de.

Co-author: Markus Stahl; Georg-August-University Göttingen, Platz der Göttinger Sieben 3, 37073 Göttingen, Germany; Tel: +49 (0) 55139 7337, Fax:+49 (0) 55139 7093, E-mail: markus.stahl@wiwi.uni-goettingen.de.
} 
JEL Classifications: C38, F15, F45, O57

Keywords: Economic and Monetary Union, Macroeconomic Imbalance Procedure, Economic Integration, Macroeconomic Disparities, Cluster Analysis

\section{Introduction}

The ongoing crisis of the euro area shows that even after 16 years of common currency, a one size fits all monetary policy cannot be conducted smoothly in a distinct coreperiphery framework. Even though many economists warned early-on against the rapid introduction of the euro within a large heterogeneous group of insufficiently prepared economies, ${ }^{1}$ the famous endogenous theory of Frankel and Rose (1998) raised hopes of ultimately overcoming any disparities. So far, this remains a vision, and the initially claimed stability orientation ${ }^{2}$ - marked by similar and low inflation, a stable exchange rate, and sustainable debt levels_remains out of sight. Instead, the monetary union itself fostered macroeconomic imbalances both within and between Greece, Ireland, Italy, Portugal, Spain (GIIPS countries) in the south and the core countries in the north. Large economic disparities in terms of competitiveness, indebtedness, and economic performance have put the European Central Bank (ECB) in a desperate position: while, for instance, many countries in the latter group now need a stronger euro and higher interest rates, the opposite holds for the southern periphery. However, during the crisis, the ECB found itself forced to apply an expansive monetary policy aiming to support the GIIPS countries' struggle for recovery, simultaneously fighting an alleged deflation risk. This recent monetary policy has often been criticized by the core countries for its negative effects on domestic savings, price bubbles, and the ECB's balance sheet, as well as for dangerous fiscal debt financing, which in turn will establish negative incentives for budgetary discipline and the necessary structural reforms. In addition to the one size fits some monetary policy described above, the European Union (EU) has also introduced the European Stability Mechanism (ESM) for highly indebted countries, as well as other

\footnotetext{
${ }^{1}$ Feldstein (1997), p. 41. The critique of German economists can be found in the Financial Times of February 9, 1998: "The Euro starts too early." Jonung and Drea (2010) provide an extensive overview of critical American economists.

2 The concept of a stability orientation was put forward by the German Federal Constitutional Court as a precondition for Germany's participation in the EMU in the Maastricht Judgement (BVerfGE 89, 155, October 12, 1993, Az: 2 BvR 2134, 2159/92).
} 
measures aimed at addressing high youth unemployment and low investment activity on the southern periphery. The reassessment of core-periphery structures is thus important not only for establishing a proper monetary policy but also for developing common economic policy strategies to overcome tenuous disparities.

The following analyses provide a clear data-based picture of core-periphery structures, depicting more precisely what is often thought of as a simple north-eastsouth division. To do so, we follow a multidimensional approach rather than only looking at, for example, output synchronization, as is often done to distinguish between core and peripheral areas within the Economic and Monetary Union (EMU). Instead, we apply different cluster algorithms and Principal Components Analysis (PCA) to the Macroeconomic Imbalance Procedure (MIP) indicator set, which was designed to capture the most relevant economic developments responsible for the smooth functioning of EMU (European Commission 2012). As these indicators were chosen against the background of the euro area crisis experience, we believe cluster analysis on this basis to be a new and reasonable approach to assess the core-periphery dynamics of the EMU. Moreover, the MIP scoreboard includes data for every EU member state and thus allows us to identify a relatively stability-oriented and homogeneous group of EU core countries that are theoretically suitable for a common currency. Our results provide an economic indication of how well the current EMU members and outsiders fit into the currency area. While our findings suggest that countries such as the United Kingdom (UK), Denmark, and Sweden could easily share a common currency with the core countries, others, such as the GIIPS countries, clearly require different treatment. With respect to the appropriate level of integration, this article provides new impetus to the recently heated debates about Greek Exit (GREXIT) from the euro area and British Exit (BREXIT) from the EU. Therefore, we analyze the magnitude and similarity of internal and external imbalances to contribute to academic and political solution strategies to the euro crisis.

The remainder of this study is organized as follows. Section II first introduces the existing literature on core-periphery dynamics in the EMU. Then, we explain why the MIP scoreboard provides a proper basis for assessing the underlying disparities. The methodology and data are introduced in Section III, followed by the presentation of the results of the cluster analyses and PCA in Section IV. Section V addresses the policy implications and Section VI concludes. 


\section{Macroeconomic Imbalance Procedure}

This article contributes to the literature on core-periphery dynamics, especially those related to European monetary integration. Before the introduction of the euro in 1999, it was questioned as to which countries would belong to a promising core group or periphery in light of the optimum currency area theory (Bayoumi and Eichengreen 1993, 1994, 1997). In contrast, the theory of an endogenous currency area proposed by Frankel and Rose (1998) states that potential member countries did not have to fulfill certain optimal conditions ex ante but would rather form an optimal currency area ex post. Advocates of the endogeneity hypothesis saw a positive correlation between trade integration and output synchronization as monetary unification itself would increase intra-industry trade flows. Economic theory, however, suggests that economic integration could lead to more specialization and increased inter-industry trade, facilitating asymmetric supply shocks (Caporale et al. 2014). In this theoretical controversy, Europe's business cycle synchronization has usually been the focus of empirical investigation and is seen as a meta criterion for an optimal currency area (Mongelli 2008, de Haan et al. 2007). If shocks and business cycles were found to converge in the EMU, this was interpreted as support for the endogenous view (Gachter and Riedl 2014). However, other studies discovered decreasing output synchronization and a diverging pattern of core and peripheral areas (Pentecote and Huchet-Bourdon 2012, Caporale et al. 2014, Lehwald 2013).

When the euro crisis emerged in 2010, other dimensions of the core-periphery division of EMU came back into academic focus. Macroeconomic imbalances in and between southern and northern EMU member states concerning competitiveness, indebtedness, and economic performance became apparent and required some rootcause analysis to enhance future governance (for a discussion of the interdependence of different crises, see Shambaugh 2012). The formerly weak-currency countries of the southern periphery experienced extensive capital inflows due to the removal of risk premia in the run-up to EMU. While this facilitated public and private sector consumption, it rarely led to investment-driven productivity gains. Prices and wages in these countries did rise, but they subsequently lost their competitiveness and built up persistent current account deficits that could no longer be reduced by nominal depreciation (Fischer and Hobza 2014). The GIIPS countries eventually experienced slow growth, high unemployment, and deflationary pressures after the global financial 
crisis (Eichengreen 2010), but many often-labeled core countries, such as Germany, Austria, and the Netherlands, were able to recover much faster. The hope of an endogenous monetary union which could, in the meantime, find some support in business cycle patterns (European Commission 2008) gave way to an alarming divergence in output gaps between core and peripheral countries (European Commission 2014a).

Current disparities between EMU member states are closely related to certain internal imbalances. The consumptive use of capital inflows in the non-tradeable sector, which triggered housing price bubbles in Ireland and Spain, as well as extensive private and public debt accumulation, contributed to worsening current account deficits and international investment positions of the GIIPS countries (Fischer and Hobza 2014). The resulting debt crisis documented again that monetary integration itself created incentives and opportunities for the south to finance demand-side growth by borrowing from the north (Hall 2012). Although such group dynamic effects of public debt in a monetary union (Beetsma and Uhlig 1999), as well as the respective incentives to free ride, were clear from the beginning (Horstmann and Schneider 1994, Ohr 2004), all institutional arrangements to ensure stability proved to be insufficient to resolve-or even instead exacerbate - the public debt crisis (Lane 2012).

In 2011, the EU introduced MIP as a new governance tool to monitor and correct future imbalances. The MIP scoreboard of 11 macroeconomic indicators, together with critical thresholds, offers a substantial and eligible database to investigate the EU's coreperiphery structures as it transforms the multidimensional developments described above into measureable criteria essential for the smooth functioning of a monetary union. Moreover, these criteria not only include a mix of flows and stocks, as well as nominal and real figures, but also capture backward moving averages, which make them more robust to short-term fluctuations. The indicators are as follows: ${ }^{3}$

- Three-year backward-moving average of the current account balance in percentage of GDP, with a threshold of $+6 \%$ and $-4 \%$;

- Net international investment position in percentage of GDP, with a threshold of $-35 \%$;

- Five-year percentage change in export market shares measured in values, with a threshold of $-6 \%$;

- Three-year percentage change in nominal unit labor cost, with thresholds of $+9 \%$ for euroarea countries and $+12 \%$ for non-euro area countries, respectively;

\footnotetext{
${ }^{3}$ Scoreboard summary taken from European Commission (2012) and Fischer and Hobza (2014). See both for further details on indicators and the design of the MIP. The 2013 MIP scoreboard can be found in Table 1.
} 
- Three-year percentage change in real effective exchange rates based on HICP/CPI deflators, relative to 35 other industrial countries, with thresholds of $\pm 5 \%$ for euro-area countries and $\pm 11 \%$ for non-euro area countries, respectively;

- Private-sector debt in percentage of GDP, with a threshold of $160 \%$;

- Private-sector credit flow in percentage of GDP, with a threshold of $15 \%$;

- Year-on-year changes in the house price index relative to a Eurostat consumption deflator, with a threshold of $6 \%$;

- General government sector debt in percentage of GDP, with a threshold of $60 \%$;

- Three-year backward moving average of the unemployment rate, with a threshold of $10 \%$; and

- Annual growth rate of total financial sector liabilities, with a threshold of $16.5 \%$.

The MIP was designed as an early warning system that would detect risks for the monetary union as a whole. If the commission encounters violations of certain thresholds, it provides in-depth reviews and action plans for corrective policy measures in the affected countries. In the case of non-compliance, sanctions can be imposed on EMU member states as a last resort. This procedure focuses on country-specific imbalances measured by absolute indicator values. It is, of course, a legitimate approach concerning internal and external stability matters but does not check for the homogeneity of country values as another precondition of a smoothly working monetary union. From this viewpoint, a large current account surplus, as seen in Germany, can only be judged as an excessive imbalance if most of the other member states do not have similar surpluses (Gros and Giovannini 2014). Therefore, for the purpose of this study, we follow a relative perspective and consider between-country disparities of MIP indicators as risks for the stability and efficiency of EMU. Hence, the lower the disparities in real exchange rates, current account balances, unit labor costs, and unemployment, the more possible it will be to define a one size fits all monetary policy. In addition, the monetary transmission channels will work better if private-sector credit flows are fairly similar. Finally, the more alike private and public sector indebtedness levels are, the lower the risks of country-specific confidence losses, sudden liquidity stops, spillover effects, and the need for financial support or monetary action to bail out other EMU member states.

To identify relatively homogeneous groups of core and peripheral countries based on the MIP indicators, we now employ different cluster methods, which are yet to be

\footnotetext{
${ }^{4}$ Gruber and Ohr (2001) discuss the relevance of different financing structures and monetary transmission channels for the functioning of a monetary union.
} 
used in this context. For instance, König and Ohr (2013) and Rozmahel et al. (2013) recently used hierarchical cluster analyses to uncover some multidimensional politicoeconomic forms of heterogeneity in the EU. Quah (2014) groups EU countries based on their business cycle synchronicities with the euro area using a fuzzy clustering technique. Considering specifically the core-periphery division of EMU with the help of some optimal currency area criteria, Artis and Zhang's (2001) cluster analysis revealed that at the time, only five of the $13 \mathrm{EU}$ countries under investigation formed a suitable core group (France, Netherlands, Belgium, Austria, and Germany). The same authors (Artis and Zhang 2002) later applied another cluster technique to the Maastricht convergence criteria, adding Italy, Spain, and Portugal to the core cluster. Based on this work, Boreiko (2003) and Kozluk (2005) studied the readiness of Eastern European candidate countries for EMU membership using cluster analyses. Artis and Zhang (2001) formerly concluded: A finding of inhomogeneity in the ranks of the putative EMU must suggest that a one-size-fits-all monetary policy will be appropriate to certain member countries and could threaten the union's sustainability. A key issue here, which this analysis cannot comment upon, is how far this problem will prove transitory (as the endogeneity literature suggests) or, on the other hand, persistent.

Taking this as a case for reassessment, we now, after 16 years of monetary union and five years of the euro-area crisis, shed some light on the current scenario. 


\begin{tabular}{|c|c|c|c|c|c|c|c|c|c|c|c|c|c|c|c|c|c|}
\hline 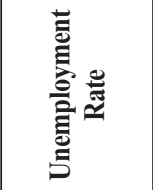 & 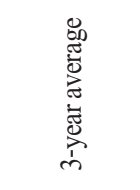 & $\stackrel{\circ}{0}$ & $\stackrel{2}{\sim}$ & તิ & જે & $\stackrel{\nabla}{\sim}$ & $\begin{array}{l}\bullet \\
\dot{n}\end{array}$ & $\stackrel{m}{\varrho}$ & 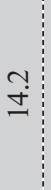 & 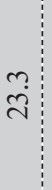 & $\overrightarrow{+}$ & $\begin{array}{l}\infty \\
\sigma \\
\sigma\end{array}$ & $\stackrel{+}{0}$ & $\begin{array}{l}\infty \\
n \\
n\end{array}$ & $\stackrel{9}{=}$ & $\stackrel{\forall}{ \pm}$ & $\stackrel{n}{\dddot{n}}$ \\
\hline 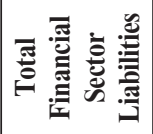 & 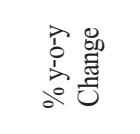 & 官 & $\stackrel{\vec{T}}{\stackrel{i}{*}}$ & $\stackrel{m}{m}$ & $\stackrel{\infty}{\circ}$ & $\vec{c}$ & भ̧: & $\partial_{\infty}$ & $\circ$ &  & \begin{tabular}{l}
$\tilde{3}$ \\
\hdashline \\
$\frac{1}{1}$
\end{tabular} & \begin{tabular}{lll}
0 \\
\hdashline
\end{tabular} & î́ & $\dot{m}$ & 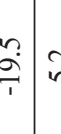 & $\begin{array}{l}\text { in } \\
\text { in }\end{array}$ & $\stackrel{\infty}{T}$ \\
\hline 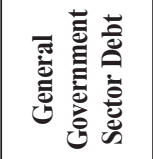 & 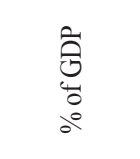 & ठ̊ํ & $\begin{array}{l}n \\
\stackrel{n}{0}\end{array}$ & $\begin{array}{l}\infty \\
\stackrel{\infty}{-}\end{array}$ & $\ddot{y}$ & $\begin{array}{l}\circ \dot{\sigma} \\
\ddot{\sigma}\end{array}$ & ڤે) & $\ddot{0}$ & $\stackrel{m}{\beth}$ & $\stackrel{\text { ț }}{\underline{\Xi}}$ & त: & 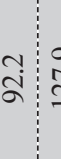 & 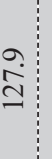 & $\stackrel{i}{i}$ &  & $\begin{array}{c}\text { co } \\
\text { co } \\
\text { ch }\end{array}$ & $\begin{array}{l}\text { ले } \\
\text { ले }\end{array}$ \\
\hline  &  & ஸे & ○் & $\begin{array}{l}\infty \\
\dot{m} \\
\stackrel{2}{*}\end{array}$ & $\stackrel{ }{\sim}$ & \begin{tabular}{c|c}
0 \\
ते \\
ते
\end{tabular} & ֻُ & $\stackrel{ナ}{\stackrel{\partial}{\prime}}$ & 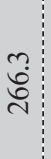 & $\begin{array}{l}\stackrel{0}{0} \\
\ddot{n}\end{array}$ & $\begin{array}{l}\text { I } \\
\text { I }\end{array}$ & $\frac{m}{m}$ & $\begin{array}{l}\infty \\
\infty \\
= \\
=\end{array}$ & $\stackrel{\nexists}{\dot{a}}$ & 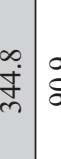 & 8 & تُ \\
\hline 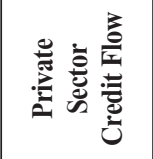 &  & $\stackrel{\stackrel{\circ}{\Xi}}{ }$ & $\exists$ & $\hat{\sigma}$ & $\vec{c}$ & $\stackrel{\nabla}{\rightarrow}$ & $\stackrel{1}{-}$ & $\stackrel{\nabla}{i}$ & $\vec{i}$ & 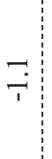 & $\stackrel{\overbrace{}}{1}$ & $\stackrel{\infty}{-}$ & $\stackrel{0}{\dot{p}}$ & $\begin{array}{l}\text { ç } \\
\text { co }\end{array}$ & 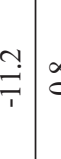 & 恶 & 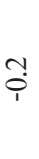 \\
\hline 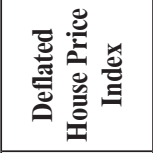 & 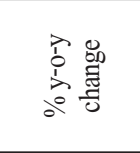 & ذి & 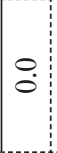 & $\vec{p}$ & T: & $\begin{array}{l}\infty \\
i\end{array}$ & $\stackrel{\infty}{-}$ & $\stackrel{?}{\sim}$ & $\tilde{o}$ & $\stackrel{m}{i}$ & $\hat{i}$ & $\begin{array}{l}0 \\
i \\
i\end{array}$ & ̧े. & $\vec{\infty}$ & $\begin{array}{ll}n \\
r \\
r\end{array}$ & ర. & ֶָ. \\
\hline 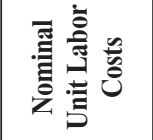 & 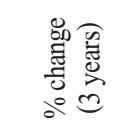 & 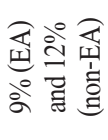 & $\begin{array}{ll}0 \\
\infty\end{array}$ & $\stackrel{\infty}{ \pm}$ & $\vec{n}$ & $\stackrel{\nabla}{\dot{m}}$ & ţ: & $\stackrel{\circ}{\circ}$ & $\stackrel{?}{?}$ & $\frac{3}{1}$ & $\begin{array}{l}\underset{0}{0} \\
\dot{+}\end{array}$ & $\vec{m}$ & F & $\hat{o}$ & 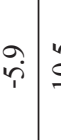 &  & $\stackrel{\circ}{\circ}$ \\
\hline 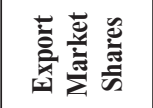 & 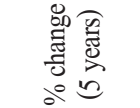 & לें & $\vec{a}$ & in & i: & $\stackrel{9}{\frac{1}{\top}}$ & $\stackrel{\imath}{0}$ & \begin{tabular}{l|l}
$\stackrel{2}{*}$ &
\end{tabular} & $\stackrel{\partial}{+}$ &  & $\vec{T}$ & $\begin{array}{l}0 \\
\frac{1}{1}\end{array}$ & $\stackrel{+}{+}$ & &  & $\dot{\infty}_{0}$ & $\overline{\mathrm{A}}$ \\
\hline 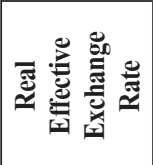 &  & 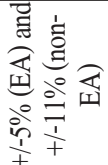 & ?⿱⺈ & \begin{tabular}{l|l}
$\circ$ \\
\end{tabular} & $\vec{r}$ & $\begin{array}{l:l} & 0 \\
i & i\end{array}$ & 9 & $\vec{m}$ & $\vec{r}$ & $\stackrel{+}{+}$ & t. & 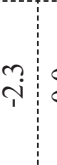 & $\stackrel{0}{\circ}$ & $\begin{array}{l}\stackrel{P}{+} \\
i\end{array}$ & 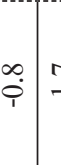 & F & $\begin{array}{l}\stackrel{0}{\circ} \\
\stackrel{\varphi}{\circ}\end{array}$ \\
\hline 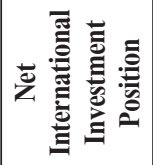 &  & के & $\mid \begin{array}{l}\infty \\
\dot{q}\end{array}$ & तु & $\begin{array}{c:} \\
\end{array}$ & $\hat{m}$ & बें & $\begin{array}{c:c}\vec{\sim} \\
\end{array}$ & $\begin{array}{l}0 \\
\dot{0}\end{array}$ & $\overrightarrow{\vec{T}}$ & $\begin{array}{l}\sigma \\
\dot{a} \\
i \\
i\end{array}$ & $\begin{array}{l}\stackrel{0}{0} \\
\stackrel{1}{1}\end{array}$ & $\begin{array}{l}\hat{0} \\
\stackrel{\oplus}{r}\end{array}$ & $\begin{array}{r}\underset{\infty}{\infty} \\
\infty \\
1\end{array}$ & 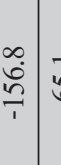 & '? & $\begin{array}{l}\stackrel{+}{0} \\
\text { ț } \\
\end{array}$ \\
\hline 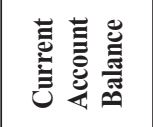 &  & 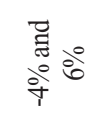 & $\stackrel{0}{-1}$ & t: & I: & $\begin{array}{r:}-6 \\
\end{array}$ & $\widehat{\overbrace{}}$ & $\underset{T}{T}$ & $\exists$ & $\vec{r}$ & iे & $\stackrel{m}{T}$ & 乌े & $\vec{\varphi}$ & \begin{tabular}{l|l}
$\stackrel{0}{+}$ \\
+
\end{tabular} & ָi & $\frac{\text { TY }}{T}$ \\
\hline & &  &  &  &  &  &  & 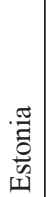 & 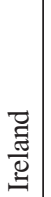 &  & 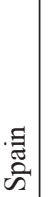 & 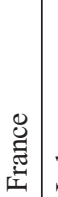 & $\vec{\Xi}$ & 菢 & 今ે & $\sum_{\tilde{\sigma}}^{\frac{\pi}{\sigma}}$ & 㞼 \\
\hline
\end{tabular}




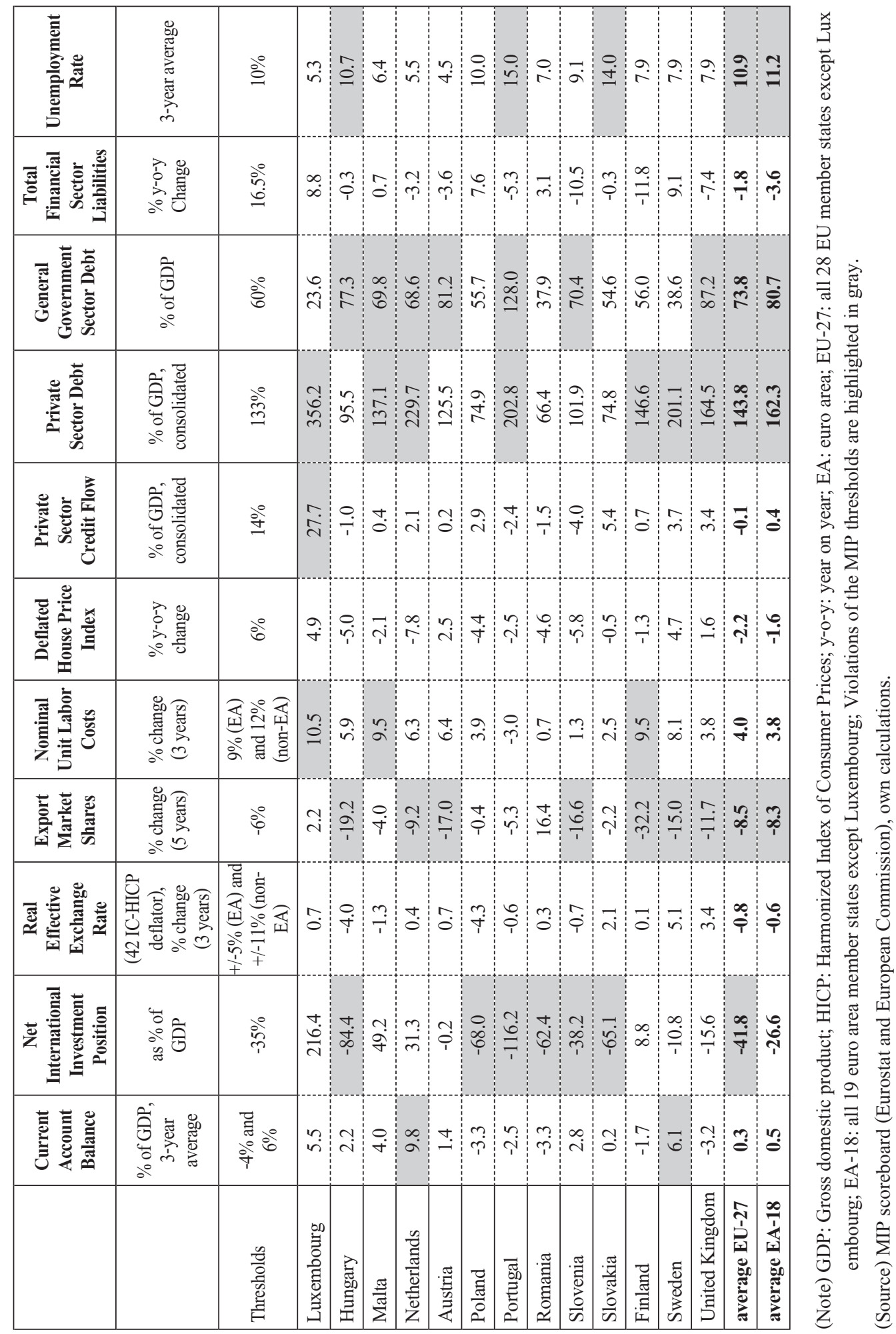




\section{Data and Methodology}

The extensive data bank of the European Commission and Eurostat for the main 11 MIP scoreboard indicators and some auxiliary indicators serve as the basis of the following analysis in Section IV and Section V. At the time of writing, complete annual scoreboard data are available for all 28 EU member states from 2004 to 2013. This period will be sufficient to investigate the effects of the global financial crisis, as well as of the euro-area crisis, on the EMU's core-periphery setting over time.

Previous empirical research employed the scoreboard indicators to predict crises and find optimal country group-specific thresholds to improve the performance of the early warning system. Therefore, Logit/Probit models and neural network analysis have been used, whereas the latter explicitly accounts for the interaction of variables (Knedlik 2015). In contrast to this literature, we make use of the scoreboard data to assess the degree of heterogeneity across EU member states.

To identify homogeneous groups within a population of objects (here countries) based on several features (here indicators), two different cluster methods are applied. First, a hierarchical agglomerative procedure is used to identify a reasonable grouping. Then, we perform a partitioning method to check the sensitivity of the first result. The algorithms used - Ward's method and Fuzzy C-Means (FCM) — are briefly described in the following pages, focusing on why these procedures were chosen (Kaufman und Rousseeuw 2005). The data were first standardized to eliminate differences in scale and treat all indicators as having the same weight.

The algorithms are based on the measurement of the squared Euclidean distance between two objects $i$ and $h$ :

$$
d=\left(x_{i}-x_{h}\right)^{2}=\sum_{k=1}^{p}\left(x_{i k}-x_{h k}\right)^{2}
$$

For all features $(\mathrm{k}=1, \ldots, p)$, the pairwise differences in the observed values $x_{i k}$ (for $\mathrm{i}=1, \ldots, n)$ are squared and afterwards summed. This yields an $n \times n$ distance matrix with each country initially forming a separate cluster.

In the first step of the Ward approach, the two countries with the smallest squared Euclidean distance between them are paired. Then, the distance of the resulting first cluster to all the other objects must be recalculated. The shortest distance is essentially 
calculated so that the smallest increase in heterogeneity would arise in the new cluster after merging different objects or clusters. This heterogeneity within formed clusters can be determined based on the sum of squared errors $(\mathrm{V})$ of a cluster $j$ :

$$
V_{j}=\sum_{i=1}^{n_{j}} \sum_{k=1}^{p}\left(x_{i k j}-\bar{x}_{k j}\right)^{2}
$$

with $x_{i k j}=$ observation of indicator $k$ of country $i$ (for every country in cluster $j$ ) $x_{k j}=$ mean of indicator $k$ in cluster $j$

If there are $n$ individual clusters at the starting point, the sum of squared errors is zero in each case as no variation within the cluster exists. In each step of the process, the distance between object or cluster $\mathrm{A}$ and a new cluster $(\mathrm{B}+\mathrm{C})$ is updated using the following equation:

$$
D(A ; B+C)=\frac{1}{n^{A}+n^{B}+n^{C}} *\left\{\left(n^{A}+n^{B}\right) * d(A ; B)+\left(n^{A}+n^{C}\right) * d(A ; C)-n^{A} * d(B ; C)\right\}
$$

with $n^{A}, n^{B}, n^{C}=$ number of objects in clusters A, B, and C

where D is here twice the increase in the sum of squared errors in Equation (2). If every time the specific objects and clusters with the smallest distance between them are combined, only one cluster exists in the end, which includes all objects (Backhaus et al. 2008).

Ward's method is often regarded as the best hierarchical clustering algorithm as the true grouping in the data can reliably be identified (Bergs 1981). It also tends to form equal group sizes, so its use in the context of core-periphery structures seems sensible. However, the grouping results in Section IV can be replicated in a very similar manner using the average linkage method (see Appendix 1).

A general problem in cluster analysis is determining the optimal number of clusters corresponding to the data as far as possible. As there is usually no substantive information on the accuracy of the number of clusters that should be chosen, several statistical test criteria can be used to provide a more objective definition. For instance, when applying Ward's method, we can use the Calinski-Harabasz pseudo F-test (Backhaus et al. 2008). However, in our case, with only 19 or 28 objects, it is also possible to check the optimal number of clusters through plausible assumptions. While Ward's method also makes it 
possible to choose a proper classification visually using the dendrogram, with the FCM algorithm the number of clusters must be determined ex ante, so that the results vary depending on the initial setting. Concerning the data corresponding to best choice, there is a wide literature on cluster validity (Whang and Zhang 2007).The FCM algorithm used here goes back to Bezdek (1981). In contrast to the clear assignment of an object to a cluster with hard clustering, in fuzzy logic, a degree of membership $u_{i j}$ is determined for each object $i$ in all clusters $j$. Hence, a fuzzy partition matrix $U_{c x n}$ is formed with $\sum_{j=1}^{C} u_{i j}=1$. The aim of this procedure is to recalculate the position of the predetermined number of cluster centers and the membership degrees iteratively, so that at the end of the process, no further improvement in the cluster assignment is possible.

To this end, the objective function

$$
J(U, V)=\sum_{i=1}^{n} \sum_{j=1}^{c} u_{i j}^{m}\left\|x_{i}-v_{j}\right\|^{2}
$$

must be minimized. ${ }^{5}$ Here, $u$ denotes the degree of membership of a country $i$ in cluster $j$ and $\left\|x_{i}-v_{j}\right\|^{2}$ is the squared Euclidean distance between country $i$ and cluster center $v$. We can use Equation (5) and Equation (6)

$$
\begin{gathered}
V_{j}=\frac{\sum_{i=1}^{n}\left(u_{i j}\right)^{m} x_{i}}{\sum_{i=1}^{n}\left(u_{i j}\right)^{m}}, 1 \leq j \leq c \\
u_{i j}=\left[\sum_{g=1}^{c}\left(\frac{\left\|x_{i}-v_{j}\right\|^{2}}{\left\|x_{i}-v_{g}\right\|^{2}}\right)^{1 /(m-1)}\right]^{-1}, 1 \leq j \leq c, 1 \leq i \leq n
\end{gathered}
$$

to minimize the objective function. (Wang and Zhang 2007)

\footnotetext{
${ }^{5}$ The $m$ parameter has an influence on how clearly the cluster allocation to the objects appears. In the following analysis, it is set to the value of 2 .
} 


\section{Results}

\section{A. Results of the Ward algorithm}

First, an agglomerative cluster analysis is undertaken of all current EU member states for the year 2013 using the Ward algorithm. Figure 1 shows the results of this analysis in the form of a dendrogram. It can immediately be seen that three different groups of countries ${ }^{6}$ are identified at a distance of 37-apart from Luxembourg, which can be assessed in many ways as an outlier. ${ }^{7}$ The cluster at the bottom of the dendrogram comprises Belgium, France, Austria, Italy, Finland, Hungary, Slovenia, Slovakia, the UK, Denmark, Germany, Malta, the Netherlands, and Sweden. As this group primarily consists of powerful economies in Central and Northern Europe, it will be referred to as the core group hereafter.

\footnotetext{
${ }^{6}$ Also, the Calinski-Harabasz pseudo $F$-test indicates a reasonable number of four clusters (with Luxembourg).

${ }^{7}$ In particular, due to the net international investment position, private-sector credit flow, and private-sector debt (see Table 1).

${ }^{8}$ Although even core group countries exceed MIP thresholds (see Table 3 below), this cluster best fits the requirements of a stable monetary union.
} 
Figure 1. Dendrogram of the cluster analysis for the EU in 2013



(Note) Cluster analysis using the Ward algorithm.

(Source) MIP scoreboard (Eurostat and European Commission), own calculations and presentation.

Countries of the EU enlargement (Bulgaria, Latvia, Estonia, Czech Republic, Poland, Lithuania, and Romania) are clustered with some distance into an eastern periphery group. Finally, at a further considerable distance, a group often referred to as the Greece, Ireland, Portugal, and Spain (GIPS countries) together with Cyprus and Croatia, is located at the top of the dendrogram. This cluster may be labeled as the southern periphery because it includes primarily those countries most affected by the euro-area crisis and partly dependent on EU assistance. Today, the euro area with its 19 members comprises the majority of countries in the core group and those of the southern periphery (except Croatia). It thus comprises two groups of countries with extremely different economic conditions. This result confirms the intuitively used core-periphery structure during the euro area crisis and proves cluster analysis based on the MIP indicators is a proper empirical tool for examining the functioning of EMU. 
Figure 2. Evolution of clusters in the euro area from 2004 to 2013

Figure 2a: Euro area 2004



Figure 2b: Euro area 2007

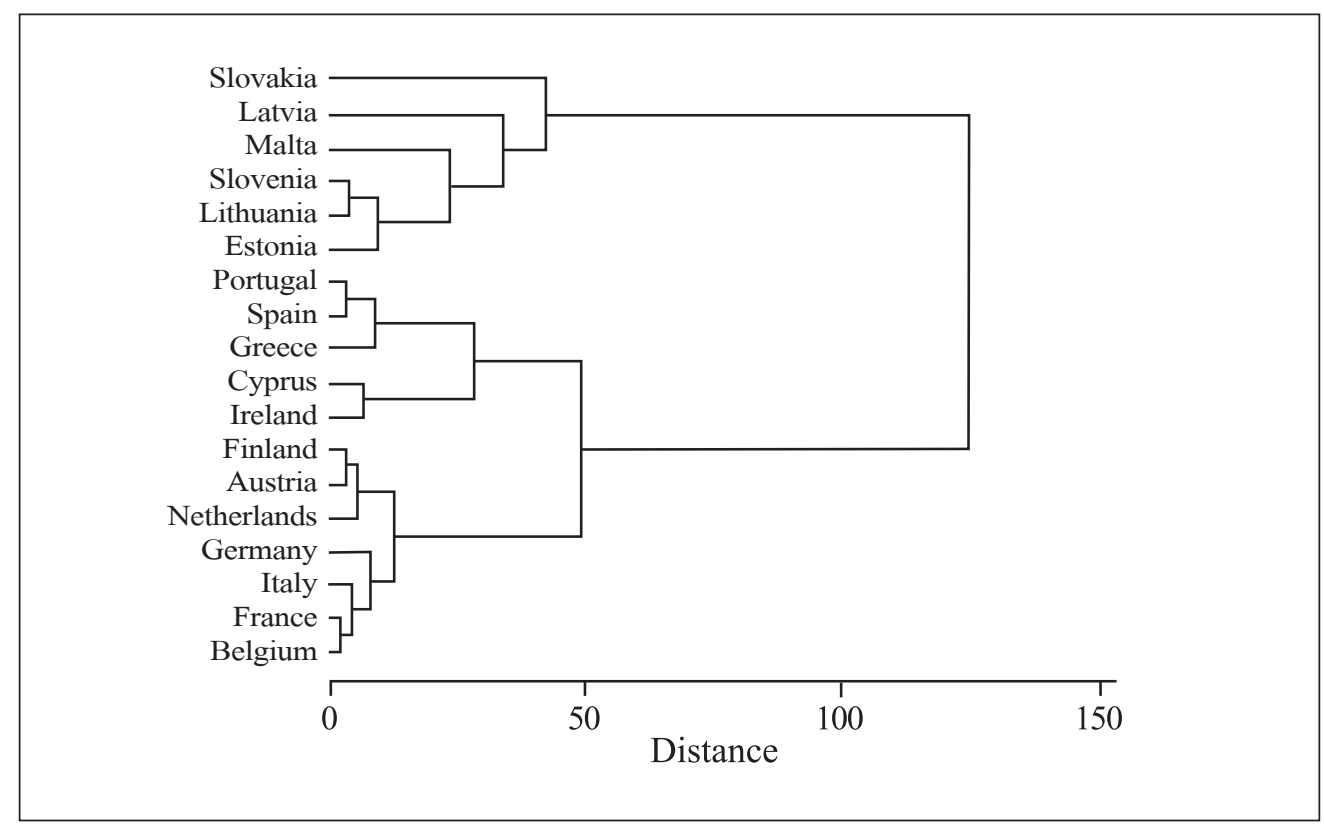


Figure 2c: Euro area 2010



Figure 2d: Euro area 2013

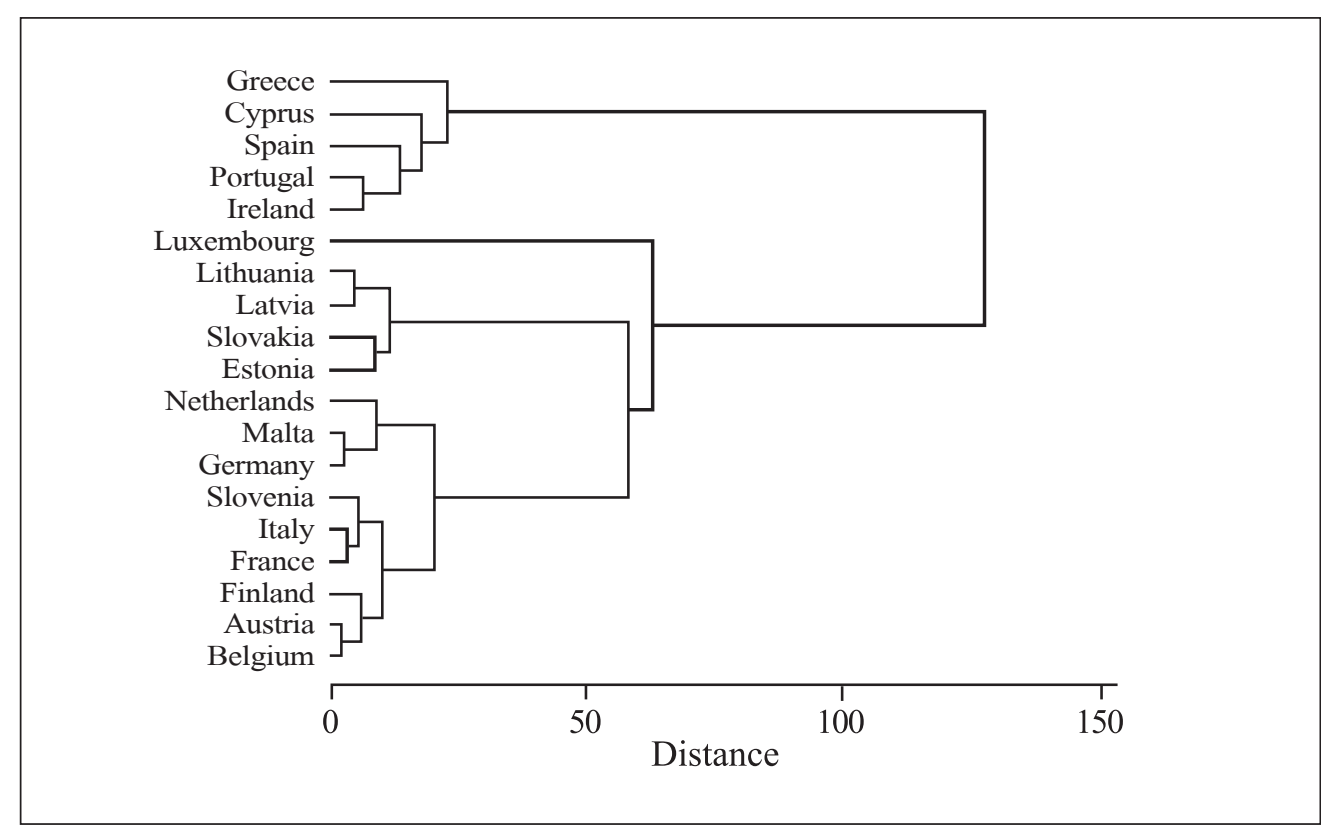

(Note) Cluster analysis using the Ward algorithm. Luxembourg and the house price index variable were dropped due to data gaps in the scoreboard for 2004.

(Source) MIP scoreboard (Eurostat and European Commission), own calculations and presentation. 
Considering now only the current euro-area member states, remarkable insights can also be obtained into the evolution of heterogeneity over the past 10 years. The dendrogram for 2004 (Figure 2a) shows that the core group differs by a wide margin from both the eastern and southern member states. Moreover, in 2007 (Figure 2b), before the financial crisis, the countries now in crisis can clearly be identified as a separate group, although the most marked distance is still that occurring between the core countries and the group of Eastern European countries. By 2010 (Figure 2c), three countries (Malta, Slovenia, and Estonia) from the eastern peripheral group are seen to be approaching the core cluster, even though they still remain identifiable therein as a homogeneous group. Meanwhile, the countries of the southern peripheral group move away from the core group (Figure 2c). Finally, in 2013, they are clustered far from both the eastern periphery and the core (Figure 2d).

\section{B. Results of the Fuzzy C-means algorithm}

According to the results of the Ward method, the countries of the Eastern European periphery and the GIPS countries (plus Cyprus and Croatia) clearly differ from the core group in 2013. Looking at the bottom of the dendrogram in Figure 1, further differentiations within the core group itself seem possible. At this point, the advantages of the FCM clustering algorithm can be used to calculate degrees of membership instead of the explicit assignment of a country to a cluster, as previously undertaken. The countries are therefore each assigned by a certain percentage to all clusters. Assuming again three clusters in the EU-28, the cluster analysis allows a more accurate assessment of countries' extent of belonging to the respective groups (Table 2, left).

Measured by the highest degrees of membership, the FCM algorithm largely confirms the cluster structure of Figure 1. However, Slovakia is instead assigned to cluster 2 of the Eastern European countries and Italy to cluster 3 of the GIIPS countries, which seem both geographically and economically plausible. Italy especially is often considered one of the crisis countries in terms of declining competitiveness, rising debt levels, and increasing unemployment rates. Furthermore, it is striking that Hungary, the only country from the 2004 EU enlargement in cluster 1, has a relatively low level of membership in this cluster and is relatively similar to all clusters. Moreover, Italy is added to cluster 3 but has a slightly lower coefficient for cluster 1. Croatia, the youngest member of the EU, has the greatest similarity to the crisis countries due to its recent poor 
economic situation.

Table 2. Cluster membership of the EU in 2013

\begin{tabular}{|l|c|c|c|c|c|c|c|}
\hline \multirow{2}{*}{ Country } & \multicolumn{2}{|c|}{ Degree of membership if $\boldsymbol{c}=\mathbf{3}$} & \multicolumn{3}{|c|}{ Degree of membership if $\boldsymbol{c}=\mathbf{4}$} \\
\cline { 2 - 7 } & Cluster 1 & Cluster 2 & Cluster 3 & Cluster 1 & Cluster 2 & Cluster 3 & Cluster 4 \\
\hline Belgium & 0.592 & 0.273 & 0.135 & 0.379 & 0.384 & 0.161 & 0.075 \\
\hline Bulgaria & 0.274 & 0.607 & 0.119 & 0.191 & 0.184 & 0.557 & 0.068 \\
\hline Czech Republic & 0.316 & 0.544 & 0.140 & 0.230 & 0.321 & 0.364 & 0.085 \\
\hline Denmark & 0.568 & 0.265 & 0.167 & 0.481 & 0.268 & 0.158 & 0.093 \\
\hline Germany & 0.622 & 0.249 & 0.129 & 0.527 & 0.257 & 0.145 & 0.071 \\
\hline Estonia & 0.290 & 0.569 & 0.141 & 0.203 & 0.180 & 0.533 & 0.084 \\
\hline Ireland & 0.241 & 0.217 & 0.542 & 0.190 & 0.261 & 0.161 & 0.389 \\
\hline Greece & 0.214 & 0.199 & 0.587 & 0.142 & 0.191 & 0.130 & 0.537 \\
\hline Spain & 0.175 & 0.178 & 0.647 & 0.114 & 0.156 & 0.115 & 0.615 \\
\hline France & 0.484 & 0.299 & 0.217 & 0.143 & 0.721 & 0.081 & 0.054 \\
\hline Italy & 0.349 & 0.226 & 0.425 & 0.218 & 0.438 & 0.132 & 0.212 \\
\hline Croatia & 0.263 & 0.260 & 0.477 & 0.195 & 0.296 & 0.181 & 0.328 \\
\hline Cyprus & 0.234 & 0.198 & 0.568 & 0.162 & 0.201 & 0.132 & 0.504 \\
\hline Latvia & 0.241 & 0.617 & 0.141 & 0.153 & 0.177 & 0.591 & 0.079 \\
\hline Lithuania & 0.240 & 0.600 & 0.160 & 0.159 & 0.186 & 0.562 & 0.093 \\
\hline Luxembourg & 0.404 & 0.371 & 0.225 & 0.321 & 0.253 & 0.275 & 0.151 \\
\hline Hungary & 0.391 & 0.309 & 0.300 & 0.242 & 0.445 & 0.168 & 0.144 \\
\hline Malta & 0.664 & 0.258 & 0.079 & 0.597 & 0.223 & 0.139 & 0.041 \\
\hline Netherlands & 0.525 & 0.272 & 0.203 & 0.445 & 0.267 & 0.169 & 0.119 \\
\hline Austria & 0.691 & 0.215 & 0.094 & 0.517 & 0.297 & 0.131 & 0.055 \\
\hline Poland & 0.273 & 0.518 & 0.209 & 0.191 & 0.319 & 0.365 & 0.125 \\
\hline Portugal & 0.103 & 0.103 & 0.794 & 0.075 & 0.124 & 0.073 & 0.728 \\
\hline Romania & 0.267 & 0.543 & 0.190 & 0.192 & 0.246 & 0.442 & 0.121 \\
\hline Slovenia & 0.430 & 0.233 & 0.337 & 0.287 & 0.399 & 0.136 & 0.177 \\
\hline Slovakia & 0.270 & 0.572 & 0.159 & 0.197 & 0.255 & 0.448 & 0.100 \\
\hline Finland & 0.502 & 0.277 & 0.221 & 0.341 & 0.354 & 0.174 & 0.131 \\
\hline Sweden & 0.444 & 0.383 & 0.173 & 0.366 & 0.245 & 0.280 & 0.109 \\
\hline United Kingdom & 0.431 & 0.340 & 0.228 & 0.299 & 0.327 & 0.231 & 0.144 \\
\hline
\end{tabular}

(Note) Cluster analysis using FCM algorithm; $c$ : number of clusters; highest degrees of membership are highlighted in gray.

(Source) MIP scoreboard (Eurostat and European Commission), own calculations and presentation. 
Further differentiation is possible if the EU-28 is separated into four clusters (Table 2 , right). Now cluster 2, except Italy, only comprises countries from the former core group (Belgium, France, Italy, Hungary, Slovenia, Finland, and the UK). Hence, when allowing for some heterogeneity within the clusters, the previous analysis confirms the assumption of three major distinct groups within the EU-28: the Northern European economies, the countries of EU enlargement, and the southern peripheral crisis countries.

\section{Indicators defining the core and the periphery}

The current disparities in Europe are thus confirmed very clearly by cluster analysis. Now, taking a closer look at the single indicators should help to clarify the characteristics and causes of the north-east-south division described above in greater detail. Table 3 shows the average indicator values for the three country groups, ${ }^{9}$ as well as the total euro area. As can be seen, until 2013, significant disparities exist between the core countries and the eastern and southern European peripheries in terms of competitiveness, debt levels, and unemployment.

While the core group as a whole has a positive current account balance averaged over three years, the other two clusters run negative balance sheets. Hence, a stronger euro would suit the core countries, whereas the two peripheral groups could clearly benefit from a weaker currency. This problem can also be seen on the capital account side, where large negative net foreign investment positions are found in the latter group. It is striking that both the southern periphery and Eastern European countries are far below the MIP threshold of $-35 \%$. This can at least partly be seen as an indication of an economic catching-up process. However, the high external liabilities, particularly of the crisis countries, still represent a high risk because they consist a large extent of debt rather than FDI inflows (Fischer and Hobza 2014, European Commission 2015a).

${ }^{9}$ For the exact cluster classification below, the results of FCM clustering (Table 2, left) are used. 
Table 3. Features of the identified clusters in 2013

\begin{tabular}{|c|c|c|c|c|c|c|c|c|c|c|c|}
\hline & 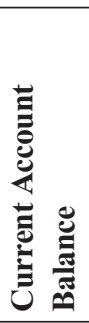 & 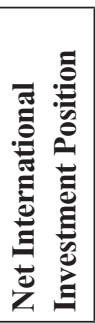 &  & 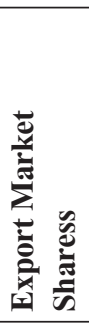 &  & 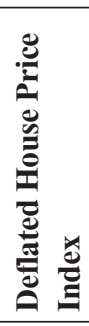 & 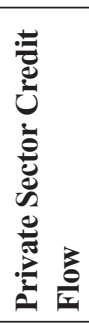 &  & 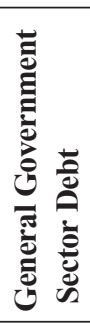 &  & 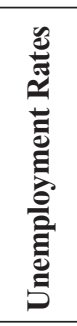 \\
\hline Thresholds & $\begin{array}{l}-4 \% \\
\text { and } \\
6 \%\end{array}$ & $-35 \%$ & $\begin{array}{c}+/-5 \% \\
(\mathrm{EA}) \\
\text { and } \\
\text { (non- } \\
\text { EA) }\end{array}$ & $-6 \%$ & $\begin{array}{c}9 \% \\
(\mathrm{EA}) \\
\text { and } \\
12 \% \\
\text { (non- } \\
\text { EA) }\end{array}$ & $6 \%$ & $14 \%$ & $133 \%$ & $60 \%$ & $16.5 \%$ & $10 \%$ \\
\hline Core group & 2.1 & 10.4 & -0.6 & -14.5 & 6.2 & -2.5 & 0.1 & 140.4 & 83.1 & -4.3 & 7.4 \\
\hline $\begin{array}{l}\text { Eastern } \\
\text { periphery }\end{array}$ & -1.3 & -55.9 & 0.7 & 10.6 & 7.2 & 3.4 & 2.9 & 85.4 & 35.5 & 3.0 & 13.1 \\
\hline $\begin{array}{l}\text { Southern } \\
\text { periphery }\end{array}$ & -2.0 & -118.3 & -2.0 & -14.4 & -4.5 & -5.4 & -6.2 & 224.3 & 124.1 & -10.1 & 17.7 \\
\hline Euro area & 0.5 & -26.6 & -0.6 & -8.3 & 3.8 & -1.6 & 0.4 & 162.3 & 80.7 & -3.6 & 11.2 \\
\hline
\end{tabular}

(Note) EA: euro area.

(Source) MIP scoreboard (Eurostat and European Commission), own calculations and presentation.

On the other hand, the real devaluation and reduction in unit labor costs in the southern periphery over the three years prior to 2014 seem to be less of a concern. This was a necessary adaptation that led to better competitiveness of the Southern European crisis countries. However, it again reflects the dilemma of current monetary policy that low inflation or even deflation is necessary to regain competitiveness in the southern periphery while for the rest of the euro area, an inflation rate of more than $2 \%$ would have to be sought for this purpose. Therefore, a single monetary policy with an average inflation target of $2 \%$ is not equally suitable for all countries. On the part of the core countries and the eastern periphery, unit labor costs increased in this period.

Apart from some Eastern European countries, export market shares decreased from 2009 to 2013 in all countries. Therefore, even the average of all euro-area countries is below the threshold of $-6 \%$ in this period. However, this development can also be 
explained by changes in the global economic situation and the larger export market shares of emerging economies in Asia. The observation of individual country values for this indicator is not very productive.

Rather, a comparison with the average loss of the euro area makes sense (Gros and Giovannini 2014). According to the 2013 scoreboard, 17 EU countries exceed the threshold. However, compared with the average loss of export market shares especially, the situations of Greece and Cyprus, as well as that of Finland, with losses considerably more than twice the average, are worrying (European Commission 2015b).

Although most core countries also exceed the private and public sector debt thresholds, with limits of $133 \%$ and $60 \%$ respectively, they are still well below the extreme values of the countries of the southern periphery (with averages of $224 \%$ and $124 \%$ respectively). In contrast, the Eastern European countries are at much lower and harmless levels (an average of $85 \%$ and 35\%). However, while the negative private credit flows in the southern periphery can be seen - at least for Spain, Portugal, and Ireland - as a sign of private debt reduction, this has not yet happened in Greece (European Commission 2015b). The core and east of the euro area differ in their private sector credit flows at a low level and only slightly from each other. Overall, despite ECB's expansionary monetary policy, a weak demand for credit has so far undermined the intended effect on growth.

The change in the inflation-adjusted house price indicator, which is intended to show the risk of price bubbles in the real estate market, develops differently between the country groups. Besides the significant negative corrections of previous years in the Southern European countries and apart from slight increases in Germany and the Netherlands, the house price indicator also declines moderately in the core countries. The positive average in the Eastern European countries is caused by increases in Estonia and Latvia, which are more than four times as high as the euro-area average.

Unemployment rates still differ greatly between country groups. While they are moderate at $7.4 \%$ in the core group, they are at $17.7 \%$ in the southern periphery. In the crisis countries, and in Croatia particularly, youth unemployment has reached record levels of close to or above $40 \%$. Ongoing fiscal austerity and the expectation of only weak economic growth worsen the prospects of a quick improvement in the situation (European Commission 2015b). Against this background, it is difficult to say whether and when the ECB will be able to reverse its low interest rate policy in favor of the Southern European crisis economies. This underlines the need for effective economic policy measures in these countries. 


\section{Robustness}

The previous division into groups was initially based on an equally weighted use of all 11 scoreboard indicators. Therefore, the similarity in current account balances was assumed to be just as important as the similarity in lending or unemployment rates. However, aside from this assumption, it is important to know which disparities are potentially more dangerous than others and which variables might have common explanatory power. Ultimately, a differently weighted or modified number of indicators might explain the core-periphery structure. Thus, in accordance with Kozluk (2005), we carry out PCA, which reduces the number of 11 original variables to three underlying main components that explain $70 \%$ of the total variation. High values for the first principal component generally correspond to declining unit labor costs and housing prices, a negative net international investment position, negative private sector credit flows, and a decrease in total financial sector liabilities, as well as high general government debt and a high unemployment rate. In contrast, the second principal component correlates strongly and positively with the indicators for current account and private debt levels and negatively with export market share. A graphical representation of the first two principal components in Figure 3 shows that such an analysis identifies the same three clusters as in the previous cluster analysis. (The third principal component, which is highly correlated with the real exchange rate, was not shown for reasons of clarity of illustration but would not change the cluster structure.) Also visible is the unclear attribution of Italy and Hungary, which are found lying between two groups, as well as the classification of Luxembourg as an outlier. 
Figure 3. Country groups according to the first two principal components



(Note) The correlation matrix between variables and main components and the cumulative variance explained can be found in Appendix 2.

(Source) MIP scoreboard (Eurostat and European Commission), own calculations and presentation.

\section{Policy Suggestions}

\section{A. Suitability for EMU membership}

Our results indicate that recent economic developments in Denmark, the UK, and Sweden are similar to those in the core countries of the euro area. In particular, all cluster specifications suggest that Denmark and Sweden exhibit strong similarities with Malta, the Netherlands, and Germany. Based on these results, the functioning of the EMU would not be impaired by the accession of these countries. Hence, our findings do not 
provide economic justification for the countries' opting out decisions and thus clearly differ from the earlier results of Artis and Zhang (2002). But citizens of Denmark, the UK, and Sweden have always been skeptical towards the euro primarily for social and political rather than for economic reasons (see Müller-Peters et al. 1998 for a crossnational study on these factors). Issues like national pride and identity seem to play a crucial role for the attitude of a country towards the euro (Müller Peters 1998). In this regard, the first referendum decisions of Denmark and Sweden to retain their national currencies could be attributed to a more general feeling of meddling by the European Union. In the case of Denmark, the EMU referendum debate was influenced by other political issues like immigration policy (see Bering 2000 for the case of Denmark and Sunnus 2004 for Sweden). Since then, the Eurobarometer frequently confirmed that the degree of skepticism against the EMU is highest among the Danish, Swedish and British population compared to other member states of the European Union.

Resistance may have increased further due to the fact that the majority of voting power in the European Union is now held by EMU member states. This links European decision-making with the common needs of the euro area and its current crisis, which may also explain, why the UK will rather hold referendum about the withdrawal from the European Union as a whole. In general, skepticism towards the European Union and its decision-making process is a phenomenon common across all EU member states. However, in the northern European countries such as the UK, Denmark, and Sweden this skepticism focusses primarily on currency matters (Condruz-Băcescu 2014). The experience from the euro area crisis even has worsened this situation since the deteriorating economic conditions in other member countries have additional negative impacts on domestic public attitudes towards the European Union (Ioannou, Jamet, and Kleibl 2015).

Those countries at the southern euro area periphery are already part of the monetary union. This group is significantly different from the rest with regard to many indicators, thereby causing existential problems for the functioning and stability of the euro area as a whole such that even its continued existence in the current constellation is at risk. If these countries remain inside the monetary union this is likely to further reduce the attractiveness of the euro, in particular for stronger economies like the UK, Denmark and Sweden.

The Eastern European group also differs from the core group, so it would be difficult to define a single monetary policy. However, these disparities should not be considered solely negative. Indeed, although there is a relatively high unemployment rate, at the 
same time, those economies gain export market share and run only moderate current account deficits. Moreover, they historically have very low private and public debt, which makes them much less prone to solvency crises than southern EMU member states.

\section{B. Achieving greater homogeneity in the EMU}

The analysis has shown that the current euro area comprises countries with very diverse features. Hence, with respect to a "one size fits all" monetary policy considering union-wide average values, basically two possible conclusions emerge. The most obvious one would be the break-up of the existing euro area offering the chance for countries suffering from the crisis to devaluate their new domestic currencies. From the perspective of a smoothly working monetary union, this is what our results clearly suggest. However, the actual decision of countries to participate in the euro area (or even in the EU) should also depend on country specific considerations such as network externalities and switching costs (Dowd and Greenaway 1993), which are beyond the scope of this article.

If, on the other hand, these countries were to retain the euro for political reasons, our results show that it would be essential for core and peripheral groups to converge regarding the MIP indicators. To achieve such convergence within the current euro area, internal devaluation and structural reforms in this case are thought of as important means of adjustment (Shambaugh 2012). Figure 4 shows recent developments in selected MIP indicators for the previously defined clusters. At first glance, reforms appear to be successful and disparities between country groups tend to resolve. For example, nominal unit labor costs in the southern periphery have declined since 2008 (Figure 4a). Due to falling wages and prices, these countries have experienced a real depreciation (see also Table 3), which has helped them regain their price competitiveness to some extent. However, the corresponding current account improvements (Figure 4b) are based predominantly on crisis-related import reductions, making them unsustainable in the case of economic recovery (European Commission 2015a, 5). If one also takes into account that the GIIPS countries appreciated between 1995 and 2007 by $30 \%$ relative to the remaining EMU member states (Sinn 2013, 3), a further substantial readjustment of relative prices seems unavoidable to rebalance current accounts in the long run (Kang and Shambaugh 2013, 18). 
To permanently reestablish the competitiveness of the southern periphery, further wage adjustments thus need to be supplemented by productivity gains (Frankel 2015, 431). Moreover, the scoreboard analysis shows that external imbalances are only one part of the problem. Besides low exports, also restrained private and government spending and lack of investment currently contributes to persistent weak aggregate demand in the GIIPS countries. Growth and employment are suffering from the ongoing private deleveraging and consolidation of public finances in addition to the deflationary environment. Overcoming this weakness in demand by promoting public and particularly private investments, as conducted by the so-called Juncker plan, appears to be one step in the right direction. If it succeeded in raising productivity, unit labor costs could further be reduced, aggregate demand increased, and the still high unemployment will continue to fall (Figure 4d). Moreover, such investment driven growth is essential to consolidate public budgets and could contribute to their ongoing improvement, which is apparent in Figure 4c.

As a baseline for the needs of the south described above, far-reaching structural reforms influencing competitiveness, growth, and employment through a variety of short- and long term channels would be indispensable. Even in a highly integrated euro area, positive spillovers can indeed emanate from coordinated structural reforms for core and peripheral country groups (European Commission 2014b). 
Figure 4. Average values of selected indicators

Figure 4a. Nominal unit labor costs, year-on-year change

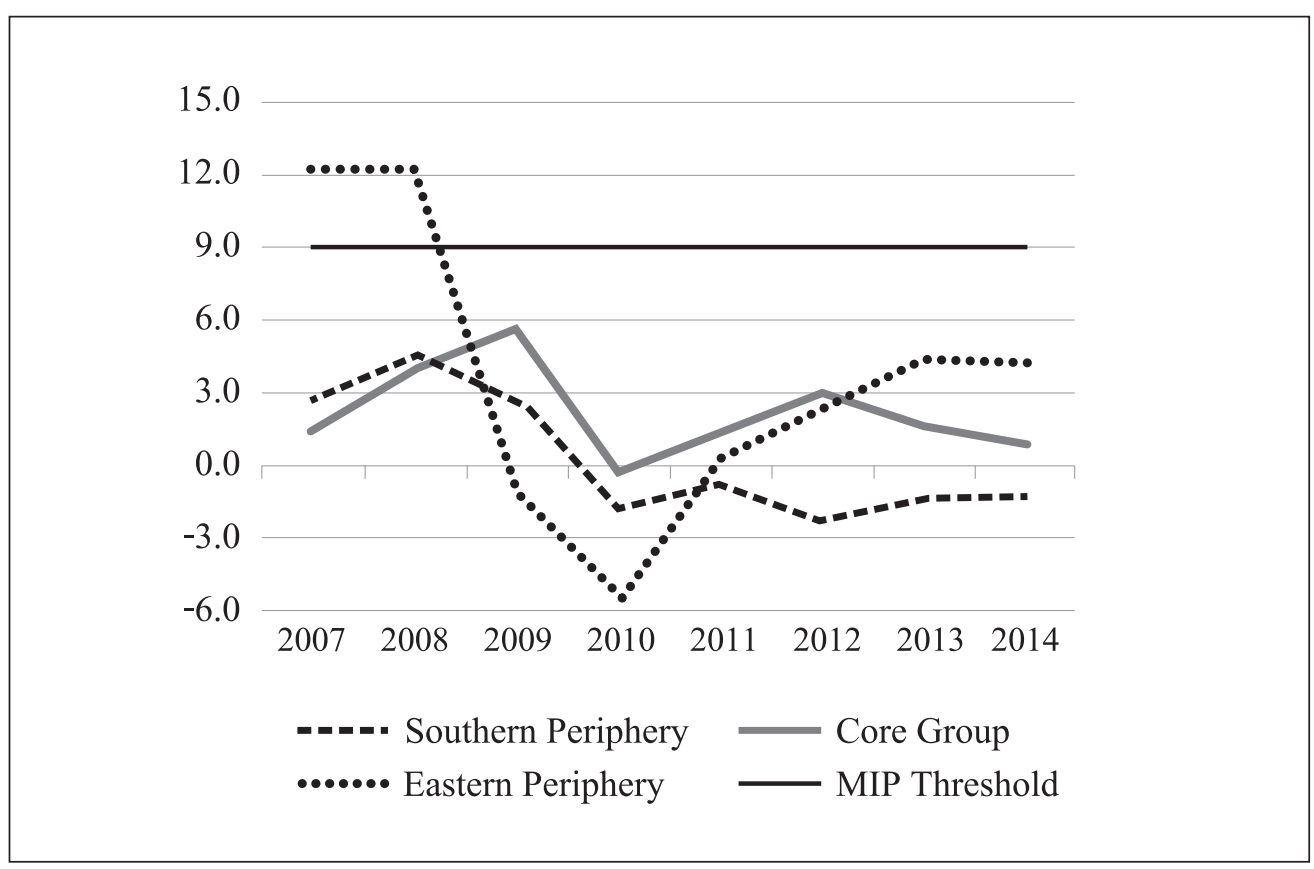

(Note) MIP threshold: 9\%.

(Source) Eurostat, own calculations. 
Figure 4b. Current account balance

(\% of GDP)



(Note) MIP threshold: $-4 \%$ and $6 \%$.

(Source) OECD, own calculations. 
Figure 4c. Fiscal deficits

(\% of GDP)



(Note) Annual data.

(Source) Eurostat, own calculations. 
Figure 4d. Unemployment rate

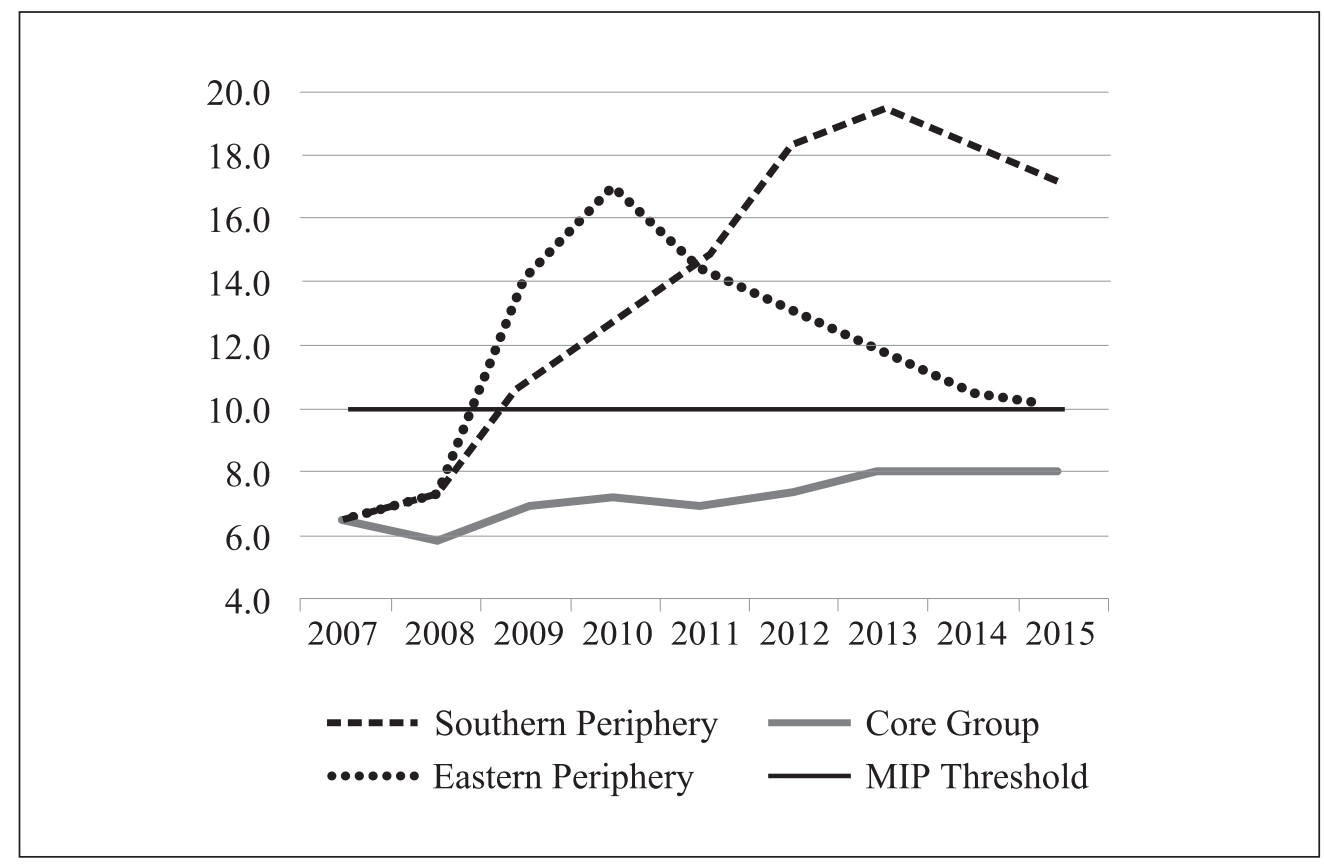

(Note) MIP threshold: $10 \%$.

(Source) Eurostat, own calculations.

\section{Conclusion}

In this paper we have used the MIP scoreboard indicators to investigate cluster structures within the EU and EMU. By applying two different cluster methods we found large heterogeneities between the southern and eastern periphery, and the core countries in central Europe. Hence, our findings are in sharp contrast to the endogeneity hypothesis of an optimal currency area and also question the commitment of an ever closer union at least for all countries. Our results not only confirm earlier research on the economic disparities between the GIIPS and the core countries during the euro crisis but may also serve as an indication of how well an EU member state fits into the monetary union. Regarding the economic suitability, on the one hand, the clustering would suggest the UK to join the euro area rather than holding a referendum about the so-called BREXIT 
from the EU. On the other hand, the results support the view that most of the deficit countries, especially Greece, should rather exit the euro area, as their membership seriously impairs the efficiency and stability of the monetary union. For the euro area in its current formation, our analysis highlights the need for fundamental structural reforms in order to reestablish the well-functioning of EMU. Therefore, our approach helps detecting significant disparities across countries and finding adequate policy responses for each group of countries exhibiting different economic features. Future research may carry out cluster analysis on the upcoming MIP scoreboard data to evaluate, weather the EMU succeeds to increase the degree of homogeneity across member states.

Received 22 December 2015, Revised 29 February 2016, Accepted 26 April 2016

\section{References}

Artis, Michael J., and Wenda Zhang. "Core and Periphery in EMU: A Cluster Analysis." Economic Issues 6 (2001): 39-59.

Artis, Michael J., and Wenda Zhang. "Membership of EMU: A Fuzzy Clustering Analysis of Alternative Criteria." Journal of Economic Integration 17 (2002): 54-79.

Backhaus, Klaus, Bernd Erichson, Wulf Plinke, and Rolf Weiber."Multivariate Analysemethoden, Eine anwendungsorientierte Einführung." $12^{\text {th }}$ ed. Berlin: Springer, 2008.

Bayoumi, Tamim, and Barry Eichengreen. "Shocking aspects of European monetary integration." Adjustment and Growth in the European Monetary Union, edited by Torres, Francisco, and Francesco Giavazzi. Cambridge: Cambridge University Press, 1993.

Bayoumi, Tamim, and Barry Eichengreen. "One Money or Many? Analysing the Prospects for Monetary Unification in Various Parts of the World." Princeton Studies in International Finance 76 (1994).

Bayoumi, Tamim, and Barry Eichengreen. "Ever closer to heaven? An optimumcurrency-area index for European countries." European Economic Review 41 (1997): 761-770. 
Beetsma, Roel, and Harald Uhlig. "An Analysis of the Stability and Growth Pact." The Economic Journal 109 (1999): 546-571.

Bergs, Siegfried. Optimalität bei Clusteranalysen: Experimente zur Bewertung numerischer Klassifikationsverfahren. Münster, 1981.

Bering, Henrik. "Denmark, the Euro, and Fear of the Foreign." Policy Review (2000): 63-72.

Bezdek, James C. Pattern Recognition with Fuzzy Objective Function Algorithms. New York: Plenum Press, 1981.

Boreiko, Dimitri. "EMU and accession countries: Fuzzy cluster analysis of membership." International Journal of Finance and Economics 8 (2003): 309-325.

Caporale, Guglielmo M., Roberta De Santis, and Alessandro Girardi. "Trade intensity and output synchronisation: On the endogeneity properties of EMU." Journal of Financial Stability 16 (2014): 154-163.

Condruz-Bacescu, Monica. "Euroscepticism Across Europe: Drivers and Challenges." European Journal of Interdisciplinary Studies 6 (2014): 52-59.

De Haan, Jakob, Robert Inklaar, and Richard Jong-A-Pin. "Will Business Cycles in the Euro Area Converge? A Critical Survey of Empirical Research." Journal of Economic Surveys 22 (2007): 234-273.

Dowd, Kevin, and David Greenaway. "Currency Competition, Network Externalities and Switching Costs: Towards an Alternative View of Optimum Currency Areas." The Economic Journal 103 (1993): 1180-1189.

Eichengreen, Barry. "The Breakup of the Euro Area." Europe and the Euro, edited by Alesina, Alberto and Francesco Giavazzi, 11-41. Chicago: University of Chicago Press, 2010 .

European Commission. "EMU@10, Successes and challenges after ten years of Economic and Monetary Union." European Economy 2 (2008).

European Commission. "Scoreboard of the surveillance of macroeconomic imbalances." European Economy Occasional Papers 92 (2012).

European Commission. "Focus: Growth differences between EA Member States since the crisis." Quarterly Report on the Euro Area 13 (2014a): 7-20. 
European Commission. "Focus: Cross-border spillovers in the euro area." Quarterly Report on the Euro Area 13 (2014b): 7-22.

European Commission. "Macroeconomic Imbalances, Main Findings of the In-Depth Reviews 2015.” European Economy Occasional Papers 228 (2015a).

European Commission. “Alert Mechanism Report.” (2015b).

Feldstein, Martin. "The Political Economy of the European Economic and Monetary Union: Political Sources of an Economic Liability.” Journal of Economic Perspectives 11 (1997): 23-42.

Fischer, Jonas, and Aleksandr Hobza. "Balancing Imbalances: Integrated Surveillance and the Role of the MIP" Banca d'Italia: Fiscal Policy and Macroeconomic Imbalances, Workshops and Conferences 16 (2014).

Frankel, Jeffrey. "The euro crisis: Where to from here?" Journal of Policy Modeling 37 (2015): 428-444.

Frankel, Jeffrey, and Andrew K. Rose. "The Endogeneity of the Optimum Currency Area Criteria." The Economic Journal 108 (1998): 1009-1025.

Gächter, Martin, and Aleksandra Riedl. "One money, one cycle? The EMU experience." Journal of Macroeconomics 42 (2014): 141-155.

Gros, Daniel, and Alessandro Giovannini. "The "Relative" Importance of EMU Macroeconomic Imbalances in the Macroeconomic Imbalance Procedure." Documenti IAI 02 Istituto Affari Internazionali (2014).

Gruber, Torsten, and Renate Ohr. "The significance of different financial structures in EMU." European economic and monetary union: Regional and global challenges, edited by Caesar, Rolf and Hans-Eckhart Scharrer. Baden-Baden, 2001: 281-300.

Hall, Peter A. "The Economics and Politics of the Euro Crisis." German Politics 21 (2012): 355-371.

Horstmann, Winfried, and Friedrich Schneider. "Deficits, Bailout and Free Riders: Fiscal Elements of a European Constitution." Kyklos 47 (1994): 355-383.

Ioannou, Demosthenes and Jean-François Jamet, and Johannes Kleibl. "Spillovers and Euroscepticism.” ECB Working Paper Series 1815 (2015). 
Jonung, Lars, and Eoin Drea. 'It Can't Happen, It's a Bad Idea, It Won't Last: U.S. Economists on the EMU and the Euro, 1989 2002." Econ Journal Watch 7 (2010): 4-52.

Kang, Joong S., and Jay Shambaugh. "The Evolution of Current Account Deficits in the Euro Area Periphery and the Baltics: Many Paths to the Same Endpoint." IMF Working Paper 169 (2013).

Kaufman, Leonard, and Peter J. Rousseeuw. Finding Groups in Data, An Introduction to Cluster Analysis. New York, 2005.

Knedlik, Tobias. "The Usefulness of the Scoreboard of the Macroeconomic Imbalances Procedure in the European Union: Potentials for Reform." Swedish Institute for European Policy Studies European Policy Analysis (2015):14.

König, Jörg, and Renate Ohr. "Different Efforts in European Economic Integration: Implications of the EU Index." Journal of Common Market Studies 51 (2013): 1074-90.

Kozluk, Tomasz. "CEEC Accession Countries and the EMU - An Assessment of Relative and Readiness for Euro-Area Membership." Journal of Economic Integration 20 (2005): 439-474.

Lane, Philip R. "The European Sovereign Debt Crisis." Journal of Economic Perspectives 26 (2012): $49-68$.

Lehwald, Sybille. "Has the Euro Changed Business Cycle Synchronization? Evidence from the Core and the Periphery." Empirica 40 (2013): 655-684.

Mongelli, Franceso Paolo. "European economic and monetary integration and the optimum currency area theory.” European Economy Economic Papers 302 (2008).

Müller-Peters, Anke. "The significance of national pride and national identity to the attitude towards the single European currency: A Europe-wide comparison." Journal of Economic Psychology 19 (1998): 701-719.

Müller-Peters, Anke, Roland Pepermans, Guido Kiell, Nicole Battaglia, et al. "Explaining attitudes towards the euro: Design of a cross-national study." Journal of Economic Psychology 19 (1998): 663-680.

Ohr, Renate. "The Euro in its Fifth Year: Expectations Fulfilled?" The Price of the Euro, edited by Jonas Ljungberg, 59-69. Basingstoke and New York: Palgrave Macmillan, 
2004.

Pentecôte, Jean-Sébastien, and Marylin Huchet-Bourdon. "Revisiting the core-periphery view of EMU." Economic Modelling 29 (2012): 2382-2391.

Quah, Chee-Heong. "Revisiting business cycles in the Eurozone: A fuzzy clustering and discriminant approach." Acta Oeconomica 64 (2014): 161-180.

Rozmahel, Petr, Ludek Kouba, Ladislava Grochová, and Nikola Najman. "Integration of Central and Eastern European Countries: Increasing EU Heterogeneity?" WWW for Europe Working Paper 9 (2013).

Shambaugh, Jay. “The Euro's Three Crises.” Brookings Papers on Economic Activity 44 (2012): 157-231.

Sinn, Hans-Werner. "Verantwortung der Staaten und Notenbanken in der Eurokrise, Gutachten im Auftrag des Bundesverfassungsgerichts." ifo Schnelldienst, special edition, June (2013): 3-33.

Sunnus, Milena. "Swedish Euroscepticism: Democracy, Sovereignty and Welfare." European Studies 20 (2004): 193-205.

Wang, Weina, and Yunjie Zhang. "On fuzzy cluster validity indices.” Fuzzy Sets and Systems 158 (2007): 2095-2117. 


\section{Appendix 1: Dendrogram of the cluster analysis for the EU in 2013}

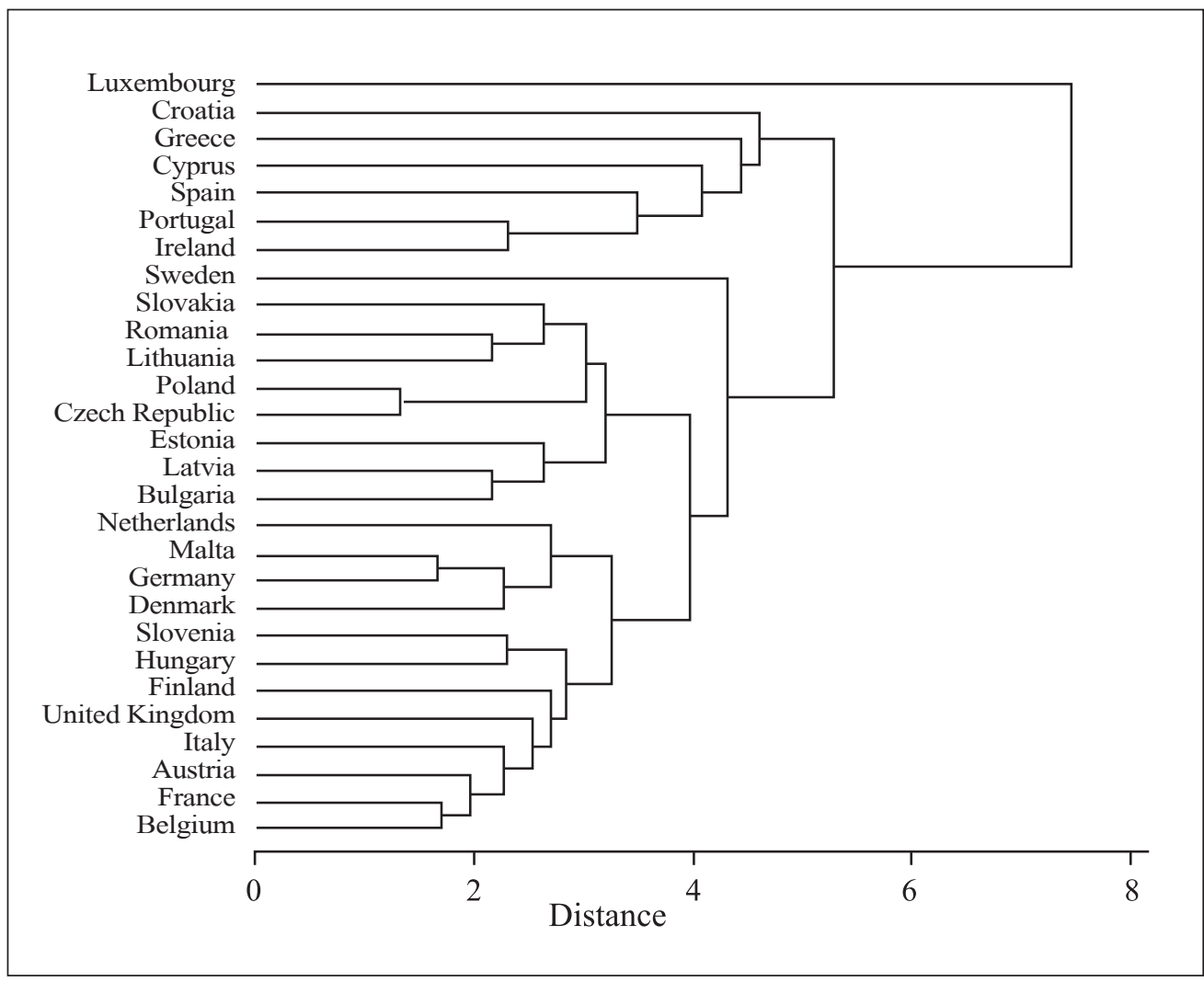

(Note) Cluster analysis using the average linkage algorithm.

(Source) MIP Scoreboard (Eurostat and European Commission), own calculations and presentation. 


\section{Appendix 2: Correlation matrix and cumulative variances}

\begin{tabular}{|l|c|c|c|c|c|}
\hline MIP-Indicators & $\begin{array}{c}\text { Component } \\
\mathbf{1}\end{array}$ & $\begin{array}{c}\text { Component } \\
\mathbf{2}\end{array}$ & $\begin{array}{c}\text { Component } \\
\mathbf{3}\end{array}$ & Component & $\begin{array}{c}\text { Cumulative } \\
\text { variance explained }\end{array}$ \\
\hline $\begin{array}{l}\text { Current Account } \\
\text { Balance }\end{array}$ & -0.496 & 0.564 & -0.308 & 1 & 0.429 \\
\hline $\begin{array}{l}\text { Net Internat. } \\
\text { Investment Position }\end{array}$ & -0.756 & 0.475 & -0.158 & 2 & 0.604 \\
\hline $\begin{array}{l}\text { Real Effective } \\
\text { Exchange Rate }\end{array}$ & -0.467 & 0.102 & 0.730 & 3 & 0.702 \\
\hline $\begin{array}{l}\text { Export Market } \\
\text { Shares }\end{array}$ & -0.483 & -0.677 & 0.144 & 4 & 0.776 \\
\hline $\begin{array}{l}\text { Nominal Unit } \\
\text { Labor Costs }\end{array}$ & -0.860 & -0.095 & -0.116 & 5 & 0.831 \\
\hline $\begin{array}{l}\text { Deflated House } \\
\text { Price Index }\end{array}$ & -0.707 & -0.067 & 0.440 & 6 & 0.877 \\
\hline $\begin{array}{l}\text { Private Sector } \\
\text { Credit Flow }\end{array}$ & -0.771 & 0.087 & -0.093 & 7 & 0.912 \\
\hline Private Sector Debt & -0.029 & 0.715 & 0.306 & 8 & 0.942 \\
\hline $\begin{array}{l}\text { General Government } \\
\text { Sector Debt }\end{array}$ & 0.787 & 0.328 & 0.004 & 9 & 0.971 \\
\hline $\begin{array}{l}\text { Total Financial } \\
\text { Sector Liabilities }\end{array}$ & -0.699 & -0.413 & -0.284 & 10 & 0.990 \\
\hline Unemployment Rate & 0.709 & -0.322 & 0.120 & 11 & 1.000 \\
\hline
\end{tabular}

(Note) Cumulative variance explained for the principal components of the scoreboard indicators in 2013.

(Source) MIP scoreboard (Eurostat and European Commission), own calculations and presentation. 


\title{
The core-periphery pattern of European business cycles: A fuzzy clustering approach
}

\author{
Markus Ahlborn*, Marcus Wortmann \\ Georg-August-University Göttingen, Platz der Göttinger Sieben 3, 37073 Göttingen, Germany
}

\section{A R T I C L E I N F O}

\section{Article history:}

Received 17 March 2017

Revised 15 August 2017

Accepted 16 August 2017

Available online 18 August 2017

\section{JEL Classification:}

C38

E32

F15

F45

Keywords:

Business cycles

Core-periphery

Euro area

Fuzzy cluster analysis

\begin{abstract}
A B S T R A C T
The literature on business cycle synchronization in Europe frequently presumes an alleged 'core-periphery' pattern without providing empirical verification of the underlying cyclical (dis)similarities or the supposed but unobservable 'European business cycle(s)'. To provide a data-based country group analysis, we apply a fuzzy clustering approach to quarterly output gap series of 27 European countries over the period 1996-2015. Our results confirm the existence of a persistent core cluster as opposed to clusters on the Eastern and Southern European peripheries, highlighting the inadequate composition of the euro area (EA). Moreover, we find that Germany's business cycle is not a suitable substitute for the core. By analyzing the relation between the identified 'European core business cycle' and the peripheral cycles over time, we show diverging patterns for the southern periphery after the financial crisis as well as convergence for the eastern periphery.
\end{abstract}

(c) 2017 Elsevier Inc. All rights reserved.

\section{Introduction}

Since the adoption of a single European currency in the early 1990s, the synchronization of business cycles between European economies has become a major field of both theoretical and empirical research. The main objective of this literature is to investigate the extent to which a common 'European business cycle' is established that applies as a basic condition for a smoothly working monetary union (Artis et al., 2004). In fact, the global financial crisis and the subsequent euro crisis have rather provided evidence of large economic discrepancies primarily between groups of countries within and beyond the euro area (EA). Therefore, cyclical (dis)similarities should be considered from a group perspective, for instance between the 'vulnerable' economies in Southern Europe (European Commission, 2014) or the Central and Eastern European countries (CEECs; Fidrmuc and Korhonen, 2006; Stanisic, 2013; Di Giorgio, 2016) and the Central European countries.

A conventional scheme for the analysis of business cycle patterns among groups of (prospective) EA members is the coreperiphery division (Camacho et al., 2006). As opposed to the Southern, the Eastern and sometimes the Northern European 'periphery,' a homogeneous 'core' group is typically identified among the founding EU Member States, with Germany at its center (see, for instance, Arestis and Phelps, 2016). Assuming that the supposed core countries share similar business cycles, say the 'European core business cycle,' policy makers may thus be interested in how closely countries are associated with this cycle compared with other group-specific European cycles. However, the identification of core and peripheral European business cycles and the potential group composition remain inconsistent in the literature. In this paper we propose a more

\footnotetext{
* Corresponding author.

E-mail addresses: markus.ahlborn@wiwi.uni-goettingen.de (M. Ahlborn), marcus.wortmann@wiwi.uni-goettingen.de (M. Wortmann).
} 
comprehensive way to explore the core-periphery pattern empirically by conducting a fuzzy cluster analysis of business cycle time series, which allows us to provide detailed information on countries' accordance with group-specific European business cycles.

Some previous studies, like those by Artis and Zhang (2002), König and Ohr (2013) and Wortmann and Stahl (2016), identify a suitable core group for the EA through cluster analyses based on different sets of static macroeconomic criteria, partly related to the optimum currency area (OCA) theory. Among these cyclical similarities are only considered implicitly. Despite taking into account a variety of criteria, the multivariate approaches face difficulties in selecting and weighting the potential variables that may be regarded as relevant preconditions for a smoothly working monetary union. Consequently the obtained country groups may be driven by inadequate, potentially correlated country features dominating the clustering process. Artis and Zhang (2001) also point to the fact that multivariate cluster analysis groups countries regardless of whether their similarity is due to negative or positive features in terms of a well-functioning monetary union. If the driving factors of the group assignment remain unclear, the suitability of any cluster for monetary unification will be unclear too. However, the few multivariate analyses are the exceptions, as the vast majority of studies dealing with the core-periphery division concentrate on business cycle synchronization. ${ }^{1}$ For these reasons the present paper focuses on business cycles and connects all the results to the extensive literature summarized below.

When time series data on business cycles are used, basically two different ways of assessing the core-periphery pattern can be distinguished. Darvas and Szapary (2008), Hughes Hallet and Richter (2008), Crespo-Cuaresma and FernándezAmador (2013), Lehwald (2013), Caporale et al. (2015), Arestis and Phelps (2016) and Belke et al. (2016) analyze business cycles using various methods within or across putative groups like the 'GIPS countries,' the 'peripheral countries' or the 'core countries' that are set in advance. Hence, the assignment of each country to its group is subject to general assumptions at best taken from the literature. As pointed out by Belke et al. (2016), 'there exists no exact definition as to which countries belong to the core or to the periphery.' For instance, there is no consensus on the classification of Italy. Some studies locate it on the southern periphery (e.g. Hughes Hallet and Richter, 2008; Caporale et al., 2015), but recent evidence suggests that it shows a great deal of business cycle synchronization with the core (Belke et al., 2016; Campos and Macchiarelli, 2016). Following the idea that countries will be more or less connected to any existing group-specific European business cycle, the fuzzy clustering approach adopted here allows us to quantify each country's degree of belongingness to all the identified clusters. Moreover, while the literature focuses on the distinction between the core and the Southern European periphery, the classification of the CEECs, among them prospective EA member countries, is of special interest.

The second approach to classifying countries as belonging to the 'core' or the 'periphery' is to analyze their relation to a reference cycle. The first authors to do so are Bayoumi and Eichengreen (1993), who base their analysis on correlations of the national supply and demand shocks with those of Germany as an 'anchor' or 'center' country. Pentecôte and HuchetBourdon (2012) repeat this exercise but additionally control for correlations vis-à-vis the EA (11) reference area. They find that 'France, rather than Germany has served as an anchor point for convergence of the other EU countries.' The study by Aguiar-Conraria et al. (2013) uses wavelet tools to analyze the synchronization between an aggregate EA (10) economic sentiment cycle and the national cycles. Their findings also reveal that the composition of a core group is not quite intuitive, because the core itself can even be divided into a 'German pole' and a 'French pole' also comprising Italy and Spain, respectively. Based on industrial production data, Aguiar-Conraria and Soares (2011) reach similar conclusions, confirming the leading role of the French business cycle.

Obviously, an important assumption of such analyses is the choice of a suitable proxy for the supposed but unobservable European business cycle. So far Germany's business cycle, a weighted EA average and the EA's aggregate cycle are used frequently as such reference measures for business cycle synchronization analyses. ${ }^{2}$ Using a representative core country, like Germany, as a reference is generally justified by the 'leading economy' argument but will be problematic if this country's business cycle, temporarily and for idiosyncratic reasons, deviates from all the others. As will be discussed in Section 3 below, our results indicate that Germany's cycle indeed does not qualify as a suitable anchor. Even the EA's aggregate cycle is an inappropriate proxy for the European core business cycle, as it may be distorted by large economies, like Spain or Italy, that possibly belong to peripheral clusters. Darvas and Szapary (2008) cope with this problem to a certain extent by estimating a common factor of the supposed core group as a reference. However, membership of this core is again arbitrary and not based on cyclical similarities. Finally, Camacho et al. (2006) and Mink et al. (2012) state that neither the existence of one single European cycle nor its compliance with any chosen reference can readily be assumed in advance, casting doubt on many results of previous business cycle analyses.

Similarly, the previous clustering analyses of Artis and Zhang (2002), Boreiko (2003), Kozluk (2005), Crowley (2008) and Quah (2014) assess the suitability of (prospective) EA member countries by grouping them according to their synchronicities

\footnotetext{
1 In the OCA theory, business cycle synchronization is regarded as a 'catch all' or 'meta criterion' in analyzing the costs and benefits of monetary unions. Participating countries with synchronized business cycles will need less autonomy in monetary and exchange rate policies, and thus the costs of losing direct control over such policy areas are reduced (Mongelli, 2005). However, whether having synchronized business cycles should be considered as a prerequisite for a smoothly working monetary union is still subject to debate. According to the endogeneity hypothesis of Frankel and Rose (1997), a high degree of business cycle synchronization may rather be achieved ex post due to increased trade linkages. De Haan et al. (2008) and Kappler and Sachs (2013) provide surveys of business cycle synchronization in Europe.

2 See, for instance, Artis and Zhang (1997), Furceri and Karras (2008), Afonso and Sequeira (2010), Savva et al. (2010), Aguiar-Conraria and Soares (2011), Gächter et al. (2012), Mink et al. (2012) and Kolasa (2013), among others.
} 
with the same references. The clustering algorithms used are based on static feature data, such as the pairwise correlation coefficients between the national and the reference cycle. However, as pointed out by Mink et al. (2012), the simple correlation coefficient of two time series does not provide a proper basis for assessing the coherence of the business cycles. Despite perfectly coinciding phases of up- and downswings, the cycles may only be correlated imperfectly due to their heteroscedasticity. Conversely, in the case of perfect correlation, the amplitude of the cycles may still differ substantially. To deal with these shortcomings, we apply a time series cluster analysis that is based on cyclical distances. Instead of imposing any reference cycle beforehand, the algorithm generates group-specific representative cycles during the clustering process. Hence, we let the data decide the number, location and shape of any such reference cycle, be it that of a European core or any other peripheral cluster. This enables us to investigate further whether there is convergence or divergence between the peripheral cycles and the European core cycle, especially since the global financial crisis and the subsequent euro crisis. While the previous cluster analyses do not include the recent time period, we specifically focus on the impact of these crises on the cluster structure. Some evidence by Gächter et al. (2012) and Degiannakis et al. (2014) indeed shows that the countries that were most affected by the crises, mainly on the southern EA periphery, experienced a decline in synchronization with the EA aggregate cycle thereafter. Ferroni and Klaus (2015) also find that, since the outbreak of the crisis, the Spanish cycle fluctuations have evolved asymmetrically to the other EA (core) countries of their study (Germany, France and Italy). We contribute to this rather limited literature by studying the changes that the crises caused for the core-periphery pattern of 27 European countries, including the CEECs. Therefore, we divide our sample into a 'pre-crisis period' from 1996 to 2007 and a 'post-crisis period' from 2008 to 2015.

In a nutshell, this paper's purpose is to clarify empirically both the number of existing European business cycles and the countries belonging to them. In particular, the following questions will be answered. (1) Is there a European core business cycle? (2) How many peripheral cycles have been established and how do they relate to the core cycle? (3) To what extent can each country's business cycle be associated with these different business cycle clusters?

We address these questions simultaneously by employing a fuzzy clustering approach to output gaps extracted from national real GDP time series. The fuzzy c-means (FCM) algorithm directly separates the most similar business cycles into several clusters, assigning to each country a degree of membership of the group-specific European business cycles at the center of the clusters. To our best knowledge, this immediate way of assessing groups in the data has not yet been applied to output gap series and provides some advantages for both future research and policy advice. In particular, our contributions to the literature are the following. First, we offer a precise classification of countries within the complex core-periphery pattern of European business cycles, clarifying the position of controversial cases like Italy, the CEECs and Germany as an anchor country. This classification can provide valuable guidance for future studies on business cycle synchronization, in which core and peripheral country groups have to be set beforehand. Second, we specifically analyze how this coreperiphery pattern has changed over time, especially since the global financial crisis. Third, we provide a European core business cycle that can be used as a more suitable anchor cycle in future studies. Finally, fourth, the relative belongingness of each country to this representative core cycle provides information on the costs of sharing a common currency with the core countries in terms of business cycle synchronization.

With regard to the three questions posed above, our main results can be summarized as follows. (1) We find evidence supporting the existence of a persistent core cluster among the Central European economies. Remarkably, Germany exhibits a lower degree of belongingness to the European core cycle, which clearly questions its common use as a reference country. (2) There are some peripheral business cycle clusters corresponding to regional proximity in Europe: the CEECs split up into clusters on the eastern periphery, most evidently in the Baltic and the South Eastern region. These clusters have apparently converged towards the core since the global financial crisis of 2008/2009, contrary to the members of the southern periphery, the other distinct business cycle cluster to be found in the data. This latter cluster has rather diverged from the core since the crisis. (3) Among other findings the 'core membership coefficients' show that especially the 'EA outs' and 'EU outs,' Denmark, Sweden, Switzerland and the UK, as well as some CEECs, especially Hungary and to a lesser degree the Czech Republic and Poland, could adopt the euro at lower costs than countries on the eastern and southern peripheries, as they apparently possess greater business cycle similarities to the core group.

The remainder of this paper is organized as follows. Section 2 introduces the data set and the clustering methodology that we employ. Section 3 presents the results of the main cluster analyses, including the sample splits, and studies the relationship between the European core business cycle and the peripheral cycles. Moreover, the robustness of our findings is checked by altering the clustering design and the distance measurement as well as by dropping the crisis years 2008/2009 and including other OECD control countries. Finally, Section 4 concludes.

\section{Methodology}

\subsection{Data and filtering}

The following cluster analyses are based on output gaps extracted from time series of (seasonally adjusted) quarterly real GDP for 25 EU Member States (the EU-28 minus Cyprus, Malta and Luxembourg) plus Norway and Switzerland ranging from 1996 Q1 to 2015 Q4. We consider the latter two countries as they are highly integrated with the EU and because we try to give a comprehensive picture of European business cycles regardless of EU or EA membership. However, the cluster solutions obtained are not sensitive to their inclusion. The time series for most of the countries are collected from the 
OECD main economic indicators (Belgium, Denmark, Germany, Greece, Spain, France, Italy, the Netherlands, Austria, Portugal, Finland, Sweden, the United Kingdom, Norway, Switzerland, Ireland, Bulgaria, Romania, Hungary, the Czech Republic, Croatia, Poland and Slovakia, plus - for robustness purposes - the USA, Japan and Korea). The remaining statistics, for Estonia, Latvia, Lithuania and Slovenia, are obtained from the Oxford Economics database. The reason for not considering previous business cycle data is the lack of reasonable data for the CEECs, of which the cyclical accordance with the core countries may be regarded as a key criterion for future accession to the monetary union.

To avoid dropping any further data points at the edges of the sample period, we extract the stationary cyclical components from the time series using the band-pass filter developed by Christiano and Fitzgerald (2003, [CF]). The filter is set to extract periodic fluctuations lasting between 6 and 32 quarters. For robustness purposes, however, we also apply the high-pass filter by Hodrick and Prescott (1997, [HP]), which does not change the general cluster solutions apart from some deviations in membership degrees (see Section 3.4). All the output gaps are then expressed as a percentage of the cyclical component of the trend component. We choose the CF band-pass and the HP high-pass filter as these are two of the most commonly used filters in the literature with which to compare our results. The CF filter is used for the main analysis, as it is specifically suitable for GDP series supposing a random walk with drift. It dominates the other commonly used Baxter-King band-pass filter in real-time applications and does not require the omission of data points at the beginning or end of the time series (Christiano and Fitzgerald, 2003).

\subsection{Fuzzy c-means clustering}

The FCM algorithm that we employ is a widely used unsupervised clustering technique generalized by Bezdek (1981). ${ }^{3}$ Its purpose is to partition the data into a given number of $c$ clusters, each characterized by a cluster 'centroid' or 'prototype' at the center. An iterative procedure varies the location of these centroids to find the solution, which minimizes the weighted sum of the squared Euclidean distances ${ }^{4}$ between the objects (here countries) and the centroids. During that process each object is repeatedly given a set of weights corresponding to the similarity that it exhibits to the varying centroids. The more closely an object resembles the centroid of a specific cluster, the greater is the weight that it receives for that cluster. By using these weights, also called membership coefficients, the coordinates of the centroids are recalculated as similarityweighted averages ('c-means') of all the objects until an optimal solution is found. As the membership coefficients sum up to one, the fuzzy partition matrix $u$ indicates how close an object is to the centroid of one cluster relative to the others.

In particular, the following objective function should be minimized:

$$
J_{m}(U, V)=\sum_{i=1}^{n} \sum_{j=1}^{c} u_{i j}^{m}\left\|x_{i}-v_{j}\right\|^{2}
$$

where $u$ is the fuzzy membership matrix indicating the weights of time series $x_{i}$ in each cluster $\mathrm{j}$ and $\left\|x_{i}-v_{j}\right\|^{2}$ denotes the squared Euclidean distance between the time series $x_{i}$ and each cluster's centroid time series $v_{j}$, while m stands for the fuzzifier. ${ }^{5}$ Minimizing $J$ under the constraints $0<\sum_{i=1}^{n} u_{i j}<n, \sum_{j=1}^{c} u_{i j}=1$ and $\sum_{j=1}^{c} \sum_{i=1}^{n} u_{i j}=n$ yields:

$$
\begin{aligned}
& v_{j}=\frac{\sum_{i=1}^{n}\left(u_{i j}\right)^{m} x_{i}}{\sum_{i=1}^{n}\left(u_{i j}\right)^{m}}, 1 \leq j \leq c \\
& u_{i j}=\left[\sum_{g=1}^{c}\left(\frac{\left\|x_{i}-v_{j}\right\|^{2}}{\left\|x_{i}-v_{g}\right\|^{2}}\right)^{1 /(m-1)}\right]^{-1}, 1 \leq j \leq c, 1 \leq i \leq n
\end{aligned}
$$

The algorithm generally proceeds in the following way:

1 Randomly initialize $u_{j i}$.

2 Calculate $c$ cluster centroids $v_{j}$ with Eq. (2).

3 Update $u$ according to Eq. (3).

4 Calculate objective function $J$.

5 Return to step 2 until the improvement in $\mathrm{J}$ is less than the selected threshold.

\footnotetext{
${ }^{3}$ The following description of FCM is based on Wang and Zhang (2007). Liao (2005) provides a short history of this method in his survey of time series clustering. For further details see Kaufman and Rousseeuw (2005).

${ }^{4}$ The FCM algorithm was developed using the Euclidean distance norm (11 norm), which we use for our main analyses. For robustness purposes, in Section 3.4 we also perform the clustering with the 'Manhattan' distance norm (12 norm). Having time series data of equal length and scale, we rely on these two commonly used standard distance measures as they are parameter-free and competitive with other, more complex approaches that have been developed for time series clustering (Wang et al., 2012).

${ }^{5}$ The fuzzifier controls the degree of fuzziness during the clustering process. According to Nikhil and Bezdek (1995), $m$ is usually set between 1.5 and 2.5 depending on the degree of 'fuzziness' or 'overlap' in the data. Depending on the length of the time series we investigate and hence depending on the degree of fuzzy overlap in our different analyses, we adjust $\mathrm{m}$ to values within the usual bounds to achieve the highest silhouette (explained below) at a reasonable level of fuzziness.
} 
In the context of business cycle analysis, the resulting centroid time series $v_{j}$ correspond to the existing group-specific European business cycles, whereas the respective membership coefficient matrix $u$ provides detailed information on the extent to which a country can be assigned to each of the identified centroid cycles. Since a higher membership coefficient signifies greater proximity to the respective cluster's centroid, this allows a ranking of countries according to their degree of belongingness.

A wide array of different clustering algorithms is available. However, we are convinced that the FCM algorithm best suits our research purposes, as its properties - clustering that is fuzzy and partitional - offer several advantages over other algorithms for our application. First, as mentioned above, fuzzy clustering - as opposed to 'crisp' or 'hard' clustering algorithms (e.g. those applied by Camacho et al., 2006, 2008) - allows for different degrees of membership of all the clusters and does not assign countries irrevocably and exclusively to just one group. On the one hand, such fuzziness enables us to rank the countries according to their cyclical similarities to the European core business cycle, providing information on the costs of joining the monetary union with the core countries. On the other hand, a fuzzy algorithm is better suited to dealing with outliers. In a crisp partition, outliers tend to form separate clusters containing only that single object, while, in a fuzzy partition, they tend to lie between the clusters exhibiting equal membership coefficients. Consequently, the fuzzy partition is less dominated by such single-object clusters, so outliers can be detected without distorting the remaining group structure (Bezdek et al., 1982).

Choosing a partitional algorithm as opposed to one that is 'hierarchical' ${ }^{6}$ (e.g. that employed by Camacho et al., 2006) offers a further advantage for our purposes. While the FCM algorithm does not provide information on the cluster hierarchy, it identifies cluster centroids as similarity-weighted averages of all the countries based on their membership coefficients. ${ }^{7}$ Using these representative cycles, we investigate their relationship over time, which clearly sets our analysis apart from previous cluster analyses on business cycle data that only focus on the classification of countries.

However, the results of such a partitional cluster analysis will depend on the supposed number of clusters, which we do not know beforehand. The problem of finding an optimal $c$ without any prior information is known as cluster validity and requires some measurement to compare the quality of the achieved cluster solutions with changing numbers of clusters. ${ }^{8}$ According to Nikhil and Bezdek (1995), the number of clusters to choose is generally between two and the square root of $n$. Note that increasing the number of clusters and hence creating more centroids will most likely alter individual membership coefficients, as these are relative values. With just 27 countries in our sample, the illustration of all the cluster solutions thus allows us to trace the changes in the cluster assignment. Following Artis and Zhang (2002), we consider the average silhouette value $s(i)$ for the comparison of these cluster solutions, which is defined as:

$$
s(i)=\frac{b(i)-a(i)}{\max [a(i), b(i)]}
$$

$a_{i}$ : average distance from the $i$ th point to the other points in the same cluster as $i$

$b_{i}$ :minimum average distance from the $i$ th point to points in different clusters

The silhouette measures how well a cluster solution matches the actual data. Its values range from -1 to +1 , with higher values indicating a superior solution, that is, the objects are well matched within their own cluster and poorly matched by the others. Hence, a higher sample average value for $s(i)$ indicates a cluster solution fulfilling the objectives of a cluster analysis - homogeneity within and heterogeneity between clusters - to a higher degree.

\section{Results}

\subsection{Business cycle clusters in Europe, 1996-2015}

The results of our main cluster analysis are presented in Table 1, which summarizes the membership coefficients of different numbers of clusters $c$ for all 27 countries. A membership coefficient close to 1 indicates that the country is close to the center of its cluster, while low values indicate a large distance between the country and the respective cluster centroids. The classification of countries according to their highest membership coefficient (bold figures) shows a clear core-periphery pattern of European business cycles. Every specification yields a cluster, which is centered by those countries typically referred to as the European core countries.

This core cluster consists of the following twelve countries ranked by their average membership coefficients over all the cluster solutions: Austria (0.97), France (0.9-0.99), Denmark (0.92-0.96), Italy (0.88-0.98), the Netherlands (0.86-0.97), the UK (0.8-0.96), Hungary (0.77-0.94), Sweden (0.78-0.9), Switzerland (0.72-0.93), Germany (0.76-0.84), Belgium (0.610.97 ) and Finland (0.60-0.76). Quite surprisingly, Germany's membership coefficients are even slightly lower than those of

\footnotetext{
${ }^{6}$ Most hierarchical clustering algorithms merge objects and clusters in an agglomerative order, that is, initially all the objects form single clusters and are subsequently merged until there is one cluster comprising all the objects. These mergers are informed by distance measures (objects and/or clusters with the smallest distance are merged) and the grouping process can be depicted in a dendrogram.

${ }^{7}$ This 'weighting by similarity' constitutes a major advantage over 'crisp' partitional algorithms, such as $k$-means, as well. The centroids of $k$-means clustering are simply the averages of all the members of the clusters, while the centroids calculated with FCM are more influenced by countries close to the center of a particular cluster, as indicated by the membership coefficients.

${ }^{8}$ For a survey on this issue, see Wang and Zhang (2007).
} 
Table 1

FCM results (whole period 1996 Q1-2015 Q4).

\begin{tabular}{|c|c|c|c|c|c|c|c|c|c|c|c|c|}
\hline \multirow[b]{2}{*}{$\begin{array}{l}m=1.5 \mathrm{CF} \\
\text { Filtered Data }\end{array}$} & \multicolumn{3}{|c|}{ 3-Cluster Solution } & \multicolumn{4}{|c|}{ 4-Cluster Solution } & \multicolumn{5}{|c|}{ 5-Cluster Solution } \\
\hline & $\begin{array}{l}\text { Cluster } 1 \\
\text { Core }\end{array}$ & $\begin{array}{l}\text { Cluster } 2 \\
\text { Baltics }\end{array}$ & $\begin{array}{l}\text { Cluster } 3 \\
\text { Eastern P. }\end{array}$ & $\begin{array}{l}\text { Cluster } 1 \\
\text { Core }\end{array}$ & $\begin{array}{l}\text { Cluster } 2 \\
\text { Baltics }\end{array}$ & $\begin{array}{l}\text { Cluster } 3 \\
\text { Eastern P. }\end{array}$ & $\begin{array}{l}\text { Cluster } 4 \\
\text { Southern P. }\end{array}$ & $\begin{array}{l}\text { Cluster } 1 \\
\text { Core }\end{array}$ & $\begin{array}{l}\text { Cluster } 2 \\
\text { Baltics }\end{array}$ & $\begin{array}{l}\text { Cluster } 3 \\
\text { Eastern P. }\end{array}$ & $\begin{array}{l}\text { Cluster } 4 \\
\text { Southern P. }\end{array}$ & $\begin{array}{l}\text { Cluster } 5 \\
\text { Bul. \& Rom. }\end{array}$ \\
\hline Austria & 0.97 & 0.00 & 0.03 & 0.97 & 0.00 & 0.01 & 0.02 & 0.97 & 0.00 & 0.01 & 0.02 & 0.00 \\
\hline Belgium & 0.97 & 0.00 & 0.03 & 0.61 & 0.00 & 0.02 & 0.37 & 0.61 & 0.00 & 0.02 & 0.36 & 0.00 \\
\hline Bulgaria & 0.12 & 0.00 & 0.88 & 0.05 & 0.00 & 0.89 & 0.06 & 0.06 & 0.00 & 0.10 & 0.06 & 0.79 \\
\hline Croatia & 0.35 & 0.01 & 0.64 & 0.30 & 0.01 & 0.43 & 0.26 & 0.05 & 0.00 & 0.89 & 0.04 & 0.02 \\
\hline Czech Republic & 0.45 & 0.00 & 0.55 & 0.41 & 0.00 & 0.28 & 0.31 & 0.41 & 0.00 & 0.13 & 0.32 & 0.13 \\
\hline Denmark & 0.96 & 0.00 & 0.04 & 0.92 & 0.00 & 0.01 & 0.06 & 0.92 & 0.00 & 0.02 & 0.06 & 0.00 \\
\hline Estonia & 0.01 & 0.98 & 0.01 & 0.01 & 0.97 & 0.01 & 0.01 & 0.01 & 0.97 & 0.01 & 0.01 & 0.00 \\
\hline Finland & 0.75 & 0.03 & 0.22 & 0.76 & 0.02 & 0.09 & 0.13 & 0.60 & 0.01 & 0.25 & 0.11 & 0.03 \\
\hline France & 0.99 & 0.00 & 0.01 & 0.90 & 0.00 & 0.01 & 0.10 & 0.92 & 0.00 & 0.01 & 0.08 & 0.00 \\
\hline Germany & 0.76 & 0.00 & 0.24 & 0.84 & 0.00 & 0.07 & 0.09 & 0.76 & 0.00 & 0.14 & 0.09 & 0.02 \\
\hline Greece & 0.41 & 0.02 & 0.57 & 0.20 & 0.01 & 0.27 & 0.52 & 0.18 & 0.01 & 0.21 & 0.43 & 0.17 \\
\hline Hungary & 0.94 & 0.00 & 0.06 & 0.79 & 0.00 & 0.02 & 0.19 & 0.77 & 0.00 & 0.04 & 0.18 & 0.01 \\
\hline Ireland & 0.52 & 0.05 & 0.43 & 0.31 & 0.03 & 0.21 & 0.45 & 0.26 & 0.03 & 0.17 & 0.40 & 0.14 \\
\hline Italy & 0.98 & 0.00 & 0.02 & 0.89 & 0.00 & 0.01 & 0.10 & 0.88 & 0.00 & 0.02 & 0.10 & 0.00 \\
\hline Latvia & 0.00 & 0.99 & 0.00 & 0.00 & 0.99 & 0.00 & 0.00 & 0.00 & 0.99 & 0.00 & 0.00 & 0.00 \\
\hline Lithuania & 0.04 & 0.91 & 0.05 & 0.05 & 0.86 & 0.06 & 0.03 & 0.05 & 0.77 & 0.11 & 0.03 & 0.04 \\
\hline Netherlands & 0.97 & 0.00 & 0.03 & 0.86 & 0.00 & 0.01 & 0.13 & 0.87 & 0.00 & 0.01 & 0.12 & 0.00 \\
\hline Norway & 0.82 & 0.00 & 0.18 & 0.37 & 0.00 & 0.07 & 0.55 & 0.38 & 0.00 & 0.10 & 0.50 & 0.03 \\
\hline Poland & 0.89 & 0.00 & 0.11 & 0.27 & 0.00 & 0.03 & 0.70 & 0.26 & 0.00 & 0.04 & 0.69 & 0.01 \\
\hline Portugal & 0.79 & 0.00 & 0.20 & 0.11 & 0.00 & 0.02 & 0.86 & 0.11 & 0.00 & 0.03 & 0.86 & 0.01 \\
\hline Romania & 0.17 & 0.02 & 0.82 & 0.08 & 0.01 & 0.81 & 0.10 & 0.01 & 0.00 & 0.02 & 0.01 & 0.96 \\
\hline Slovakia & 0.16 & 0.01 & 0.83 & 0.14 & 0.01 & 0.74 & 0.11 & 0.02 & 0.00 & 0.94 & 0.02 & 0.02 \\
\hline Slovenia & 0.23 & 0.01 & 0.76 & 0.31 & 0.01 & 0.53 & 0.16 & 0.21 & 0.00 & 0.59 & 0.11 & 0.07 \\
\hline Spain & 0.74 & 0.00 & 0.26 & 0.03 & 0.00 & 0.01 & 0.96 & 0.03 & 0.00 & 0.01 & 0.96 & 0.00 \\
\hline Sweden & 0.90 & 0.00 & 0.09 & 0.82 & 0.00 & 0.03 & 0.15 & 0.78 & 0.00 & 0.06 & 0.15 & 0.01 \\
\hline Switzerland & 0.93 & 0.00 & 0.07 & 0.72 & 0.00 & 0.03 & 0.24 & 0.74 & 0.00 & 0.03 & 0.21 & 0.01 \\
\hline \multirow{2}{*}{$\begin{array}{l}\text { United } \\
\text { Kingdom }\end{array}$} & 0.96 & 0.00 & 0.03 & 0.81 & 0.00 & 0.02 & 0.18 & 0.80 & 0.00 & 0.04 & 0.16 & 0.00 \\
\hline & \multicolumn{3}{|c|}{$\begin{array}{l}\text { Sample average silhouette } \\
0.3974\end{array}$} & \multicolumn{4}{|c|}{$\begin{array}{l}\text { Sample average silhouette } \\
0.3301\end{array}$} & \multicolumn{5}{|c|}{$\begin{array}{l}\text { Sample average silhouette } \\
0.3212\end{array}$} \\
\hline
\end{tabular}

Notes: The table summarizes the cluster results of our FCM approach of CF-filtered quarterly real GDP (1996 Q1-2015 Q4; $m=1.5$; $c$ from 3 to 5 ). The values express relative membership of each cluster $\left(u_{i j}\right)$. The highest cluster membership is signified by bold letters.

Hungary, Sweden and the UK, all countries that are not part of the EA. This confirms previous evidence questioning the 'leading role' of the German business cycle (e.g. Aguiar-Conraria and Soares, 2011; Pentecôte and Huchet-Bourdon, 2012; Aguiar-Conraria et al., 2013) and is a strong indication against using Germany's cycle as a proxy for the European core business cycle (as for example in the analyses by Artis and Zhang, 2002; Boreiko, 2003; Campos and Macchiarelli, 2016). Belgium, another country that might be expected to be near the center of the core, is not a clear member of this cluster either. The membership coefficients show that it lies between the core (0.61) and the southern periphery (0.37) at $c=5$. At first sight the clear core membership of Italy and Hungary might seem surprising, given that they are sometimes assigned to peripheral clusters (especially Italy) or not included in an analysis of the European core-periphery pattern at all (especially Hungary). As described above, there is some controversy over the classification of Italy in the literature. We find evidence that Italy should not be included in a peripheral country group, as performed for example by Hughes-Hallet and Richter (2008), Caporale et al., (2015) and Belke et al. (2016). We also confirm the consensual finding of the literature on the synchronization of the CEECs that Hungary is the country that is the most synchronized with the EA (see Fidrmuc and Korhonen, 2006; Savva et al., 2010; Kolasa, 2013; Di Giorgio, 2016). The synchronization with the core is so far advanced that it should be assigned to a core group rather than a group of CEECs, as in the study by Arestis and Phelps (2016).

The second business cycle cluster to be found in all the specifications consists of the Baltic states of Estonia (0.970.98), Latvia (0.99) and Lithuania (0.77-0.91). ${ }^{9}$ The high membership coefficients indicate that these countries form a very distinct cluster in which the centroid apparently lies the furthest away from all the others. The third cluster, which we label the eastern periphery, comprises Croatia (0.43-0.89), Slovakia (0.74-0.94) and Slovenia (0.53-0.76) in each cluster solution. When the number of clusters is increased to four, the southern periphery - previously part of the core - is made up of Portugal (0.86) and Spain (0.96), joined by countries with lower membership coefficients, such as Poland (0.70), Norway (0.55), Greece (0.52) and Ireland (0.45). This composition might be due to the recent crisis experience of the so-called GIPS countries, which will be controlled for below. Remarkably, the membership coefficients of the latter two countries as well as that of the Czech Republic do not significantly exceed 0.5 . They can thus be considered as outliers that are not clearly

\footnotetext{
${ }^{9}$ In the two-cluster solution, which is not depicted here, the country sample is always divided into a cluster containing the Baltics and another cluster comprising all the other countries.
} 
assigned to one of the business cycle clusters. Finally, Bulgaria and Romania, which have so far been part of the eastern periphery, form a distinct cluster at $c=5$.

The documented results reveal that the core-periphery pattern among European business cycles is complex. Any study that explicitly divides the sample into a core group on the one hand and a peripheral group on the other oversimplifies the group structure of European business cycles that is revealed by the fuzzy clustering. First, the membership matrix shows that - apart from Hungary and to a lesser degree Poland and the Czech Republic - most CEECs have a rather low degree of business cycle synchronization with the European core. This confirms the results of Kolasa (2013), Stanisic (2013) and Di Giorgio (2016), who find a low synchronization between CEECs and the EA. Second, however, they do not constitute a homogeneous group of synchronized countries. Our results reveal a great deal of heterogeneity among the CEECs, as they split up into three different business cycle clusters at $c=5$. Hence, any study of European business cycle synchronization that includes the CEECs should take this heterogeneity into account. Third, our result of a separate southern periphery cluster around Spain and Portugal contradicts the findings of previous studies investigating the pre-euro crisis period, in which a high degree of synchronization between the European core and these countries is detected (see, e.g., Camacho et al., 2006, 2008; Pentecôte and Huchet-Bourdon, 2012; Aguiar-Conraria et al., 2013; Lehwald, 2013). The finding is in line with more recent studies of the post-crisis period (Gächter et al., 2012; Ferroni and Klaus, 2015; Degiannakis et al., 2014; Belke et al., 2016) that assign the two countries to the southern periphery. We will discuss this issue further in the context of the crisis impacts below. Furthermore, the inclusion of Ireland and Greece in this group (as undertaken by various studies analyzing the core vs. the GIPS, e.g. Lehwald, 2013; Caporale et al., 2015; Arestis and Phelps, 2016; Belke et al., 2016) might be problematic, as our results indicate that these two countries constitute outliers and may, if included in any business cycle group, drive the results due to their very idiosyncratic development.

According to the OCA literature, an ideal monetary union would consist of countries with synchronized business cycles. Hence, since all the members of the clusters that we identify exhibit a high degree of business cycle similarity, these clusters would qualify as separate OCAs, at least in terms of business cycle synchronization. In reality, of course, more is involved in determining the costs of sharing a currency. However, as the countries of the core are the economically and politically powerful leaders of the European integration process (and most of them have already adopted the euro), the European core business cycle obviously represents the only feasible anchor for current and prospective members of the monetary union. The membership coefficients thus allow for inference on the costs of being a member of the EA. In this regard the adoption of the euro in the 'opt out' countries of Denmark, Sweden and the UK, as well the 'EU out' Switzerland, would be unproblematic, a result that supports the finding of the multivariate cluster analysis by Wortmann and Stahl (2016). The same holds for Hungary, since it is, as described, the only CEEC that is unambiguously a member of the core. In contrast, other CEECs that are not yet part of the EA, such as Bulgaria, Croatia and Romania, show very low membership coefficients of the core, signifying high potential costs of EA accession. Several countries that have already adopted the euro unfortunately share this pattern, for example the Baltics, Slovakia and Slovenia or countries on the southern periphery, such as Portugal or Spain. In line with the findings of Wortmann and Stahl (2016), this demonstrates that the current composition of the EA is far from optimal. The countries that could share a common currency with the core are not members of the EA, while others are part of the EA although membership appears to be costly.

\subsection{The relationship between core and peripheral business cycles}

Having defined the overall degree of belongingness that each country exhibits to the different clusters, we now examine the relationship between the group-specific centroid cycles (Fig. 1). A visual inspection of the four peripheral business cycles in comparison with the core cycle allows the first conclusions about the drivers of our clustering results from the previous section. Compared with the core, the Baltics apparently have business cycles with a much higher amplitude, especially (but not exclusively) during the immediate crisis period of 2008/2009. The eastern periphery, on the other hand, appears to be largely asynchronous with the core before the global financial crisis, while the amplitude was comparable. Since the crisis, however, the core and the eastern periphery have apparently shared largely similar output gaps. The opposite seems to be the case for the southern periphery. Its business cycle was apparently very synchronized with the core before the crisis and has increasingly differed since 2009 (e.g. due to a less severe immediate crisis experience and the 'double-dip' recession). To investigate this relation between the clusters further, we use the European core business cycle of the FCM analysis as a reference cycle for three time-varying synchronization measures.

First, we compute the time-varying correlation coefficient $\rho_{i, r}(t)$, as proposed by Cerqueira and Martins (2009) and Cerqueira (2013), between the time series of the four peripheral clusters and the core time series. ${ }^{10}$ Furthermore, we follow Mink et al. (2012) in distinguishing between two aspects of business cycle synchronization that overlap when only the correlation coefficient between two time series is used. They suggest involving both business cycle synchronicity $\varphi_{\text {ir }}(t)$, that is, if the two time series of interest are in the same phase of the business cycle, and business cycle similarity $\gamma$ ir $(t)$ to compare

\footnotetext{
10 The correlation between time series $g_{i}$ and reference series $g_{r}$ is calculated at each point in time using the following formula: $\rho_{i, r}(t)=1-$ $\frac{1}{2}\left(\frac{g_{i, t}-\bar{g}_{i}}{\sqrt{\frac{1}{T} \sum_{t=1}^{T}\left(g_{i, t}-\bar{g}_{i}\right)^{2}}}-\frac{g_{r, t}-\bar{g}_{r}}{\sqrt{\frac{1}{T} \sum_{t=1}^{T}\left(d_{r, t}-\bar{d}_{r}\right)^{2}}}\right)^{2}$. The average of $\rho_{i, r}(t)$ over $t$ yields the correlation coefficient between the two time series. Several authors use this measure in their studies of business cycle synchronization in Europe. For instance, Gächter and Riedl (2014) compute pair-wise correlations for their sample countries, while Belke et al. (2016) additionally use time-varying correlations with an EA (12) reference time series.
} 


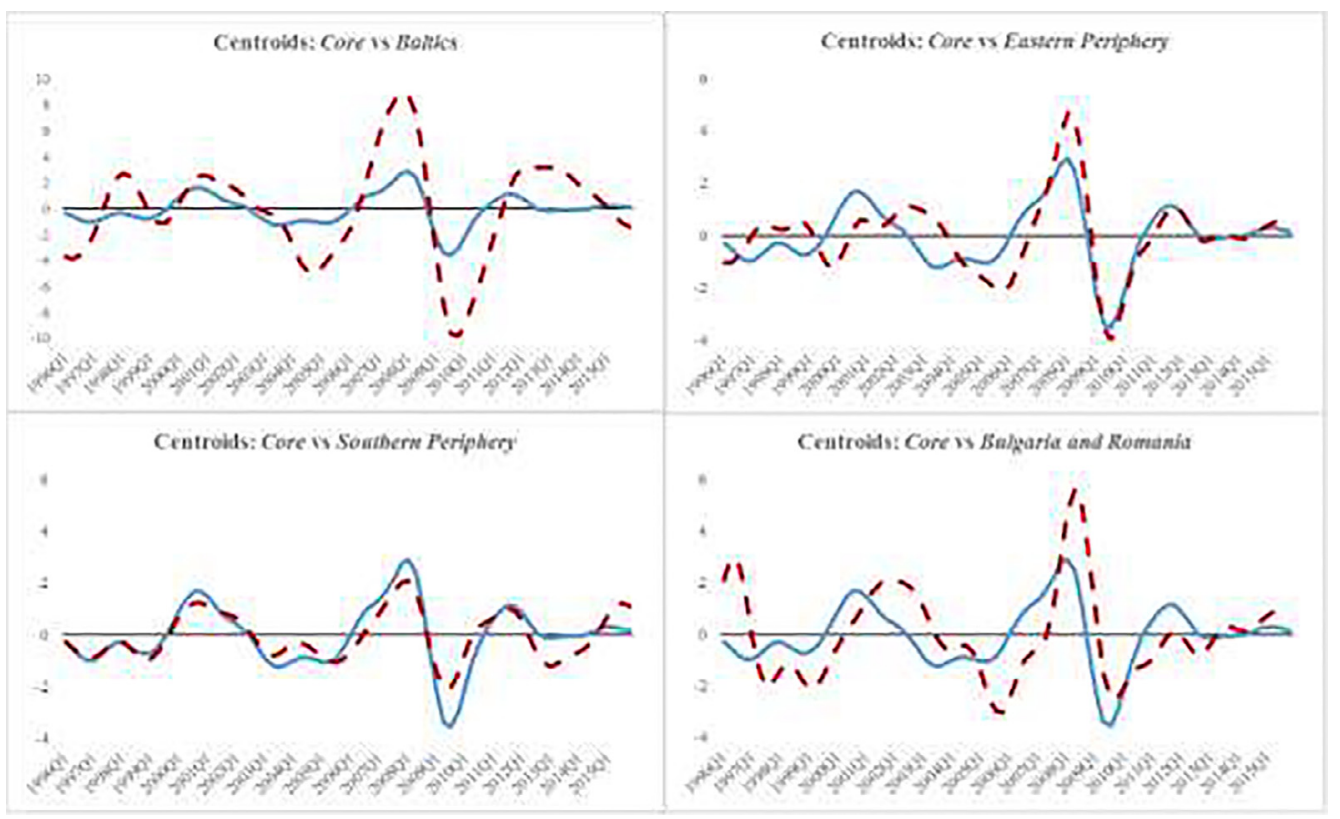

Fig. 1. Cluster centroids. Notes: The figure depicts the respective cluster centroids (dashed lines) compared with the centroids of the core cluster (dotted lines) based on the FCM solution for $c=5$ and $m=1.5$ over the period 1996 Q1-2015 Q4.

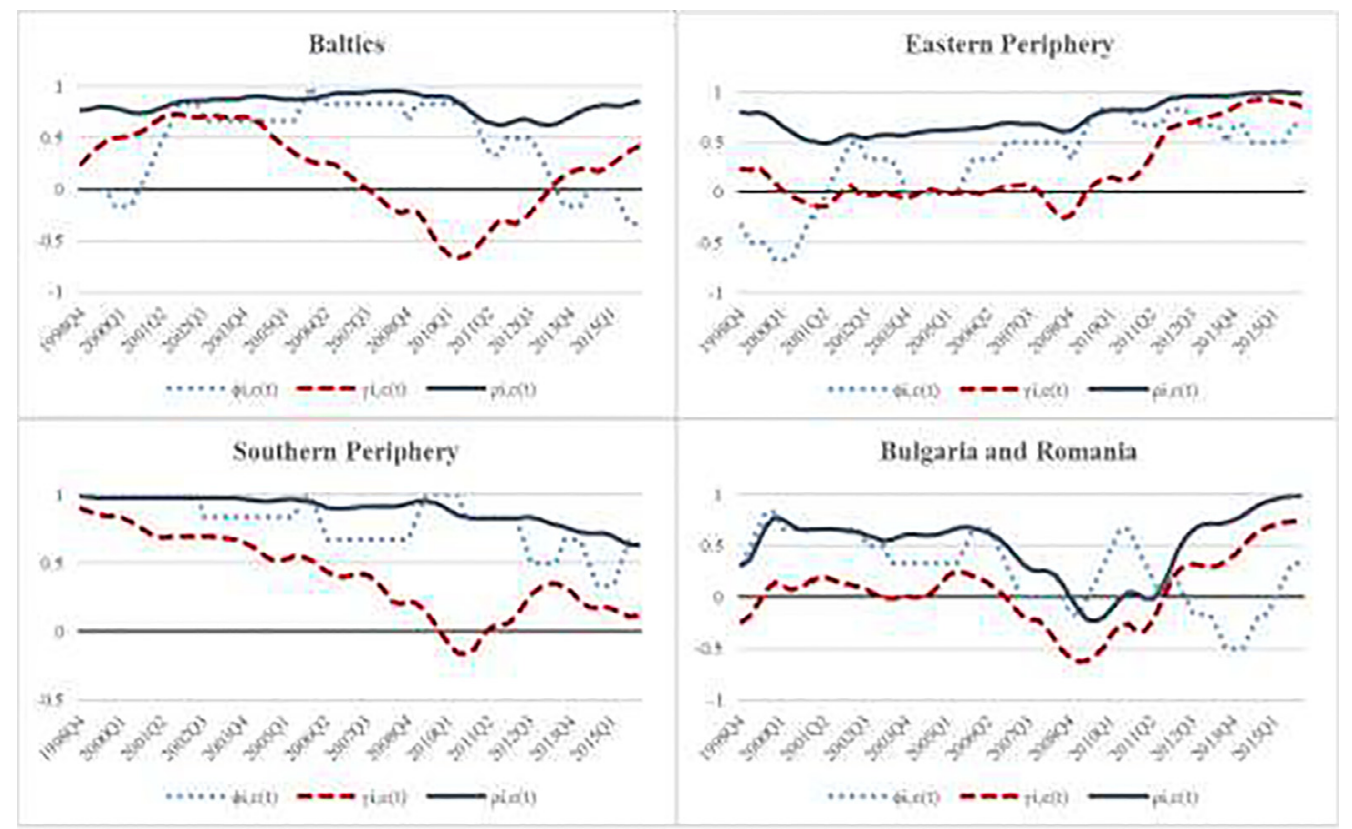

Fig. 2. Relation of the peripheral business cycles to the core. Notes: The figure depicts the relation between the centroids of the four peripheral clusters and the core. This relation is measured using the following variables (1) $\varphi_{i, c}(t)$ : business cycle synchronicity (dotted lines), $(2) \gamma_{i, c}(t)$ : business cycle similarity (dashed lines) and (3) $\rho_{i, c}(t)$ : time-varying correlation (straight lines). In this case $i$ denotes the respective cluster in comparison with the centroid time series of the core, denoted by $C$.

the amplitudes of the two business cycles. ${ }^{11}$ Fig. 2 compares the three-year moving average ${ }^{12}$ of these measures for all four cluster centroids with the core time series as a reference. This allows us to draw several conclusions.

\footnotetext{
${ }^{11}$ Business cycle synchronicity $\phi_{i r}(t)$ and business cycle similarity $\gamma_{i r}(t)$ between time series $g_{i}$ and reference series $g_{r}$ are defined as: $\phi_{i r}(t)=$ $\frac{g_{i}(t) g_{r}(t)}{\left|g_{i}(t) g_{r}(t)\right|} ; \gamma_{i r}(t)=1-\frac{\left|g_{i}(t)-g_{r}(t)\right|}{\sum_{i=1}^{n}\left|g_{i}(t)\right| / n}$.

${ }_{12}$ As we are rather interested in the trends of business cycle synchronization than in short-term developments, we concentrate on three-year moving averages. In fact, when depicting the indicators of Mink et al. (2012) short-term fluctuations might dominate the figure if the quarterly time series were
} 
First, the Baltics have a high correlation with the core time series (an overall correlation coefficient of 0.88), which is around 0.9 for most of the time period. This is remarkable, as our cluster results show that the Baltics form a very distinct business cycle cluster. The values for business cycle synchronicity and similarity offer an explanation for this discrepancy and confirm our suspicion mentioned above. While the timing of the up- and downswings of the core and Baltic business cycles coincide (indicated by high synchronicity), their amplitudes differ widely, which explains the clear distinction between the Baltics and the core in the clustering. From about 2004 onwards (i.e. since the Baltics' EU accession), a clear trend of less similar business cycles, at least in terms of amplitude, is observable. Hence, the business cycle of the Baltics shows an ambivalent relation to the core: temporal accordance but large differences in amplitude. Since the end of the global financial crisis around 2010, this relationship has changed, with increasing similarity and decreasing synchronicity between the Baltics and the core.

Second, the business cycle of the eastern periphery relates differently to the core. The correlation between the two time series remained rather low between the mid-1990s and the onset of the financial crisis. Hence, the two business cycles were largely asynchronous, as further indicated by both low similarity and low synchronicity during that time period. From 2009 onwards, however, this relationship changed. Apparently, the business cycles of the eastern periphery and the core converged in the aftermath of the global financial crisis: the correlation, similarity and (to a lesser extent) synchronicity increased strongly. The business cycle of the cluster around Bulgaria and Romania developed differently. Their already-low correlation with the core time series declined significantly between 2006 and 2010. Since then the similarity and correlation have increased while the synchronicity has remained low.

The convergence of most clusters among the CEECs towards the core confirms the findings of previous studies on business cycle synchronization that detect the convergence of these countries (at least) since the global financial crisis as well (see Kolasa, 2013; Stanisic, 2013; Di Giorgio, 2016). Still, there is a high degree of heterogeneity in these developments among the CEECs. The eastern periphery relates differently to the core from the Baltics, which in turn differ significantly from outlier countries like Romania, Bulgaria and the Czech Republic or Hungary.

Third, the business cycle of the southern periphery exhibits yet another development in its relation to the core. Between the mid-1990s and circa 2010, the two time series correlated strongly, while the synchronicity measure showed coinciding up- and downswings. From the early 2000s onwards, however, the amplitudes of the two business cycles differed increasingly, while the same holds for correlation and synchronicity since 2009. Obviously, the business cycles of the core and the southern periphery have diverged since the global financial crisis. This divergence in the aftermath of the crisis seems to have driven our clustering results. This is in line with studies focusing on the pre-crisis period and detecting a high degree of synchronization between the southern periphery and the core during that time (Camacho et al., 2006, 2008; Aguiar-Conraria and Soares, 2011; Pentecôte and Huchet-Bourdon, 2012; Aguiar-Conraria et al., 2013; Lehwald, 2013) but also confirms the findings of studies that include the post-crisis period (Gächter et al., 2012; Ferroni and Klaus, 2015; Degiannakis et al., 2014; Belke et al., 2016). The divergence since 2008 can be seen in the context of the unwinding of the economic balances that piled up in the pre-crisis period and led to the 'euro crisis' in southern Europe (Baldwin et al., 2015). Simultaneous fiscal and banking crises produced the need for deleveraging in both the public and the private sector, reinforcing the growth crisis in these countries and triggering the divergence of the cyclical fluctuations between the southern periphery and the core (European Commission, 2014). ${ }^{13}$

\subsection{The core and periphery before and after the crisis}

Our analysis above shows that the relationship between the peripheral business cycle clusters and the core exhibits profound changes between the time period before and that after the crisis. To check whether our overall cluster solutions are robust with respect to these differences and whether the trends that we identify can be confirmed, we split the time period into a pre-crisis (1996 Q1-2007 Q4) and a post-crisis period (2008 Q1-2015 Q4). We then conduct separate FCM analyses for each period and present those solutions in Table 2 that result in the highest average silhouette at different values of $c$.

The first point to notice here is that the silhouette values indicate two different numbers of clusters for the two time periods: in the pre-crisis period a four-cluster solution is superior, while in the post-crisis period $c=3$ is the preferred partition. A core cluster is identified in both periods as well as a cluster around the Baltics (consisting only of Estonia and Latvia in the first period). The composition of the remaining peripheral clusters, however, changes. While in the pre-crisis period two separate clusters on the eastern periphery are identified (one around the Czech Republic; the other around Croatia and Romania), no such cluster is evident after the crisis at $c=3$. Instead, most countries of the former eastern

\footnotetext{
used, especially when the compared output gaps are close to zero. Particularly the binary synchronization indicator is thus less appropriate if not used with moving averages.

${ }^{13}$ As the focus of the present paper lies on assessing the group pattern of European business cycles, we do not explicitly analyze potential driving forces behind these developments. There is, however, a large literature dealing with possible determinants of business cycle synchronization (for a survey, see De Haan et al., 2008). Primarily, the role of trade linkages has been studied (see, for instance, Inklaar et al. 2008 and Gächter and Riedl, 2014), but other dimensions, such as the effects of EU and EA membership per se, have been investigated as well (Goncalves et al., 2009, Christodoulopoulou, 2014, Gächter and Riedl, 2014 or Bierbaumer-Polly et al., 2016). In a more recent study, Gächter et al. (2017) analyze the role of wage developments. They find that wage growth divergence led to a reduction of business cycle co-movement within the EA, which might be one explanation for the diverging patterns we find between the core and the southern periphery.
} 
Table 2

Pre- and post-crisis FCM results (Period 1: 1996 Q1-2007 Q4; Period 2: 2008 Q1-2015 Q4).

\begin{tabular}{|c|c|c|c|c|c|c|c|}
\hline \multirow[b]{2}{*}{$\begin{array}{l}\mathrm{m}=1.7 \mathrm{CF} \\
\text { filtered data }\end{array}$} & \multicolumn{4}{|c|}{ First period (1996 Q1-2007 Q4) } & \multicolumn{3}{|c|}{ Second period (2008 Q1-2015 Q4) } \\
\hline & $\begin{array}{l}\text { Cluster 1: } \\
\text { Core }\end{array}$ & $\begin{array}{l}\text { Cluster 2: } \\
\text { Baltics }\end{array}$ & $\begin{array}{l}\text { Cluster 3: } \\
\text { Eastern Periphery }\end{array}$ & $\begin{array}{l}\text { Cluster 4: South } \\
\text { Eastern Periphery }\end{array}$ & $\begin{array}{l}\text { Cluster 1: } \\
\text { Core }\end{array}$ & $\begin{array}{l}\text { Cluster 2: } \\
\text { Baltics }\end{array}$ & $\begin{array}{l}\text { Cluster 3: } \\
\text { Southern Periphery }\end{array}$ \\
\hline Austria & 0.97 & 0.00 & 0.02 & 0.01 & 0.90 & 0.00 & 0.10 \\
\hline Belgium & 0.88 & 0.00 & 0.07 & 0.05 & 0.44 & 0.00 & 0.56 \\
\hline Bulgaria & 0.18 & 0.01 & 0.64 & 0.16 & 0.66 & 0.02 & 0.31 \\
\hline Croatia & 0.06 & 0.01 & 0.03 & 0.90 & 0.87 & 0.01 & 0.12 \\
\hline Czech Republic & 0.09 & 0.01 & 0.87 & 0.03 & 0.65 & 0.00 & 0.34 \\
\hline Denmark & 0.84 & 0.01 & 0.10 & 0.04 & 0.88 & 0.00 & 0.11 \\
\hline Estonia & 0.02 & 0.95 & 0.01 & 0.02 & 0.03 & 0.95 & 0.02 \\
\hline Finland & 0.80 & 0.02 & 0.09 & 0.10 & 0.74 & 0.08 & 0.17 \\
\hline France & 0.98 & 0.00 & 0.01 & 0.00 & 0.65 & 0.00 & 0.34 \\
\hline Germany & 0.52 & 0.01 & 0.38 & 0.09 & 0.93 & 0.00 & 0.07 \\
\hline Greece & 0.15 & 0.01 & 0.11 & 0.73 & 0.33 & 0.04 & 0.63 \\
\hline Hungary & 0.89 & 0.01 & 0.06 & 0.05 & 0.81 & 0.00 & 0.19 \\
\hline Ireland & 0.24 & 0.02 & 0.69 & 0.06 & 0.38 & 0.09 & 0.53 \\
\hline Italy & 0.92 & 0.00 & 0.05 & 0.03 & 0.65 & 0.01 & 0.34 \\
\hline Latvia & 0.01 & 0.96 & 0.01 & 0.01 & 0.02 & 0.97 & 0.01 \\
\hline Lithuania & 0.18 & 0.26 & 0.13 & 0.43 & 0.03 & 0.96 & 0.02 \\
\hline Netherlands & 0.94 & 0.00 & 0.05 & 0.01 & 0.80 & 0.00 & 0.20 \\
\hline Norway & 0.79 & 0.01 & 0.09 & 0.11 & 0.39 & 0.01 & 0.59 \\
\hline Poland & 0.75 & 0.01 & 0.13 & 0.11 & 0.22 & 0.00 & 0.78 \\
\hline Portugal & 0.77 & 0.01 & 0.12 & 0.11 & 0.15 & 0.00 & 0.85 \\
\hline Romania & 0.17 & 0.03 & 0.61 & 0.20 & 0.54 & 0.08 & 0.38 \\
\hline Slovakia & 0.05 & 0.01 & 0.05 & 0.89 & 0.83 & 0.02 & 0.16 \\
\hline Slovenia & 0.30 & 0.02 & 0.45 & 0.23 & 0.75 & 0.03 & 0.22 \\
\hline Spain & 0.66 & 0.00 & 0.25 & 0.08 & 0.03 & 0.00 & 0.97 \\
\hline Sweden & 0.87 & 0.01 & 0.08 & 0.04 & 0.65 & 0.02 & 0.32 \\
\hline Switzerland & 0.88 & 0.00 & 0.09 & 0.03 & 0.62 & 0.01 & 0.38 \\
\hline \multirow[t]{2}{*}{ United Kingdom } & 0.89 & 0.00 & 0.05 & 0.05 & 0.73 & 0.00 & 0.27 \\
\hline & \multicolumn{4}{|c|}{$\begin{array}{l}\text { Sample average silhouette } \\
0.5382\end{array}$} & \multicolumn{3}{|c|}{$\begin{array}{l}\text { Sample average silhouette } \\
0.4473\end{array}$} \\
\hline
\end{tabular}

Notes: The table summarizes the cluster results of our FCM approach of CF-filtered quarterly real GDP for two separate time periods: 1996 Q1-2007 Q4 as the first and 2008 Q1-2015 Q4 as the second period. The values again express relative membership of each cluster ( $u_{i j}$ ). The highest cluster membership is signified by bold letters.

peripheries enter the core cluster, indicating greater proximity than in the first period. ${ }^{14}$ The clear separation between the CEECs and the rest of Europe in the pre-crisis period is in line with the findings of Camacho et al. (2006, 2008), who detect such a division with their cluster analyses. In their analysis of data between 1990 and 2003, the CEECs constitute separate clusters, while the southern European countries are part of an EU15 cluster.

Our sample split analysis, however, shows that this pattern has changed, as, in the second period, the southern periphery cluster is formed around Portugal and Spain, while most of the CEECs enter the core. These results confirm our findings reported above, as the global financial crisis apparently constitutes a structural break in the relationship between the European core and the periphery. Since then the eastern periphery has converged towards the core while the southern periphery has diverged, forming a separate cluster. Another remarkable development can be seen for Belgium, Italy and France. All three countries show very high membership coefficients of the core in the first period. Conversely, in the second period, they belong to the southern periphery to a high degree (Belgium even switches membership). ${ }^{15}$

\subsection{Robustness analysis}

The results of a cluster analysis can be sensitive to the specifications used, such as the selected variables and objects, the distance measures and the clustering algorithms. Hence, we conduct several additional analyses to test the robustness of our main results. Specifically, (1) we vary the filtering method that we employ to extract the output gaps from the GDP series, (2) we expand our country sample with additional OECD countries, (3) we employ an additional hierarchical clustering algorithm, (4) we repeat the main FCM analysis with a different distance measure and (5) we exclude the years of the immediate crisis impact, 2008/2009, from our sample split analysis. All five robustness checks confirm our main results.

\footnotetext{
${ }^{14}$ If, however, the inferior four-cluster solution (silhouette value of 0.29 ) is used in the second period, an eastern periphery (including Germany to a high degree) appears again. Therefore, despite having core membership coefficients between 0.11 and 0.39 , this country group cannot be regarded as being completely integrated into the core cluster. All the cluster solutions are available on request.

15 Our robustness checks, however, show that these results disappear for Belgium and France when the immediate crisis periods are omitted from the analysis. The result for Italy remains robust (see below).
} 
The first robustness check is concerned with the filtering of the original data. In all the main analyses, we employ the band-pass filter of Christiano and Fitzgerald (2003). Table A1 in the appendix summarizes the results of our cluster analyses, which are based on output gaps that have been extracted using the high-pass filter of Hodrick and Prescott (1997). In line with the former results, we find a stable core cluster opposed to peripheral clusters that form when the number of clusters is increased. At $c=3$ the country sample is divided into the core, the Baltics and the eastern periphery. While at $c=4$ the southern periphery is separated from the core, at $c=5$ an outlier cluster forms around Romania and (now to a lesser degree) Bulgaria. The composition of the clusters remains stable as well. The only exception is the southern periphery, since Poland and Norway are members of the core (albeit with rather low membership coefficients) and Portugal shows a lower membership degree of this cluster at $c=5$. Apart from these deviations, however, the main results are robust to this change in the filtering method.

The same holds for a variation of the country sample. To check whether such a variation changes our cluster membership, we include three additional non-European industrialized OECD countries (Japan, South Korea and the United States). The results are presented in Appendix Table A2. We detect a core cluster opposed to clusters on the eastern and southern peripheries and a cluster containing the Baltic States. The latter cluster, however, changes at $c=5$, as Lithuania now constitutes an outlier cluster as opposed to Bulgaria and/or Romania previously. This result might be driven by differences between Lithuania and the other two Baltic States in the pre-crisis period, as indicated by our results from the sample split. The US and Japan enter the core cluster, while Korea switches membership at different values of $c$ and hence constitutes an outlier. These results for the US and Japan are quite interesting, as they indicate a high degree of business cycle synchronization among fully developed industrial nations, regardless of their regional proximity, as for example is also found by Lehwald (2013), who conducts a similar robustness check.

In addition to these variations of the filtering and the country sample, we employ a different clustering algorithm and distance measure. Although in our view a partitional clustering algorithm such as FCM is better suited to our purposes, we compare our findings with those arising from hierarchical clustering (weighted average linkage ${ }^{16}$ ). The results are depicted in a dendrogram (Table A3 in the Appendix) indicating that the overall composition of our clusters does not change. The core cluster is the most obvious group with the smallest within-cluster differences and comprises exactly those twelve countries that centered the core cluster in our main analysis. The results for the remaining clusters resemble our findings as well. The Baltics constitute a separate cluster, furthest away from all the others and exhibiting considerable heterogeneity within the cluster (especially regarding Lithuania). Furthermore, the hierarchical analysis confirms the existence of clusters on the southern (again comprising Spain and Portugal as well as Poland and Norway) and the eastern periphery (several clusters comprising Bulgaria and Romania, Croatia and Slovakia, and the Czech Republic and Slovenia) and confirms that Greece and Ireland constitute outliers. As the second variation of our clustering method, we repeat our FCM analysis with another distance measure (Manhattan distance, Table A4) and are again able to reproduce our main results. Apart from smaller deviations in the membership coefficients, the cluster structure and membership resemble our findings, as we again detect a stable cluster around the twelve core countries, opposed to the Baltics and the eastern and southern peripheries.

Lastly, we repeat our sample split analysis and exclude the years 2008 and 2009 to check whether the immediate crisis impact drives our results for the second (post-crisis) period. That, however, is not the case. The silhouette again indicates that the three-cluster solution is superior for the post-crisis period. In this solution most countries from the eastern periphery again join the core cluster while the southern periphery cluster is separated from that core. Hence, the main finding of the sample split analysis - convergence of the eastern and divergence of the southern periphery - is confirmed. The results for France and Belgium, however, change, as they are now again unambiguous members of the core cluster. The similar result for Italy, however, remains robust, since its membership of the core remains rather low, signifying proximity to the southern periphery in the post-crisis period.

\section{Conclusion}

The recent euro crisis has underlined the need to address European business cycle patterns from a country group perspective. Previous research often uses the distinction between the core and the periphery either to analyze cyclical synchronization in arbitrarily predefined groups or to classify countries' synchronicities with respect to several reference measures. Differently from these studies, we propose a time series fuzzy clustering approach to assess the core-periphery pattern empirically in a direct manner that does not require strict assumptions. By applying the FCM clustering algorithm to output gap series of 27 European countries, we identify a core group consisting of Central European countries opposed to several clusters on the eastern and southern European peripheries along with the representative group-specific European business cycles. Both the classification and the obtained reference cycles may be used by the literature dealing with business cycle synchronization. For instance, the detected European core business cycle can be regarded as an anchor cycle for all countries wishing to share a common currency with the core countries (which mostly have already adopted the euro). We find evidence against using Germany's business cycle as a proxy for that cycle, as other core countries, like France, follow the

\footnotetext{
16 We choose the weighted average linkage method as it constitutes a compromise between hierarchical methods on the spectrum between the 'nearestneighbor' method (single linkage) and the 'furthest-neighbor' method (complete linkage, Hastie et al., 2008). The results for other hierarchical clustering algorithms, however, are in line with our main analysis as well and are available on request.
} 
European core business cycle more closely. Remarkably, this is also true for Italy, which is sometimes classified as belonging to the southern European periphery.

By quantifying each country's degree of belongingness to all the clusters, our analysis provides useful information about the cyclical suitability of individual countries for monetary unification with the core. While there is certainly more involved in the decision to enter the EA, the 'EA' and 'EU outs,' Denmark, Sweden, Switzerland and the UK, as well as some CEECs, especially Hungary and to a lesser degree the Czech Republic and Poland, could adopt the euro at a lower cost than the other countries on the eastern or southern European periphery. However, while some non-EA members clearly belong to the core, several peripheral countries with less synchronized cycles have adopted the euro instead (especially Greece, Ireland, Portugal and Spain). If the EA persists in its current composition, a common monetary policy and exchange rate are thus likely to remain costly for several members. Conversely, our results show that there are country groups in Europe that qualify as separate OCAs in terms of business cycle similarities. This pattern, however, changes over time. Our findings reveal that, while many CEECs converge towards the core, the southern periphery primarily around Spain and Portugal shows some divergence since the global financial crisis. Obviously, the driving forces behind these developments are of great interest to scholars and policy makers alike and constitute an interesting topic for future research.

\section{Appendix}

Tables A1-A5.

Table A1

FCM results, output gaps extracted using the Hodrick-Prescott filter (whole period 1996 Q1-2015 Q4).

\begin{tabular}{|c|c|c|c|c|c|c|c|c|c|c|c|c|}
\hline \multirow[b]{2}{*}{$\begin{array}{l}m=1.5 \mathrm{HP} \\
\text { Filtered Data }\end{array}$} & \multicolumn{3}{|c|}{ 3-Cluster Solution } & \multicolumn{4}{|c|}{ 4-Cluster Solution } & \multicolumn{5}{|c|}{ 5-Cluster Solution } \\
\hline & \multicolumn{3}{|c|}{ Cluster 1: Cluster 2: Cluster 3: } & \multicolumn{4}{|c|}{ : Cluster 1: Cluster 2: Cluster 3: Cluster 4: } & \multicolumn{4}{|c|}{ Cluster 1: Cluster 2: Cluster 3: Cluster 4: } & $\begin{array}{l}\text { Cluster 5: } \\
\text { Bul. and Rom. }\end{array}$ \\
\hline Austria & 0.98 & 0.00 & 0.02 & 0.97 & 0.00 & 0.01 & 0.03 & 0.95 & 0.00 & 0.01 & 0.04 & 0.00 \\
\hline Belgium & 0.98 & 0.00 & 0.02 & 0.95 & 0.00 & 0.01 & 0.04 & 0.92 & 0.00 & 0.01 & 0.07 & 0.00 \\
\hline Bulgaria & 0.31 & 0.05 & 0.64 & 0.19 & 0.03 & 0.50 & 0.27 & 0.13 & 0.02 & 0.21 & 0.17 & 0.47 \\
\hline Croatia & 0.23 & 0.02 & 0.75 & 0.12 & 0.01 & 0.66 & 0.20 & 0.06 & 0.01 & 0.79 & 0.08 & 0.06 \\
\hline Czech Republic & 0.38 & 0.00 & 0.61 & 0.13 & 0.00 & 0.11 & 0.77 & 0.15 & 0.00 & 0.12 & 0.67 & 0.06 \\
\hline Denmark & 0.95 & 0.00 & 0.05 & 0.85 & 0.00 & 0.03 & 0.12 & 0.80 & 0.00 & 0.04 & 0.16 & 0.01 \\
\hline Estonia & 0.01 & 0.97 & 0.01 & 0.01 & 0.96 & 0.01 & 0.01 & 0.01 & 0.95 & 0.02 & 0.01 & 0.01 \\
\hline Finland & 0.81 & 0.01 & 0.18 & 0.66 & 0.01 & 0.11 & 0.22 & 0.55 & 0.01 & 0.20 & 0.21 & 0.03 \\
\hline France & 0.99 & 0.00 & 0.01 & 0.97 & 0.00 & 0.00 & 0.02 & 0.96 & 0.00 & 0.00 & 0.03 & 0.00 \\
\hline Germany & 0.93 & 0.00 & 0.06 & 0.86 & 0.00 & 0.03 & 0.10 & 0.81 & 0.00 & 0.05 & 0.12 & 0.01 \\
\hline Greece & 0.24 & 0.02 & 0.74 & 0.15 & 0.01 & 0.46 & 0.37 & 0.13 & 0.01 & 0.26 & 0.28 & 0.33 \\
\hline Hungary & 0.61 & 0.01 & 0.38 & 0.38 & 0.00 & 0.18 & 0.44 & 0.35 & 0.00 & 0.19 & 0.39 & 0.06 \\
\hline Ireland & 0.38 & 0.08 & 0.53 & 0.23 & 0.05 & 0.26 & 0.45 & 0.20 & 0.05 & 0.22 & 0.36 & 0.18 \\
\hline Italy & 0.98 & 0.00 & 0.02 & 0.90 & 0.00 & 0.01 & 0.09 & 0.84 & 0.00 & 0.02 & 0.14 & 0.00 \\
\hline Latvia & 0.01 & 0.98 & 0.01 & 0.01 & 0.98 & 0.01 & 0.01 & 0.01 & 0.97 & 0.01 & 0.01 & 0.01 \\
\hline Lithuania & 0.03 & 0.93 & 0.04 & 0.03 & 0.88 & 0.06 & 0.03 & 0.03 & 0.82 & 0.08 & 0.03 & 0.04 \\
\hline Netherlands & 0.95 & 0.00 & 0.05 & 0.81 & 0.00 & 0.02 & 0.17 & 0.66 & 0.00 & 0.03 & 0.30 & 0.01 \\
\hline Norway & 0.82 & 0.01 & 0.18 & 0.66 & 0.01 & 0.11 & 0.23 & 0.57 & 0.00 & 0.12 & 0.26 & 0.04 \\
\hline Poland & 0.88 & 0.00 & 0.12 & 0.72 & 0.00 & 0.06 & 0.21 & 0.61 & 0.00 & 0.08 & 0.28 & 0.02 \\
\hline Portugal & 0.80 & 0.00 & 0.19 & 0.49 & 0.00 & 0.08 & 0.43 & 0.34 & 0.00 & 0.07 & 0.56 & 0.03 \\
\hline Romania & 0.18 & 0.03 & 0.79 & 0.09 & 0.02 & 0.70 & 0.19 & 0.02 & 0.00 & 0.04 & 0.02 & 0.92 \\
\hline Slovakia & 0.29 & 0.04 & 0.67 & 0.16 & 0.02 & 0.60 & 0.21 & 0.08 & 0.01 & 0.73 & 0.09 & 0.08 \\
\hline Slovenia & 0.24 & 0.01 & 0.75 & 0.16 & 0.01 & 0.36 & 0.48 & 0.13 & 0.00 & 0.47 & 0.31 & 0.09 \\
\hline Spain & 0.56 & 0.00 & 0.44 & 0.06 & 0.00 & 0.02 & 0.91 & 0.03 & 0.00 & 0.01 & 0.95 & 0.00 \\
\hline Sweden & 0.91 & 0.00 & 0.09 & 0.74 & 0.00 & 0.04 & 0.21 & 0.66 & 0.00 & 0.07 & 0.26 & 0.01 \\
\hline Switzerland & 0.97 & 0.00 & 0.03 & 0.92 & 0.00 & 0.02 & 0.06 & 0.88 & 0.00 & 0.02 & 0.10 & 0.01 \\
\hline \multirow{2}{*}{$\begin{array}{l}\text { United } \\
\text { Kingdom }\end{array}$} & 0.91 & 0.00 & 0.09 & 0.79 & 0.00 & 0.05 & 0.16 & 0.72 & 0.00 & 0.07 & 0.19 & 0.02 \\
\hline & \multicolumn{3}{|c|}{$\begin{array}{l}\text { Sample average silhouette } \\
0.4363\end{array}$} & \multicolumn{4}{|c|}{$\begin{array}{l}\text { Sample average silhouette } \\
0.3517\end{array}$} & \multicolumn{4}{|c|}{$\begin{array}{l}\text { Sample average silhouette } \\
0.2955\end{array}$} & \\
\hline
\end{tabular}

Notes: The table summarizes the cluster results of our FCM approach of HP-filtered quarterly real GDP (1996 Q1-2015 Q4; $m=1.5 ; c$ from 3 to 5). The values express relative membership of each cluster $\left(u_{i j}\right)$. The highest cluster membership is signified by bold letters. 
Table A2

FCM results, including the USA, Japan and Korea (whole period 1996 Q1-2015 Q4).

\begin{tabular}{|c|c|c|c|c|c|c|c|c|c|c|c|c|}
\hline \multirow[b]{2}{*}{$\begin{array}{l}m=1.5 \mathrm{CF} \\
\text { filtered data }\end{array}$} & \multicolumn{3}{|c|}{ 3-Cluster Solution } & \multicolumn{4}{|c|}{ 4-Cluster Solution } & \multicolumn{5}{|c|}{ 5-Cluster Solution } \\
\hline & $\begin{array}{l}\text { Cluster } \\
\text { Core }\end{array}$ & $\begin{array}{l}\text { Cluster } \\
\text { Baltics }\end{array}$ & $\begin{array}{l}\text { Cluster 3: } \\
\text { Eastern P. }\end{array}$ & $\begin{array}{l}\text { Cluster 1: } \\
\text { Core }\end{array}$ & $\begin{array}{l}\text { Cluster } \\
\text { Baltics }\end{array}$ & $\begin{array}{l}\text { : Cluster } 3 \\
\text { Eastern P }\end{array}$ & $\begin{array}{l}\text { Cluster 4: } \\
\text { Southern P. }\end{array}$ & $\begin{array}{l}\text { Cluster 1: } \\
\text { Core }\end{array}$ & $\begin{array}{l}\text { Cluster } \\
\text { Baltics }\end{array}$ & $\begin{array}{l}\text { : Cluster } 3 \\
\text { Eastern }\end{array}$ & $\begin{array}{l}\text { : Cluster 4: } \\
\text { Southern P. }\end{array}$ & $\begin{array}{l}\text { Cluster 5: } \\
\text { Lithuania }\end{array}$ \\
\hline Austria & 0.96 & 0.00 & 0.04 & 0.96 & 0.00 & 0.01 & 0.03 & 0.95 & 0.00 & 0.01 & 0.04 & 0.00 \\
\hline Belgium & 0.97 & 0.00 & 0.03 & 0.67 & 0.00 & 0.01 & 0.31 & 0.62 & 0.00 & 0.01 & 0.37 & 0.00 \\
\hline Bulgaria & 0.17 & 0.01 & 0.82 & 0.07 & 0.00 & 0.84 & 0.08 & 0.07 & 0.00 & 0.85 & 0.08 & 0.00 \\
\hline Croatia & 0.41 & 0.02 & 0.57 & 0.28 & 0.01 & 0.46 & 0.25 & 0.29 & 0.01 & 0.41 & 0.27 & 0.03 \\
\hline Czech Republic & 0.29 & 0.00 & 0.71 & 0.30 & 0.00 & 0.32 & 0.37 & 0.31 & 0.00 & 0.34 & 0.34 & 0.00 \\
\hline Denmark & 0.95 & 0.00 & 0.05 & 0.91 & 0.00 & 0.01 & 0.07 & 0.90 & 0.00 & 0.01 & 0.08 & 0.00 \\
\hline Estonia & 0.01 & 0.98 & 0.01 & 0.01 & 0.97 & 0.01 & 0.01 & 0.00 & 0.98 & 0.00 & 0.00 & 0.01 \\
\hline Finland & 0.74 & 0.03 & 0.23 & 0.70 & 0.02 & 0.12 & 0.15 & 0.69 & 0.01 & 0.11 & 0.16 & 0.03 \\
\hline France & 0.99 & 0.00 & 0.01 & 0.93 & 0.00 & 0.00 & 0.06 & 0.91 & 0.00 & 0.00 & 0.08 & 0.00 \\
\hline Germany & 0.66 & 0.00 & 0.33 & 0.72 & 0.00 & 0.12 & 0.15 & 0.73 & 0.00 & 0.11 & 0.15 & 0.00 \\
\hline Greece & 0.41 & 0.02 & 0.57 & 0.22 & 0.01 & 0.30 & 0.47 & 0.22 & 0.01 & 0.30 & 0.46 & 0.02 \\
\hline Hungary & 0.91 & 0.00 & 0.09 & 0.76 & 0.00 & 0.04 & 0.20 & 0.74 & 0.00 & 0.03 & 0.22 & 0.00 \\
\hline Ireland & 0.47 & 0.05 & 0.48 & 0.29 & 0.03 & 0.23 & 0.44 & 0.29 & 0.03 & 0.23 & 0.42 & 0.03 \\
\hline Italy & 0.96 & 0.00 & 0.04 & 0.84 & 0.00 & 0.01 & 0.15 & 0.83 & 0.00 & 0.01 & 0.16 & 0.00 \\
\hline Latvia & 0.00 & 0.99 & 0.00 & 0.00 & 0.99 & 0.00 & 0.00 & 0.00 & 0.96 & 0.00 & 0.00 & 0.03 \\
\hline Lithuania & 0.04 & 0.92 & 0.04 & 0.04 & 0.87 & 0.06 & 0.03 & 0.00 & 0.00 & 0.00 & 0.00 & 1.00 \\
\hline Netherlands & 0.93 & 0.00 & 0.07 & 0.77 & 0.00 & 0.02 & 0.21 & 0.75 & 0.00 & 0.02 & 0.23 & 0.00 \\
\hline Norway & 0.80 & 0.00 & 0.19 & 0.44 & 0.00 & 0.08 & 0.47 & 0.41 & 0.00 & 0.08 & 0.51 & 0.00 \\
\hline Poland & 0.86 & 0.00 & 0.14 & 0.35 & 0.00 & 0.04 & 0.61 & 0.32 & 0.00 & 0.04 & 0.64 & 0.00 \\
\hline Portugal & 0.73 & 0.00 & 0.27 & 0.17 & 0.00 & 0.04 & 0.79 & 0.17 & 0.00 & 0.04 & 0.79 & 0.00 \\
\hline Romania & 0.19 & 0.02 & 0.79 & 0.09 & 0.01 & 0.77 & 0.13 & 0.09 & 0.01 & 0.77 & 0.11 & 0.02 \\
\hline Slovakia & 0.24 & 0.02 & 0.75 & 0.13 & 0.01 & 0.74 & 0.12 & 0.15 & 0.01 & 0.68 & 0.14 & 0.03 \\
\hline Slovenia & 0.21 & 0.01 & 0.79 & 0.20 & 0.01 & 0.63 & 0.16 & 0.22 & 0.00 & 0.60 & 0.17 & 0.01 \\
\hline Spain & 0.54 & 0.00 & 0.46 & 0.04 & 0.00 & 0.01 & 0.95 & 0.04 & 0.00 & 0.02 & 0.94 & 0.00 \\
\hline Sweden & 0.87 & 0.00 & 0.12 & 0.77 & 0.00 & 0.04 & 0.19 & 0.77 & 0.00 & 0.04 & 0.19 & 0.00 \\
\hline Switzerland & 0.90 & 0.00 & 0.10 & 0.71 & 0.00 & 0.04 & 0.24 & 0.69 & 0.00 & 0.04 & 0.27 & 0.00 \\
\hline $\begin{array}{l}\text { United } \\
\text { Kingdom }\end{array}$ & 0.96 & 0.00 & 0.04 & 0.84 & 0.00 & 0.02 & 0.14 & 0.81 & 0.00 & 0.02 & 0.17 & 0.00 \\
\hline United States & 0.94 & 0.00 & 0.05 & 0.76 & 0.00 & 0.02 & 0.21 & 0.73 & 0.00 & 0.02 & 0.24 & 0.00 \\
\hline Japan & 0.77 & 0.00 & 0.22 & 0.60 & 0.00 & 0.10 & 0.30 & 0.59 & 0.00 & 0.09 & 0.31 & 0.00 \\
\hline \multirow[t]{2}{*}{ South Korea } & 0.43 & 0.02 & 0.54 & 0.30 & 0.02 & 0.27 & 0.42 & 0.29 & 0.01 & 0.28 & 0.40 & 0.02 \\
\hline & \multicolumn{3}{|c|}{$\begin{array}{l}\text { Sample average silhouette } \\
0.4188\end{array}$} & \multicolumn{4}{|c|}{$\begin{array}{l}\text { Sample average silhouette } \\
0.3088\end{array}$} & \multicolumn{5}{|c|}{$\begin{array}{l}\text { Sample average silhouette } \\
0.3100\end{array}$} \\
\hline
\end{tabular}

Notes: The table summarizes the cluster results of our FCM approach of CF-filtered quarterly real GDP (1996 Q1-2015 Q4; $m=1.5$; $c$ from 3 to 5) including the United States, Japan and South Korea. The values express relative membership of each cluster $\left(u_{i j}\right)$. The highest cluster membership is signified by bold letters.

Table A3

Results for hierarchical clustering using weighted average linkage and the Euclidian distance norm (whole period 1996 Q1-2015 Q4).

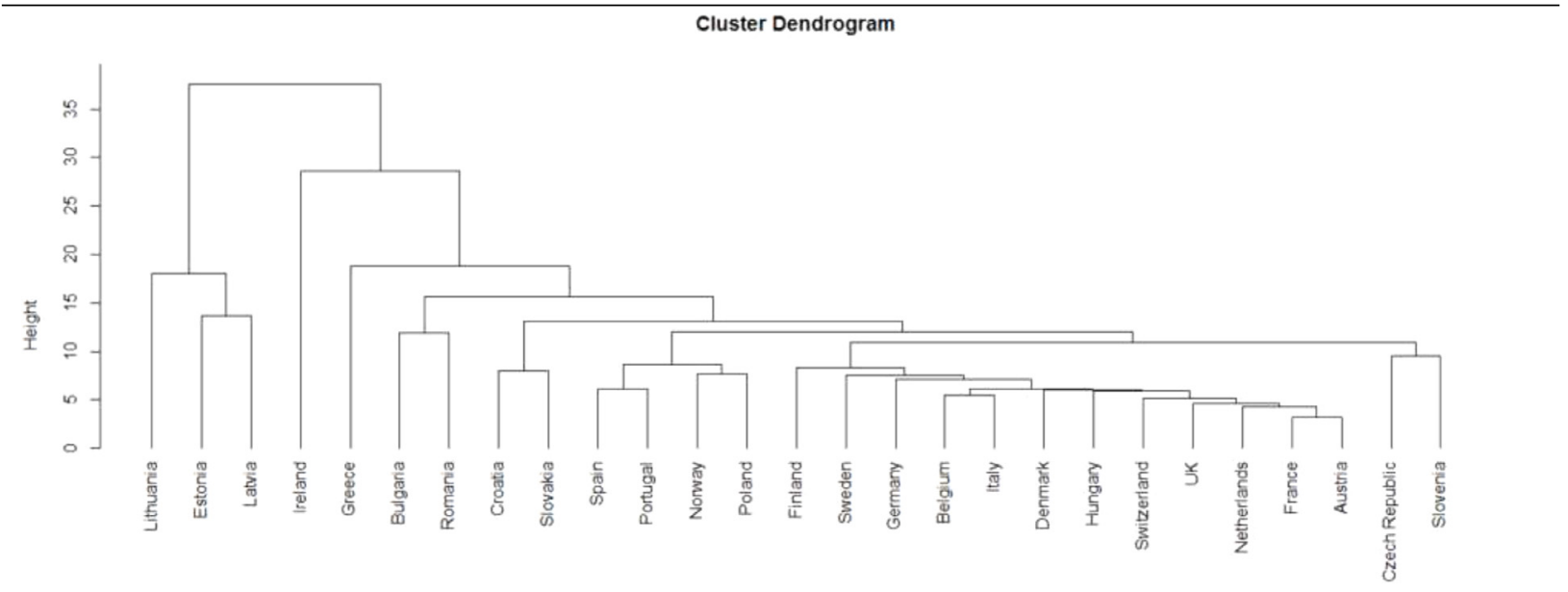

Notes: The dendrogram summarizes the cluster results of a weighted average linkage clustering approach based on the Euclidean distance norm and CFfiltered quarterly real GDP (1996 Q1-2015 Q4). 
Table A4

FCM results based on the Manhattan distance norm (whole period 1996 Q1-2015 Q4).

\begin{tabular}{|c|c|c|c|c|c|c|c|c|c|c|c|c|}
\hline \multirow[b]{2}{*}{$\begin{array}{l}m=1.6 \mathrm{CF} \\
\text { filtered data }\end{array}$} & \multicolumn{3}{|c|}{ 3-Cluster Solution } & \multicolumn{4}{|c|}{ 4-Cluster Solution } & \multicolumn{5}{|c|}{ 5-Cluster Solution } \\
\hline & $\begin{array}{l}\text { Cluster 1: } \\
\text { Core }\end{array}$ & $\begin{array}{l}\text { Cluster 2: } \\
\text { Baltics }\end{array}$ & $\begin{array}{l}\text { Cluster 3: } \\
\text { Eastern P. }\end{array}$ & $\begin{array}{l}\text { Cluster 1: } \\
\text { Core }\end{array}$ & $\begin{array}{l}\text { Cluster 2: } \\
\text { Baltics }\end{array}$ & $\begin{array}{l}\text { Cluster 3: } \\
\text { Eastern P. }\end{array}$ & $\begin{array}{l}\text { Cluster 4: } \\
\text { Southern P. }\end{array}$ & $\begin{array}{l}\text { Cluster 1: } \\
\text { Core }\end{array}$ & $\begin{array}{l}\text { Cluster 2: } \\
\text { Baltics }\end{array}$ & $\begin{array}{l}\text { Cluster 3: } \\
\text { Eastern P. }\end{array}$ & $\begin{array}{l}\text { Cluster 4: } \\
\text { Southern P. }\end{array}$ & $\begin{array}{l}\text { Cluster 5: } \\
\text { Romania }\end{array}$ \\
\hline Austria & 0.96 & 0.00 & 0.04 & 0.93 & 0.00 & 0.01 & 0.06 & 0.92 & 0.00 & 0.02 & 0.06 & 0.00 \\
\hline Belgium & 0.95 & 0.00 & 0.05 & 0.65 & 0.00 & 0.02 & 0.33 & 0.65 & 0.00 & 0.04 & 0.31 & 0.00 \\
\hline Bulgaria & 0.14 & 0.01 & 0.86 & 0.06 & 0.00 & 0.88 & 0.06 & 0.15 & 0.01 & 0.42 & 0.15 & 0.27 \\
\hline Croatia & 0.31 & 0.02 & 0.67 & 0.30 & 0.02 & 0.46 & 0.23 & 0.06 & 0.00 & 0.87 & 0.05 & 0.02 \\
\hline Czech Republic & 0.60 & 0.01 & 0.38 & 0.36 & 0.01 & 0.15 & 0.48 & 0.32 & 0.01 & 0.11 & 0.51 & 0.06 \\
\hline Denmark & 0.93 & 0.00 & 0.06 & 0.85 & 0.00 & 0.02 & 0.12 & 0.85 & 0.00 & 0.03 & 0.11 & 0.00 \\
\hline Estonia & 0.02 & 0.96 & 0.02 & 0.02 & 0.95 & 0.01 & 0.01 & 0.02 & 0.95 & 0.01 & 0.01 & 0.01 \\
\hline Finland & 0.81 & 0.04 & 0.16 & 0.70 & 0.02 & 0.08 & 0.20 & 0.63 & 0.02 & 0.14 & 0.18 & 0.02 \\
\hline France & 0.97 & 0.00 & 0.03 & 0.86 & 0.00 & 0.01 & 0.13 & 0.87 & 0.00 & 0.01 & 0.11 & 0.00 \\
\hline Germany & 0.76 & 0.01 & 0.23 & 0.69 & 0.01 & 0.08 & 0.22 & 0.63 & 0.00 & 0.13 & 0.22 & 0.01 \\
\hline Greece & 0.34 & 0.03 & 0.63 & 0.22 & 0.02 & 0.37 & 0.38 & 0.19 & 0.02 & 0.37 & 0.29 & 0.14 \\
\hline Hungary & 0.91 & 0.00 & 0.08 & 0.77 & 0.00 & 0.03 & 0.20 & 0.75 & 0.00 & 0.06 & 0.19 & 0.01 \\
\hline Ireland & 0.56 & 0.06 & 0.38 & 0.33 & 0.04 & 0.18 & 0.45 & 0.29 & 0.03 & 0.14 & 0.43 & 0.11 \\
\hline Italy & 0.96 & 0.00 & 0.03 & 0.79 & 0.00 & 0.01 & 0.19 & 0.77 & 0.00 & 0.02 & 0.21 & 0.00 \\
\hline Latvia & 0.01 & 0.98 & 0.01 & 0.01 & 0.97 & 0.01 & 0.01 & 0.01 & 0.97 & 0.01 & 0.01 & 0.00 \\
\hline Lithuania & 0.07 & 0.83 & 0.10 & 0.09 & 0.73 & 0.11 & 0.07 & 0.09 & 0.61 & 0.18 & 0.07 & 0.06 \\
\hline Netherlands & 0.95 & 0.00 & 0.05 & 0.76 & 0.00 & 0.02 & 0.22 & 0.73 & 0.00 & 0.02 & 0.24 & 0.00 \\
\hline Norway & 0.76 & 0.01 & 0.23 & 0.49 & 0.01 & 0.11 & 0.40 & 0.46 & 0.01 & 0.16 & 0.34 & 0.03 \\
\hline Poland & 0.82 & 0.01 & 0.17 & 0.38 & 0.00 & 0.05 & 0.57 & 0.37 & 0.00 & 0.08 & 0.53 & 0.01 \\
\hline Portugal & 0.67 & 0.01 & 0.32 & 0.24 & 0.00 & 0.07 & 0.69 & 0.24 & 0.00 & 0.08 & 0.66 & 0.02 \\
\hline Romania & 0.18 & 0.03 & 0.79 & 0.09 & 0.02 & 0.78 & 0.12 & 0.00 & 0.00 & 0.00 & 0.00 & 0.99 \\
\hline Slovakia & 0.22 & 0.01 & 0.77 & 0.19 & 0.01 & 0.67 & 0.13 & 0.06 & 0.00 & 0.88 & 0.04 & 0.03 \\
\hline Slovenia & 0.35 & 0.01 & 0.63 & 0.32 & 0.01 & 0.34 & 0.33 & 0.26 & 0.01 & 0.39 & 0.28 & 0.06 \\
\hline Spain & 0.62 & 0.00 & 0.38 & 0.04 & 0.00 & 0.01 & 0.95 & 0.03 & 0.00 & 0.01 & 0.96 & 0.00 \\
\hline Sweden & 0.90 & 0.01 & 0.09 & 0.73 & 0.01 & 0.04 & 0.23 & 0.70 & 0.00 & 0.06 & 0.23 & 0.01 \\
\hline Switzerland & 0.86 & 0.00 & 0.14 & 0.63 & 0.00 & 0.06 & 0.31 & 0.63 & 0.00 & 0.06 & 0.30 & 0.01 \\
\hline \multirow{2}{*}{$\begin{array}{l}\text { United } \\
\text { Kingdom }\end{array}$} & 0.90 & 0.00 & 0.10 & 0.78 & 0.00 & 0.04 & 0.18 & 0.76 & 0.00 & 0.08 & 0.16 & 0.01 \\
\hline & \multicolumn{3}{|c|}{$\begin{array}{l}\text { Sample average silhouette } \\
0.4419\end{array}$} & \multicolumn{4}{|c|}{$\begin{array}{l}\text { Sample average silhouette } \\
0.3088\end{array}$} & \multicolumn{5}{|c|}{$\begin{array}{l}\text { Sample average silhouette } \\
0.3470\end{array}$} \\
\hline
\end{tabular}

Notes: The table summarizes the cluster results of our FCM approach of CF-filtered quarterly real GDP (1996 Q1-2015 Q4; $m=1.6$; $c$ from 3 to 5) using the 'Manhattan distance.' The values express relative membership of each cluster $\left(u_{i j}\right)$. The highest cluster membership is signified by bold letters.

Table A5

Pre- and post-crisis FCM results, excluding 2008/2009 (Period 1: 1996 Q1-2007 Q4; Period 2: 2010 Q1-2015 Q4).

\begin{tabular}{|c|c|c|c|c|c|c|c|}
\hline \multirow[b]{2}{*}{$\begin{array}{l}m=1.7 \text { (period 1) } 1.9(2) \\
C F \text { filtered data }\end{array}$} & \multicolumn{4}{|c|}{ First period (1996 Q1-2007 Q4) } & \multicolumn{3}{|c|}{ Second period (2010 Q1-2015 Q4) } \\
\hline & $\begin{array}{l}\text { Cluster 1: } \\
\text { Core }\end{array}$ & $\begin{array}{l}\text { Cluster 2: } \\
\text { Baltics }\end{array}$ & $\begin{array}{l}\text { Cluster 3: } \\
\text { Eastern Periphery }\end{array}$ & $\begin{array}{l}\text { Cluster 4: South } \\
\text { Eastern Periphery }\end{array}$ & $\begin{array}{l}\text { Cluster 1: } \\
\text { Core }\end{array}$ & $\begin{array}{l}\text { Cluster 2: } \\
\text { Baltics }\end{array}$ & $\begin{array}{l}\text { Cluster 3: } \\
\text { Southern Periphery }\end{array}$ \\
\hline Austria & 0.97 & 0.00 & 0.02 & 0.01 & 0.90 & 0.02 & 0.08 \\
\hline Belgium & 0.88 & 0.00 & 0.07 & 0.05 & 0.84 & 0.01 & 0.16 \\
\hline Bulgaria & 0.18 & 0.01 & 0.64 & 0.16 & 0.87 & 0.02 & 0.11 \\
\hline Croatia & 0.06 & 0.01 & 0.03 & 0.90 & 0.88 & 0.02 & 0.10 \\
\hline Czech Republic & 0.09 & 0.01 & 0.87 & 0.03 & 0.27 & 0.01 & 0.72 \\
\hline Denmark & 0.84 & 0.01 & 0.10 & 0.04 & 0.92 & 0.01 & 0.07 \\
\hline Estonia & 0.02 & 0.95 & 0.01 & 0.02 & 0.05 & 0.92 & 0.03 \\
\hline Finland & 0.80 & 0.02 & 0.09 & 0.10 & 0.73 & 0.08 & 0.19 \\
\hline France & 0.98 & 0.00 & 0.01 & 0.00 & 0.95 & 0.00 & 0.04 \\
\hline Germany & 0.52 & 0.01 & 0.38 & 0.09 & 0.91 & 0.01 & 0.08 \\
\hline Greece & 0.15 & 0.01 & 0.11 & 0.73 & 0.41 & 0.09 & 0.50 \\
\hline Hungary & 0.89 & 0.01 & 0.06 & 0.05 & 0.67 & 0.02 & 0.31 \\
\hline Ireland & 0.24 & 0.02 & 0.69 & 0.06 & 0.34 & 0.15 & 0.51 \\
\hline Italy & 0.92 & 0.00 & 0.05 & 0.03 & 0.56 & 0.02 & 0.42 \\
\hline Latvia & 0.01 & 0.96 & 0.01 & 0.01 & 0.05 & 0.92 & 0.03 \\
\hline Lithuania & 0.18 & 0.26 & 0.13 & 0.43 & 0.06 & 0.91 & 0.03 \\
\hline Netherlands & 0.94 & 0.00 & 0.05 & 0.01 & 0.87 & 0.01 & 0.12 \\
\hline Norway & 0.79 & 0.01 & 0.09 & 0.11 & 0.76 & 0.04 & 0.19 \\
\hline Poland & 0.75 & 0.01 & 0.13 & 0.11 & 0.64 & 0.01 & 0.34 \\
\hline Portugal & 0.77 & 0.01 & 0.12 & 0.11 & 0.20 & 0.02 & 0.79 \\
\hline Romania & 0.17 & 0.03 & 0.61 & 0.20 & 0.67 & 0.06 & 0.28 \\
\hline Slovakia & 0.05 & 0.01 & 0.05 & 0.89 & 0.94 & 0.00 & 0.05 \\
\hline
\end{tabular}




\begin{tabular}{|c|c|c|c|c|c|c|c|}
\hline \multirow[b]{2}{*}{$\begin{array}{l}m=1.7 \text { (period 1) } 1.9(2) \\
C F \text { filtered data }\end{array}$} & \multicolumn{4}{|c|}{ First period (1996 Q1-2007 Q4) } & \multicolumn{3}{|c|}{ Second period (2010 Q1-2015 Q4) } \\
\hline & $\begin{array}{l}\text { Cluster 1: } \\
\text { Core }\end{array}$ & $\begin{array}{l}\text { Cluster 2: } \\
\text { Baltics }\end{array}$ & $\begin{array}{l}\text { Cluster 3: } \\
\text { Eastern Periphery }\end{array}$ & $\begin{array}{l}\text { Cluster 4: South } \\
\text { Eastern Periphery }\end{array}$ & $\begin{array}{l}\text { Cluster 1: } \\
\text { Core }\end{array}$ & $\begin{array}{l}\text { Cluster 2: } \\
\text { Baltics }\end{array}$ & $\begin{array}{l}\text { Cluster 3: } \\
\text { Southern Periphery }\end{array}$ \\
\hline Slovenia & 0.30 & 0.02 & 0.45 & 0.23 & 0.60 & 0.03 & 0.38 \\
\hline Spain & 0.66 & 0.00 & 0.25 & 0.08 & 0.06 & 0.00 & 0.93 \\
\hline Sweden & 0.87 & 0.01 & 0.08 & 0.04 & 0.46 & 0.03 & 0.51 \\
\hline Switzerland & 0.88 & 0.00 & 0.09 & 0.03 & 0.83 & 0.02 & 0.15 \\
\hline \multirow[t]{2}{*}{ United Kingdom } & 0.89 & 0.00 & 0.05 & 0.05 & 0.92 & 0.01 & 0.07 \\
\hline & \multicolumn{4}{|c|}{$\begin{array}{l}\text { Sample average silhouette } \\
0.5382\end{array}$} & \multicolumn{3}{|c|}{$\begin{array}{l}\text { Sample average silhouette } \\
0.5592\end{array}$} \\
\hline
\end{tabular}

Notes: The table summarizes the cluster results of our FCM approach of CF-filtered quarterly real GDP for two separate time periods: 1996 Q1-2007 Q4 as the first and 2010 Q1-2015 Q4 as the second period. The values express relative membership of each cluster $\left(u_{i j}\right)$. The highest cluster membership is signified by bold letters.

\section{References}

Afonso, A. and Sequeira, A. (2010) 'Revisiting Business Cycle Synchronisation in the European Union.' ISEG Economics Working Paper, No. 22/2010, ISEG.

Aguiar-Conraria, L., Martins, M., Soares, M., 2013. Convergence of the economic sentiment cycles in the Eurozone: a time-frequency analysis. J. Common Mark. Stud. 51 (3), 377-398.

Aguiar-Conraria, L., Soares, M., 2011. Business cycle synchronization and the Euro: a wavelet analysis. J. Macroecon. 33, 477-489.

Arestis, P., Phelps, P., 2016. Endogeneity analysis of output synchronization in the current and prospective EMU. J. Common Mark. Stud. 54 (3), 525-543.

Artis, M., Krolzig, H., Toro, J., 2004. The European business cycle. Oxf. Econ. Pap. 56 (1), 1-44.

Artis, M., Zhang, W., 1997. International business cycle and the ERM: Is there a European business cycle? Int. J. Financ. Econ. 2 (1), 1-16.

Artis, M., Zhang, W., 2001. Core and periphery in EMU: a cluster analysis. Econ. Issues 6 (2), 39-59.

Artis, M., Zhang, W., 2002. Membership of EMU: a fuzzy clustering analysis of alternative criteria. J. Econ. Integr. 17 (1), 54-79.

Baldwin, R., et al., 2015. Rebooting the Eurozone: Step 1 Agreeing a crisis narrative. CEPR Policy Insight No. 85.

Bayoumi, T., Eichengreen, B., 1993. Shocking aspects of European monetary integration. In: Torres, F., Giavazzi, F. (Eds.), Adjustment and Growth in the European Monetary Union. Cambridge University Press, Cambridge, pp. 193-240.

Belke, A., Domnick, C., Gros, D., 2016. Ruhr Economic Papers, No. 659. Ruhr-Universität Bochum (RUB), Department of Economics.

Bezdek, J., 1981. Pattern Recognition with Fuzzy Objective Function Algorithms. Plenum Press, New York.

Bezdek, J., Ehrlich, R., Full, W., 1982. FCM: The fuzzy c-means clustering algorithm. Comput. Geosci. 10 (2-3), 191-203.

Bierbaumer-Polly, J., Huber, P., Rozmahel, P., 2016. Regional business-cycle synchronization, sector specialization and EU accession. J. Common Mark. Stud. $54(3), 544-568$.

Boreiko, D., 2003. EMU and accession countries: fuzzy cluster analysis of membership. Int. J. Financ. Econ. 8 (4), 309-325.

Camacho, M., Perez-Quirós, G., Saiz, L., 2006. Are European business cycles close enough to be just one?'. J. Econ. Dyn. Control 30 (9-10), 1687-1706.

Camacho, M., Perez-Quirós, G., Saiz, L., 2008. Do European business cycles look like one? J. Econ. Dyn. Control 32 (7), $2165-2190$.

Campos, N., Macchiarelli, C., 2016. Core and periphery in the European Monetary Union: Bayoumi and Eichengreen 25 years later. Econ. Lett. 147, 127-130. Caporale, G., De Santis, R., Girardi, A., 2015. Trade intensity and output synchronisation: on the endogeneity properties of EMU. J. Financ. Stab. 16, 154-163. Cerqueira, P., 2013. A closer look at the world business cycle synchronization. Int. Econ. Econ. Policy 10 (3), 349-363.

Cerqueira, P., Martins, R., 2009. Measuring the determinants of business cycle synchronization using a panel approach. Econ. Lett. 102, 106-108.

Christiano, L., Fitzgerald, T., 2003. The band-pass filter. Int. Econ. Rev. 44 (2), 435-465.

Christodoulopoulou, S., 2014. The effect of currency unions on business cycle correlations: the EMU case. Empirica 41 (1), 177-222.

Crespo-Cuaresma, J., Fernández-Amador, O., 2013. Business cycle convergence in EMU: a first look at the second moment. J. Macroeconomics. 37, 265-284.

Crowley, P., 2008. One money, several cycles? Evaluation of European business cycles using model-based cluster analysis. Bank of Finland Research Discussion Papers, No. 3/2008. Bank of Finland.

Darvas, Z., Szapary, G., 2008. Business cycle synchronization in the enlarged EU. Open Econ. Rev. 19 (1), 1-19.

Degiannakis, S., Duffy, D., Filis, G., 2014. Business cycle synchronization in EU: a time-varying approach. Scott. J. Polit. Econ. 61 (4), 348-370.

De Haan, J., Inklaar, R., Jong-A-Pin, R., 2008. Will business cycles in the euro area converge? A critical survey of empirical research. J. Econ. Surv. 22 (2), 234-273.

Di Giorgio, C., 2016. Business cycle synchronization of CEECs with the euro area: a regime switching approach. J. Common Mark. Stud. 54 (2), $377-398$.

European Commission, 2014. Focus: growth differences between EA Member States since the crisis. Q. Rep. Euro Area 13, 7-20.

Ferroni, F., Klaus, B., 2015. Euro area business cycles in turbulent times: convergence or decoupling?'. Appl. Econ. 47 (34-35), 3791-3815.

Fidrmuc, J., Korhonen, I., 2006. Meta-analysis of the business cycle correlation between the euro area and the CEECs. J. Comp. Econ. 34 (3), 518-534.

Frankel, J., Rose, A., 1997. Is EMU more justifiable ex-post than ex-ante? Eur. Econ. Rev. 41, 753-760.

Furceri, D., Karras, G., 2008. Business-cycle synchronization in the EMU. Appl. Econ. 40 (12), 1491-1501.

Gächter, M., Gruber, A., Riedl, A., 2017. Wage divergence, business cycle co-movement and the currency union effect. J. Common Mark. Stud. doi:10.1111/ jcms.12574.

Gächter, M., Riedl, A., 2014. One money, one cycle? The EMU experience. J. Macroecon. 42, 141-155.

Gächter, M., Riedl, A., Ritzberger-Grünwald, D., 2012. Business cycle synchronization in the euro area and the impact of the financial crisis. Monet. Policy Econ.: Q. Rev. Econ. Policy 12 (2), 33-60.

Goncalves, C., Rodrigues, M., Soares, T., 2009. Correlation of business cycles in the euro zone. Econ. Lett. 102 (1), 56-58.

Hastie, T., Tibshirani, R., Friedman, J., 2008. The Elements of Statistical Learning: Data Mining, Inference, and Prediction, second ed. Springer, New York.

Hodrick, R., Prescott, E., 1997. Postwar U.S. business cycles: an empirical investigation. J. Money Credit Bank. 29 (1), 1-16.

Hughes Hallet, A., Richter, C., 2008. Have the Eurozone economies converged on a common European cycle?'. Int. Econ. Econ. Policy 5 (1-2), $71-101$.

Inklaar, R., Jong-A-Pin, R., De Haan, J., 2008. 'Trade and business cycle synchronization in OECD countries - a re-examination. Eur. Econ. Rev. 52 (4), 646-666.

Kappler, M., Sachs, A. (Eds.), 2013, Business Cycle Synchronisation and Economic Integration: New Evidence from the EU. Imprint: Physica, Heidelberg. Kaufman, L., Rousseeuw, P., 2005. Finding Groups in Data, An Introduction to Cluster Analysis. Wiley, Hoboken, NJ.

Kolasa, M., 2013. Business cycles in the EU new member states: How and why are they different?'. J. Macroecon. 38, 487-496.

König, J., Ohr, R., 2013. Different efforts in European economic integration: implications of the EU index. J. Common Mark. Stud. 51 (6), $1074-1090$.

Kozluk, T., 2005. CEEC accession countries and the EMU - an assessment of relative and readiness for euro-area membership. J. Econ. Integr. 20 (3), $439-474$. Lehwald, S., 2013. Has the euro changed business cycle synchronization? Evidence from the core and the periphery. Empirica 40 (4), 655-684.

Liao, T., 2005. Clustering of time series data - a survey. Pattern Recognit. 38 (11), 1857-1874. 
Mink, M., Jacobs, J., de Haan, J., 2012. Measuring coherence of output gaps with an application to the euro area. Oxf. Econ. Pap. 64 (2), 217-236.

Mongelli, F., 2005. What is European economic and monetary union telling us about the properties of optimum currency areas?'. J. Common Mark. Stud. 43 (3), 607-635.

Nikhil, R., Bezdek, J., 1995. On cluster validity for the fuzzy c-means model. IEEE Trans. Fuzzy Syst. 3 (3), $370-379$.

Pentecôte, J., Huchet-Bourdon, M., 2012. Revisiting the core-periphery view of EMU. Econ. Model. 29 (6), $2382-2391$.

Quah, C., 2014. Revisiting business cycles in the eurozone: a fuzzy clustering and discriminant approach. Acta Oecon. 64 (2), 161-180.

Savva, C., Neanidis, K., Osborn, D., 2010. Business cycle synchronization of the euro area with the new and negotiating member countries. Int. J. Financ. Econ. 15 (3), 288-306.

Stanisic, N., 2013. Convergence between the business cycles of Central and Eastern European Countries and the euro area. Baltic J Econ. 13 (1), 63-74.

Wang, X., Mueen, A., Ding, H., Trajcevski, G., Scheuermann, P., Keogh, E., 2012. Experimental comparison of representation methods and distance measures for time series data. Data Min. Knowl. Discov. 26 (2), 275-309.

Wang, W., Zhang, Y., 2007. On fuzzy cluster validity indices. Fuzzy Sets Syst. 158 (19), 2095-2117.

Wortmann, M., Stahl, M., 2016. One size fits some: a reassessment of EMU's core-periphery framework. J. Econ. Integr. 31 (2), $377-413$. 


\section{GLOBAL VS. GROUP-SPECIFIC BUSINESS CYCLES: THE IMPORTANCE OF DEFINING THE GROUPS}

Tino Berger and Marcus Wortmann

Georg-August-Universität Göttingen 


\title{
Global vs. group-specific business cycles: The importance of defining the groups
}

Tino Berger

Georg-August-University Göttingen, Göttingen, Germany

Marcus Wortmann

Georg-August-University Göttingen, Göttingen, Germany

\begin{abstract}
The literature on international business cycles has employed dynamic factor models to disentangle global from group-specific and national factors in countries' macroeconomic aggregates. Therefore, the countries have simply been classified ex ante as belonging to the same region or the same level of development. This paper estimates a DFM for a sample of 106 countries and three variables (output, consumption, investment) over the period 1960 to 2014, in which the countries are classified according to the outcome of a cluster analysis. By comparing the results with those obtained by the previous grouping approaches, we show substantial deviations in the importance of global and group-specific factors. Remarkably, when the groups are defined properly, the 'global business cycle' accounts for only a very small fraction of macroeconomic fluctuations, most evidently in the industrialized world. The group-specific factors, on the other hand, play a much greater role for national business cycles than previously thought - also in the pre-globalization period.
\end{abstract}

JEL classification: C32, C38, E32, F44

Keywords: international business cycles, globalization, regionalization, dynamic factor models, cluster analysis

Tino Berger (corresponding author): Georg-August-University Göttingen, Platz der Göttinger Sieben 3, 37073 Göttingen, Germany; E-mail: tino.berger@ wiwi.uni-goettingen.de.

Marcus Wortmann: Georg-August-University Göttingen, Platz der Göttinger Sieben 3, 37073 Göttingen, Germany; E-mail: marcus.wortmann@ wiwi.uni-goettingen.de. 


\section{Introduction}

The globalization of trade and financial linkages over the past decades coincided with many regional and group-specific integration processes affecting countries' economic developments to varying degrees. As the severity and recovery time of globally experienced shocks have differed more significantly across such country groups since the financial crisis of 2008/9, one might expect a shift in the relative importance of international factors for domestic business cycles. To quantify each country's vulnerability to foreign developments on different levels, the empirical literature has decomposed national macroeconomic fluctuations into global, group-specific, and country-specific factors using large-scale dynamic factor models (DFM).

The seminal work of Kose et al. (2003) found evidence of a 'global business cycle' dominating the importance of seven regional cycles when conducting a DFM with 60 countries and three macroeconomic aggregates over the period 1960 to 1990. Somewhat later, Helbling et al. (2007) repeated this exercise with an enlarged database of 90 countries in the period from 1960 to 2005, and found the relevance of the global cycle to have declined in the later part, while regional shocks have become more important, especially in North America, Europe, and Asia. The growing importance of regional factors relative to the global factor is underlined by Mumtaz et al. (2011), who conducted a DFM with output and inflation rates for 36 countries over more than 75 years. Based on an extended dataset of 23 industrialized economies (IEs), 24 emerging markets (EMs), and 59 developing countries (DEs) covering the period 1960 to 2008, Kose et al. (2012) found that the global business cycle has become less relevant for the IEs and EMs since the 'globalization era' starting in the mid-1980s. On the other hand, the group-specific factors have henceforth gained importance for these country groups, indicating a 'decoupling' of countries from the global business cycle. By partitioning this data of 106 countries into seven regions, Hirata et al. (2013) amend the previous results, stating that "the recent era of globalization has witnessed the emergence of regional business cycles." Ductor and Leiva-Leon (2016), conversely, show with their time-varying DFM that the sensitivity of most EMs' business cycles to the global factor has rather increased over recent times.

A crucial limitation of the studies listed above is that the group-specific factors are statically modeled as either common to the countries of a particular world region (Kose et al. 2003; Hirata et al. 2013) or at the same level of development (Kose et al. 2012). The underlying group compositions are set ex ante and, in the latter case, do not account for any time 
variation over the pre- and the globalization periods considered. By doing so, the applied DFM will only verify the potential role played by very specific common factors suspected to permanently exist in any of these country groups. If, however, the continually changing trade linkages have rather entailed cyclical interdependencies among country groups of different shapes or even within smaller sub-groups, the importance of any pre-specified group factor for domestic cycles may be significantly misinterpreted. Imagine, for example, the suspected 'European business cycle' is found to exhibit only weak explanatory power compared with the 'global business cycle' for all the European countries (Kose et al. 2003), this may simply hide the fact that some countries (like e.g. the UK and Ireland) may rather belong to a transatlantic cluster together with the USA and Canada, and that the DFM should thus account for two distinct group-specific factors, one Central European and one inter-regional Anglo-Saxon.

The only paper considering this problem of DFM is that of Francis et al. (2017), stressing indeed that imposing factors in a DFM, that are not in the data implies a misspecification and may lead to factor estimates and hence variance decompositions that deviate substantially from the true model. Francis et al. (2017) determine the number and the composition of the groups endogenously based on series-level covariates. ${ }^{1}$ In fact, the 'optimal' groups found by their approach do not correspond to the seven regions of the world presumed by Kose et al. (2003) and there are significant differences in the resulting variance decompositions, too. When they estimate their DFM based on three endogenously classified country groups, the group-specific factors explain, on average, about $23 \%$ of macroeconomic fluctuations, compared with less than 3\% found by Kose et al. (2003). The comparability of such results, however, is limited, because different from the study of Kose et al. (2003), only GDP data for 60 countries were used and, hence, no country factors were estimated. This extension is left for future research by the authors and therefore considered in the present paper. Moreover, their clustering of countries is based on 'covariate data,' limiting the applicability for larger global datasets and thus requiring a different grouping approach. To cope with this problem, we conduct a hierarchical cluster analysis that reveals the business cycle data-inherent grouping structure before estimating a DFM. This two-step approach does not require any more variables than those used in the DFM and therefore allows us to analyze large-scale

\footnotetext{
${ }^{1}$ List of covariates: (i) the degree of economic openness, defined as the ratio of imports and exports to GDP; (ii) investment share of real GDP; (iii) an index of conflict resolution and sophistication of the legal system as captured by the manner in which lower courts facilitate landlords' collection of checks (and remedies for bounced checks); (iv) an index of language diversity within each country; (v) an index of production dispersion relative to the rest of the world; (vi) an index of export dispersion from each country's exporting partners; and (vii) a similar index of import dispersion from each country's importing partners. 
datasets.

In particular, the present paper adds to the literature by assessing the relevance of the global and the group-specific factors when the original DFM designed by Kose et al. (2003/2012) is applied to the same (time-extended) global dataset of 106 countries and three macroeconomic aggregates and the number of groups as well as their compositions are varied. Thereby, the variance decompositions arising from the DFM based on the pre-specified groupings supposed by Kose et al. (2012) and Hirata et al. (2013) are directly compared with those for which the grouping pattern has been drawn from the cluster analysis. This approach is not only independent from 'covariates' but provides direct insights into the hierarchical country group pattern of global business cycles, proving the existence of any business cycle cluster rather than assuming it beforehand. Moreover, as such group pattern is likely to have changed over time, we additionally estimate the DFM for the pre- and the globalization periods using the respective data-based grouping structures in order to gain a better understanding of the previously detected 'decoupling' and 'regionalization' trends.

The main findings can be summarized as follows. The formerly used regional as well as the development-based ex ante country groupings are found inaccurate, most evidently for the pre-globalization period. By contrast, the data-based grouping is a mix of both, with regional cyclical similarities most dominant in Central Europe, South East Asia, parts of Latin America but, otherwise, often limited to some direct neighbor countries. An Anglo-Saxon cluster rather provides evidence of inter-regional cyclical linkages resulting most likely from historical connections between these countries. The formerly used grouping based on the levels of development is most apparent between most IEs of the sample and all the other countries, of which the EMs and DEs should not be separated accordingly.

When the DFM is estimated based on the underlying cyclical similarities revealed by the cluster analysis, the relevance of the group-specific factors is found to be much higher than that based on the previously used groupings. On the other hand, the contribution of the global factor becomes, on average, negligible and very much limited to the IEs. The deviations in the relative importance of these two factors are found to be even more substantial for individual country groups like the G-7, USA/CAN, and the EU-12.

Despite finding evidence in support of the regionalization trend and the decoupling hypothesis (growing importance of intra-group factors, declining relevance of the global factor over time), we show that, when the groups have been defined properly, the group-specific factors already exhibit almost equal importance as the global factor in the pre-globalization period. 
This indicates - in line with our findings from the cluster analysis - that the country groups previously supposed by Kose et al. (2012) and Hirata et al. (2013) simply did not exist at least before the mid-1980s, resulting in an incorrect estimate of the relative contribution of the global and the group-specific factors in these studies.

The remainder of this paper is organized as follows. Section 2 introduces the DFM and the clustering method that we employ as well as the dataset. The results of the cluster analysis and those of the DFM due to the different country group specifications are presented in Section 3 for the full sample period. We also assess the implications for the 'decoupling' and 'regionalization' notions by conducting the DFM for the two sub-periods using the respective data-based grouping structure. In Section 4, we draw some conclusions.

\section{Methodology and Data}

\section{The Model}

Consider a hierarchical dynamic factor model with multiple observed variables per country and multiple unobserved factors similar to Kose et al. (2003, 2012). More specifically, our factor model contains a global factor common to all variables in all countries denoted by $F_{t}^{G l o b a l}$, group-specific factors that are common to all countries and variables in a given group of countries denoted by $F_{t, j}^{\text {Group }}$, and country-specific factors, $F_{t, k}$ common to all variables in country $k$. The DFM takes the form,

$$
y_{i, t}=\alpha_{i} F_{t}^{G l o b a l}+\sum_{j=1}^{M} \beta_{i, j} F_{t, j}^{\text {Group }}+\sum_{k=1}^{N} \gamma_{i, k} F_{t, k}^{\text {Country }}+\mu_{i, t}, \quad i=1, \ldots, K \times N, t=1, \ldots, T,
$$

where $M$ denotes the number of groups, $N$ is the number of countries, and $K$ denotes the variables per country. Each observed variable $y_{i, t}$ is explained by the global factor with loading $\alpha_{i}$, by a group-specific factor with loading $\beta_{i, j}$, by its country factor with loading $\gamma_{i, k}$, and an idiosyncratic component $\mu_{i, t}$. As is common in the literature on the international business cycle, we impose a hierarchical structure, i.e. all countries and variables load on the global factor but each country only belongs to one group. As a consequence, some loadings in $\beta_{i, j}$ and $\gamma_{i, k}$ are restricted to be equal to zero, as the observed variables do not load on every group and country factor. 
The model is completed by assuming stochastic laws of motion for all unobserved factors. Following Kose et al. (2003, 2012), we assume all factors in eq. (1) to follow zero-mean $A R(3)$ processes,

$$
F_{t}^{V}=\sum_{l=1}^{3} F_{t-l}^{V}+\varphi_{t}^{V}, \quad \varphi_{t}^{V} \sim i i d N\left(0, \sigma_{\varphi^{V}}^{2}\right)
$$

for $V=1+M+N$. Similarly, all idiosyncratic components are assumed to follow zero-mean $A R(3)$ processes,

$$
\mu_{i, t}=\sum_{l=1}^{3} \mu_{i, t}+\varepsilon_{t}, \quad \varepsilon_{t} \sim \operatorname{iid} N\left(0, \sigma_{\varepsilon}^{2}\right),
$$

As it stands, the model given by eqs. (1)-(3) is not identified without further restrictions as neither the signs nor the scales of the factors and the factor loadings are separately identified. ${ }^{2}$ Scale identification is achieved by normalizing the variance of the factor innovations to some positive constant $c$, i.e., we set $\sigma_{\varphi^{V}}^{2}=c{ }^{3}$ Sign identification is achieved by restricting one of the factor loadings on each factor to be positive.

The model given by eqs. (1)-(3) can be cast in state space form and estimated using the Kalman filter and maximum likelihood techniques. This is not the approach pursued in this paper. The fairly large number of unknown parameters in combination with the large number of unobserved states makes the numerical optimization of the sample log-likelihood function quite tedious. Therefore, we analyze the state space model from a Bayesian point of view using a Gibbs sampler. The Gibbs sampler is a Markov chain Monte Carlo (MCMC) method that simplifies drawing sequences of observations from the joint and marginal posterior distributions of the unknown parameters and the unobserved states by iteratively drawing states and parameters from their conditional distributions. Intuitively, this amounts to reducing sampling from the more complex joint distribution to a sequence of blocks for subsets of parameters/states which are easier to sample conditional on the other blocks in the sequence. For details of the exact implementation we refer to Kose et al. (2003) and Otrok and Whiteman (1998).

\footnotetext{
2 The scale problem in dynamic factor models refers to the fact that it is possible to multiply the common factors and corresponding loadings by any constant without changing their product. Further, the sign of the factors and their loadings are not jointly identified, since the likelihood remains the same when both are multiplied by -1 .

${ }^{3}$ Similar to Kose et al. $(2003,2012)$, the constant $c$ is chosen based on the average innovation variance of a set of univariate autoregressions on each variable $y_{i, t}$. 


\section{Determining the country groups}

Prior to estimating the DFM, we determine the number and the compositions of the country groups. Following Ductor and Leiva-Leon (2016), we choose the Ward clustering method for partitioning the country sample, as it is one of the most frequently used standard clustering procedures and tends to form clusters of equal sizes, which enhances economic interpretation of business cycle groups. Ward's clustering method successively merges countries and clusters according to the minimal increase in the error sum of squares within a newly formed cluster that can be calculated using

$$
E S Q_{j}=\sum_{k=1}^{n_{j}} \sum_{t=1}^{T}\left(x_{k t j}-\bar{x}_{t j}\right)^{2}
$$

with $n_{j}$ being the number of countries in cluster $j, x_{k t j}$ denoting observation in $t$ of country $k$ in cluster $j$, and $\bar{x}_{t j}$ denoting the mean of observations at $t$ in cluster $j$. The recursive algorithm starts with merging the pair of countries ( $i$ and $h$ ) with the smallest squared Euclidean distance between them:

$$
d=\sum_{t=1}^{T}\left(x_{i t}-x_{h t}\right)^{2}
$$

where $x_{i / h t}$ is the observation in $t$ of countries $i$ and $h$. At each step of the following procedure, the distance between a newly created cluster of countries $\mathrm{B}+\mathrm{C}$ and any other country A can be recalculated using:

$$
\begin{aligned}
D(\mathrm{~A} ; \mathrm{B}+\mathrm{C})= & \frac{1}{n^{A}+n^{B}+n^{C}} *\left\{\left(n^{A}+n^{B}\right) * d(A ; B)+\left(n^{A}+n^{C}\right) * d(A ; C)-n^{A}\right. \\
& * d(B ; C)\}
\end{aligned}
$$

with $n^{A}, n^{B}, n^{C}$ denoting the number of objects in clusters $\mathrm{A}, \mathrm{B}$, and C. Note that these distances correspond to twice the increase of the sum of squares within the formed clusters.

The hierarchical clustering allows to take the country grouping obtained at any level of aggregation. For the interpretation of the final results, however, it might be interesting to know what number of clusters should be optimally assumed. This is especially important 
when comparing the results of the first with the second period, as within both time periods different numbers of clusters might fit the data just as well. For the determination of an optimal number of clusters, we consider the two widely used cluster stopping rules developed by Calinski and Harabasz (1974) and Duda and Hart (1973), which were found to perform best among many others (for an overview and application test, see Milligan and Cooper 1985). We compute the values on a range between three and ten possible clusters, as two clusters appear too few and more than the square root of $\mathrm{n}$ too many for reasonable economic interpretation. The higher the values of both indices the more distinct is the clustering. Results can be seen in the Appendix Table A2.

\section{Data}

For reasons of comparability, we create the same global dataset of 106 countries and three macroeconomic aggregates (real GDP, real consumption, and real investment) that has been used in the literature. All data have been obtained from Penn World Table 9.0 covering an extended time period of annual observations from 1960 to 2014. We use the aggregates with constant prices expressed in local currencies and compute the growth rates for each time series. For the cluster analysis, the data have been z-standardized in order to achieve an equal weighting. The DFM is then estimated with demeaned growth series in line with Kose et al. (2012). To compare the results due to different country group specifications, the sample can be partitioned into the seven regional groups (North America (NA); Europe; Oceania; Asia; Latin America and the Caribbean (LAC); Middle East and North Africa (MENA); and SubSaharan Africa (SSA)) used by Hirata et al. (2013), as well as into the three developmentbased groups (23 IEs, 24 EMs, 59 DEs) set by Kose et al. (2012). A detailed list of the countries of each group can be found in the Appendix. Following these authors, we also divide the sample into the pre-globalization period (1960-1984) and the globalization period (1985-2014) in order to reassess the previously detected 'decoupling' and 'regionalization' trends based on different country groupings.

\section{Results}

\section{The country group pattern of international business cycles}

Figure 1 shows the hierarchical grouping structure of the business cycle data for the full sample period in the form of a dendrogram. Starting with 106 individual country clusters at 
the bottom, countries and clusters are successively merged using Ward's clustering method until only one cluster is left. The most obvious division arising is that between all the IEs on the left side, and the EMs and DEs together on the right side of the dendrogram. When the sample is further partitioned into three clusters, the latter two country groups can, however, not be clearly separated as supposed by Kose et al. (2012). Whereas, for instance, many of the Central American DEs are grouped into the second cluster also containing the majority of the 24 EMs of the sample, some mainly South Asian EMs (e.g. China, India, Egypt, Pakistan, Jordan) rather belong to the third cluster of otherwise mostly African DEs.

Moving further to the bottom of the dendrogram by separating four, five, six, and seven clusters reveals some regional similarities in the data, most evidently in Central Europe, Southeast Asia, Latin America, and parts of Africa. When seven clusters are supposed the country groups can roughly be labelled as the following: 1. Cluster: 'Central Europe'; 2. Cluster: 'Anglo-Saxon'; 3. Cluster: 'Latin America'; 4. Cluster: 'Southeast Asia', 5. Cluster: 'South Asia and Africa'; 6. Cluster: 'Middle East and Africa'; 7. Cluster: 'Africa'. The group compositions, however, do not correspond to the seven regions that have been set by Hirata et al. (2013). For instance, countries of North America (USA and Canada) and Oceania (New Zealand and Australia) rather form a common cluster together with Anglo-Saxon and Northern European countries (Ireland, UK, Denmark, Sweden, Norway, Finland), providing evidence of inter-regional cyclical commonalities that were similarly found between these groups by the clustering approaches of Ductor and Leiva-Leon (2016) and Francis et al. (2017), but based on different and smaller databases. The only clusters found to comprise almost exclusively countries of the same region are the first cluster of Central European countries and the fourth cluster of Southeast Asian economies. Interestingly, Japan in fact is not grouped with its regional neighbors but with the European countries, indicating stronger commonalities between these IEs.

In sum, the country group pattern obtained by the clustering approach reveals cyclical similarities different from what has been previously supposed in the DFM conducted by Kose et al. (2012) and Hirata et al. (2013). The grouping structure of the data is rather a mix of both, carrying implications for the DFM conducted in the next section. Regarding the optimal number of clusters, we find no clear evidence as to how many groups should be used (see Table A2 in the Appendix). While the first index does not indicate any superior cluster solution as its values decrease continually with the number of clusters, the Duda-Hart Index prefers the three-cluster solution over the others. Thus, one first result is that the assumed 
number of clusters used by Kose et al. (2012) seems more accurate than that of Hirata et al. (2013), but in either case the group compositions do not fit the data. In the following section, we use both the three- and the seven cluster solutions, allowing us to directly compare our results regarding the importance of group factors based on an equivalent number of clusters.

Figure 1: Hierarchical grouping structure $(1960-2014)$

\section{The importance of the group specification in DFM}

Figure 2 depicts the posterior mean of the global and the group-specific factors together with the respective 5\% and 95\% quantile bands of the estimates of the DFM when seven groups have been set according to the dendrogram. We show this specification, as the group-specific factors can be interpreted more easily from clusters containing smaller intuitive country groups with less variation.

It can be seen in the upper left panel that the global factor captures some major economic events that have been experienced all around the world. For example, the drastic downturns following the oil crises of 1973/74 and 1979 are as clearly visible as the recession in the 1990s and the reversing dynamic in the beginning of the 2000s. By contrast, the immediate impact of the more recent financial crises is rather captured by the first four group-specific factors comprising primarily European, Anglo-Saxon, Latin American, and Southeast Asian countries, respectively. While the recessions of 2008/9 were most pronounced in Europe (Cluster 1) and the Anglo-Saxon countries (Cluster 2), many of these countries also experienced another prolonged downswing visible after the first recovery phase, indicating a so-called double dip recession. The other group-specific factors as well as the global factor evolved somewhat differently during that time. Overall, this may be interpreted consistent with the presumption of recently declining importance of the global factor due to more groupspecific economic developments. Specific regional events such as the Asian crisis in the late 1990s, for example, are captured by the group factor of Cluster 4 .

\section{Figure 2: Global and group-specific factors (1960 - 2014)}

Table 1 shows the variance decompositions from the DFM conducted with different group specifications. Columns 1 and 3 for each variable present the results of the DFM using the country classifications of Kose et al. (2012) and Hirata et al. (2013), respectively. In columns 2 and 4, we report the variances explained that are calculated from the DFM based on the corresponding clustering of the previous section. 
When three groups are assumed based on the levels of development, for all 106 countries, the global factor, on average, accounts for a remarkable fraction of output- $(9.1 \%)$, consumption$(9.6 \%)$, and - to a lesser degree - investment (4.1\%) growth variability (Column 1$)$. For the case of seven regions (Column 3), these numbers are even higher $(10.2 \%, 10.3 \%$, and $4.7 \%$ ), indicating the importance of the grouping structure that has been set beforehand. These figures, however, hide a substantial variation across different subsets of countries, with a much higher variance explained among the IEs. For instance, the global factor in Columns 1 and 3 , on average, accounts for $25 \%$ and $29.1 \%$ of the output variability in the IEs, while it only explains $5.7 \%$ and $4.3 \%$ and $6.4 \%$ and $4.4 \%$ of the volatility of GDP growth rates among the EMs and DEs, respectively. By contrast, for all three variables and all subsets of countries, the global factor's importance decreases dramatically when the groups are specified according to the cyclic similarities of the countries (Columns 2 and 4), implying that, if there is a 'global business cycle', its relevance in fact is very much limited to the industrialized world (and most significant in consumption growth). While for the whole sample, the contribution of the global factor shrinks to, on average, about $5.2 \%$ or $4.4 \%$ of the output variability in the second and fourth models, within the latter group of countries, it still accounts for $11.5 \%$ or $8.5 \%$. This drop by just about a half in world average of the global factor's relative importance is similarly found for consumption and investment growth rates. However, the deviations between the models are even more pronounced for the G-7 countries with the average output variance explained varying between $33.4 \%$ in the third and $7.8 \%$ in the fourth model. Similarly, the global factor's importance for, say, output volatility differs substantially for important countries like the USA and Canada, depending on whether they are grouped together with all other IEs of the sample (21\%), with Mexico on a regional basis $(23.8 \%)$, or with the cluster members of the equivalent cluster numbers $(9.2 \%$ or $5.1 \%)$.

Conversely, and in line with Francis et al. (2017), we find that, overall, the group-specific factors gain importance when the countries are classified according to their cyclical similarity. For the results obtained with three development-related groups, the group-specific factors, on average, explain $11.1 \%, 6.4 \%$, and $9.4 \%$ of all the countries' macroeconomic fluctuations, respectively (Column 1). Assuming seven regions instead, the regional component captures $14.8 \%, 7.7 \%$, and $9.9 \%$ of the variability of output, consumption, and investment growth rates, respectively (Column 3). Finally, when the underlying classification is based on the corresponding clusters drawn from the dendrogram (Columns 2 and 4), the group-specific factors account for a larger fraction of the variability of output (14.5\% or $18.8 \%$ ), consumption $(9.0 \%$ or $13.6 \%)$, and investment $(11 \%$ or $12.5 \%)$ growth rates. Again, these 11 
average deviations may seem small, but are based on a sample of 106 countries and differ substantially across many subsets: For instance, the fraction of output growth attributable to the group-specific factors of the USA and Canada varies between 15\% of the IE-factor, $49 \%$ of the regional factor, and between $26.6 \%$ and $60.4 \%$ of the corresponding cluster-specific factors. Similarly, the 'European business cycle', which loads over all 18 sample countries of the European continent, explains, on average, $20.3 \%$ of the output variation of the EU-12 countries, compared with $43.7 \%$ or $48.3 \%$ of the average EU-12 country's output growth captured by the cluster-specific factors.

Besides the deviations in the relative importance of global and group-specific factors, we find that the overall contribution of international factors relative to the domestic and idiosyncratic components does not change much at world average.

\section{Table 1: Variance decompositions using different country groupings for the full sample period (1960 - 2014)}

\section{Changing country group pattern and implications for the 'decoupling' trend}

After having shown the importance of properly specifying the group-specific factors for the full sample, we now turn to the country group patterns that have been established in the preand the globalization eras. Moreover, by assuming the optimal number of clusters in each period, we gain a better understanding of the extent of 'decoupling' of IEs and EMs or the 'regionalization' that has been detected by the literature.

Figure 3 illustrates the dendrograms obtained by the cluster analyses of each period. For the pre-globalization period, the grouping of countries does not much reflect the previous assumptions of seven regional or three development-driven group-specific business cycles. Specific regional commonalities are most visible in the first European cluster at the twocluster-level, and otherwise limited to North and Central America and some neighboring countries at lower aggregation levels. There is also a clear division among the IEs, as, for instance, the USA, Canada, and the UK are found to be separated from the European IEs and Japan. For most groups, there seems to exist no obvious economic explanation as to why member countries share cyclic commonalities, suggesting either stronger global trade linkages or coincidence. That said, it may be no surprise why the group-specific factors imposed by Kose et al. (2003/2012) and Hirata et al. (2013) explain only a negligible fraction of macroeconomic growth rates in the pre-globalization period.

Figure 3a+b: Hierarchical grouping structure (1960 - 1984 and 1985 - 2014) 
In the second period, however, the country group pattern corresponds more closely to both regional proximity and the level of development. While the division between the bulk of the IEs, on the one hand, and the EMs and DEs, on the other hand, is most visible at the twocluster-level, at least most of the (African) DEs are clustered together into a further subgroup, separated clearly from 18 out of 24 EMs on the right side of the dendrogram. Regional linkages are found to exist with increasing accuracy downwards from the five-cluster level, where the clusters can roughly be labelled as the following: 1. Cluster: 'Central Europe'; 2. Cluster: 'Anglo-Saxon'; 3. Cluster: 'Africa'; 4. Cluster: 'Latin America', 5. Cluster: 'Southeast Asia'. However the Anglo-Saxon cluster confirms some inter-regional similarities in the business cycles. This is also true for Japan and Taiwan, which are grouped together with the Central European countries.

What does this change in the group pattern of business cycles suggest about the previously detected growing importance of intra-group factors and declining relevance of the global factor over time? While it certainly indicates some development-related fragmentation and regionalization of the world's economic system after the mid-1980s, the 'decoupling' of country groups is likely to have occurred in a slightly different constellation than between the IEs, EMs or some specific regional clusters. While these country groups, indeed, have developed increasing ties in the second period, this does not necessarily mean that intra-group factors exhibited lower importance for such countries before. In fact, the groups were just different. Taking the data-based group structures in both periods instead will give us some indication of to what extent the group-specific factors' relative importance has actually changed. In combination with the optimal number of clusters shown in Table A2 in the Appendix, we can run the DFM for each period separately in order to verify the respective changes in the variance decompositions.

Table 2 depicts the variance decompositions for both sub-periods with varying country group specifications. In line with the 'decoupling' thesis, we find that the global factor's importance decreases for all countries and variables from the first to the second period (except for some countries' investment activity) regardless of what groups have been imposed. Whereas it explained, on average, up to $14.7 \%$ of the volatility of output, consumption, and investment growth in the pre-globalization era respectively, it captures at maximum $9 \%$ of the macroeconomic fluctuations in the second period within all model specifications. When the group-specific factors are modelled according to the clustering, the importance of the global factor is again the lowest compared with the results from the other groupings in both periods. 
In the pre-globalization period, however, these deviations in the global factor's importance, on average, are not very high between the models, suggesting again that distinct international country groups around the world did not play the same role as in the second period.

Conversely, the group-specific factors gain importance over time in all specifications with the highest relevance generally found again for the four and five clusters imposed. Different from the first two models, the group-specific factors of the four-cluster-model already exhibit almost equal importance as the global factor for output growth in the pre-globalization period. For countries like the USA and Canada the group factor already played a greater role. Consequently, another substantial deviation exists in the extent to which the importance of intra-group factors increased for some countries depending on the model. Whereas, with the traditional groupings, the figures for IEs went up from $11.8 \%$ and $12.5 \%$ to $50.1 \%$ and $50.1 \%$, respectively, those factors' importance has 'only' grown from $20.7 \%$ to $54.1 \%$ based on the DFM using the data-based grouping. Similarly, the average importance of the group-specific factors for the EU-12 countries has risen with factor 4.1 and 4.3 in columns 1 and 2 (from the relatively low levels of $15 \%$ and $13.7 \%$ to $62.1 \%$ and $59.2 \%$ ) compared with factor 2.7 in Column 3 (from $23.3 \%$ to $63.3 \%$ ). This confirms the perception from the cluster analysis that the dramatically increasing importance of intra-group factors among IEs, Ems, or within regions highlighted in the literature is partly to be seen as a simple result of these ex ante groupings reflecting reality more closely in the second period.

Table 2: Variance decompositions using different country groupings for sub periods 1960 1984 and 1985 - 2014

\section{Conclusion}

The literature on international business cycles has frequently employed DFM presuming the existence of group-specific factors among countries of the same region or at the same level of development. In the present paper, by contrast, we first reveal the data-inherent country group pattern of international business cycles using a cluster analysis and then estimate a DFM accordingly. By comparing the findings with those obtained with the traditional groupings, we show that the correctly specified group factors exhibit much greater, and the global factor much lower, importance for domestic business cycles. The deviations are particularly strong for countries like the USA and Canada that were previously either grouped with Mexico on a regional basis or with all other IEs of the sample. If we assume seven clusters instead of seven world regions, the cluster analysis rather provides evidence of a specific Anglo-Saxon 
business cycle cluster comprising also the UK, Ireland, Australia, New Zealand, and some Northern European countries.

Regarding the change over time, we find that the country group pattern has evolved towards greater development-related fragmentation and regionalization in the globalization era, explaining to some extent the alleged 'decoupling' of IEs and EMs, i.e. the growing relevance of the respective group factors and the decreasing importance of the global factor. The groupspecific factors of these countries, however, have played a significant role in the preglobalization era, too, albeit in another constellation.

\section{References}

Calinski, T., and J. Harabasz. 1974. "A dendrite method for cluster analysis." Communications in Statistics 3: 1-27.

Ductor, L., and D. Leiva-Leon. 2016. "Dynamics of global business cycle interdependence." Journal of International Economics 102: 110-27.

Duda, R.O., and P. E. Hart. 1973. Pattern classification and scene analysis. New York: Wiley.

Francis, N., M. T. Owyang, and O. Savascin. 2017. "An endogenously clustered factor approach to international business cycles." Journal of Applied Econometrics 2017 (0): 1-16.

Helbling, T., P. Berezin, M. A. Kose, M. Kumhof, D. Laxton, and N. Spatafora. 2007. "Decoupling the Train? Spillovers and Cycles in the Global Economy." In IMF World Economic Outlook, Chapter 4: 121-60.

Hirata, H., M. A. Kose, and C. Otrok. 2013. Regionalization vs. globalization. IMF Working Paper 13/19.

Kose, M.A., C. Otrok, and C. H. Whiteman. 2003. "International business cycles: world, region, and country-specific factors." American Economic Review 93(4): 1216-39.

Kose, M.A., C. Otrok, and E. Prasad. 2012. "Global business cycles: convergence or decoupling?” International Economic Review 53(2): 511-38.

Milligan, G. W., and M. C. Cooper. 1985. "An examination of procedures for determining the number of clusters in a dataset." Psychometrika 50: 159-79.

Mumtaz, H., S. Simonelli, and P. Surico. 2011. "International comovements, business cycle and inflation: a historical perspective." Review of Economic Dynamics 14(1): 176-98. 







\begin{tabular}{|c|c|c|c|c|c|c|c|c|}
\hline  & 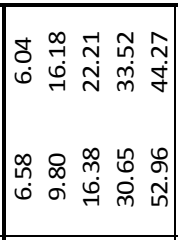 & 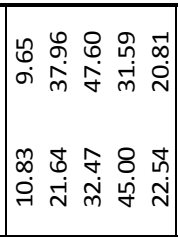 &  & 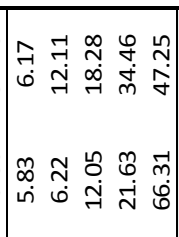 & 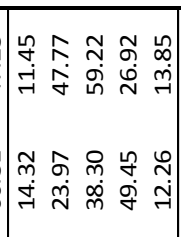 & 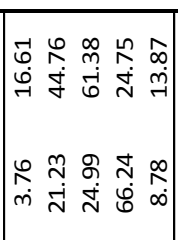 &  &  \\
\hline 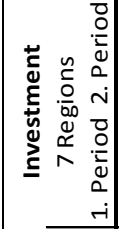 &  & 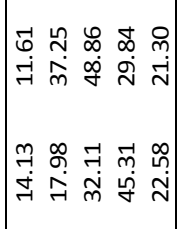 & 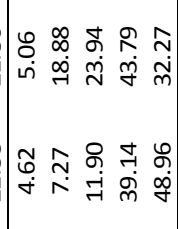 & 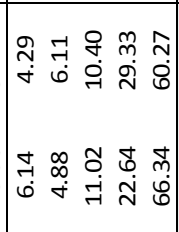 & 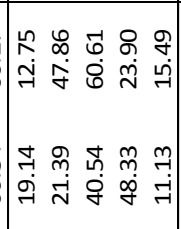 &  &  & 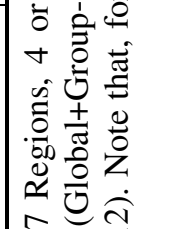 \\
\hline  & 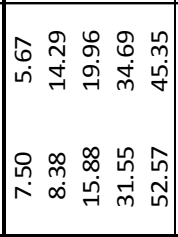 & 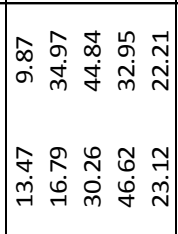 & 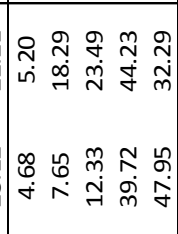 & 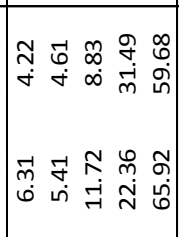 & 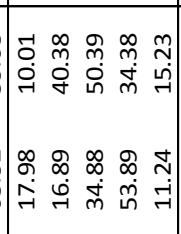 &  & 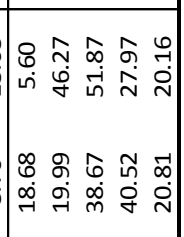 & 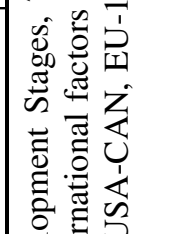 \\
\hline 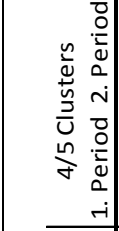 &  &  & 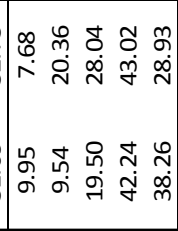 & 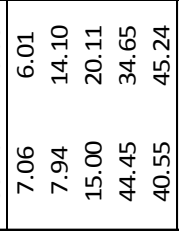 & 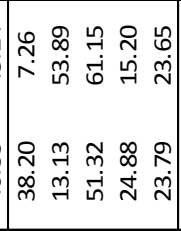 & 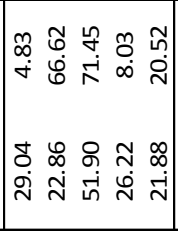 &  & 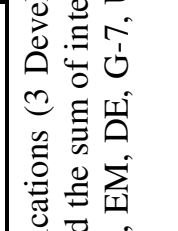 \\
\hline  & 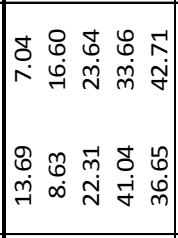 &  & 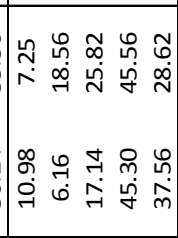 & 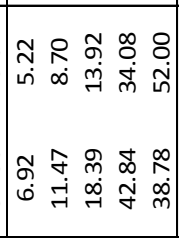 & 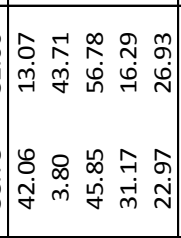 & 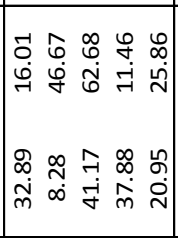 & 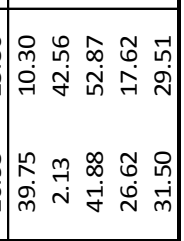 & 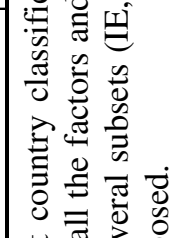 \\
\hline  &  &  & 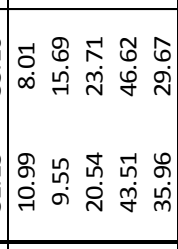 & 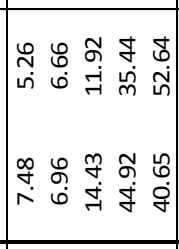 & 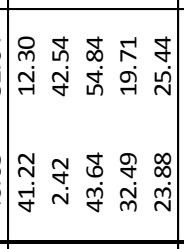 & 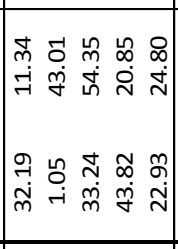 & 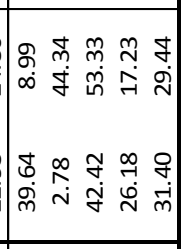 & 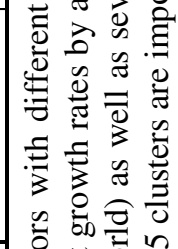 \\
\hline 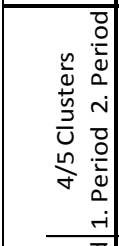 & 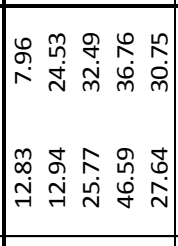 &  &  &  & 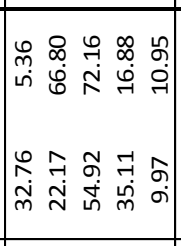 & 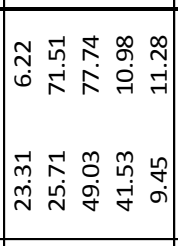 & 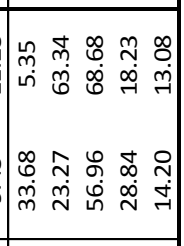 &  \\
\hline 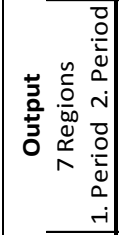 & 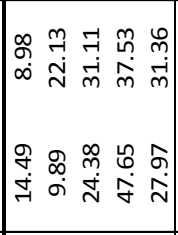 & 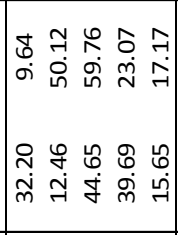 & 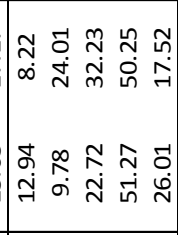 & 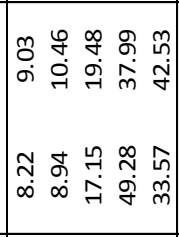 & 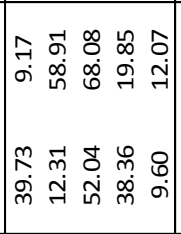 & 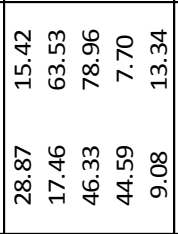 & 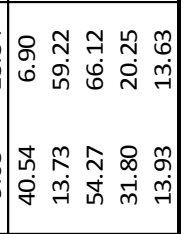 &  \\
\hline 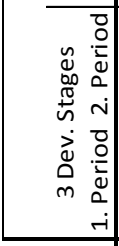 & 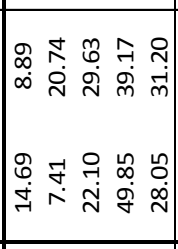 & 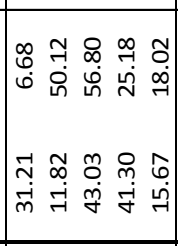 &  & 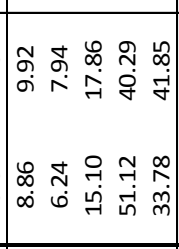 & 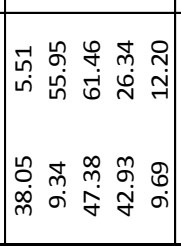 & 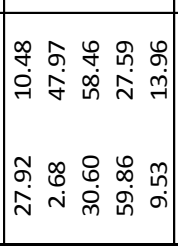 &  & 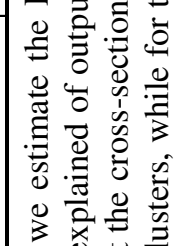 \\
\hline 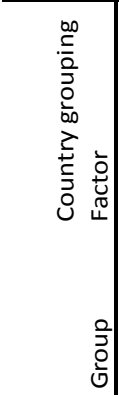 & 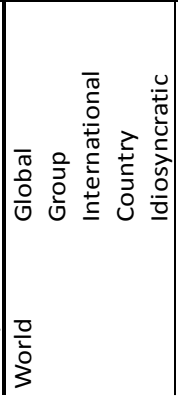 &  & 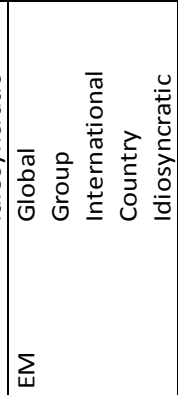 &  & 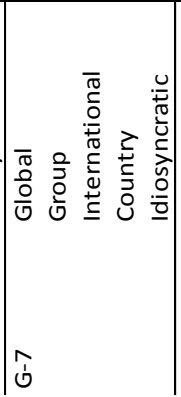 & 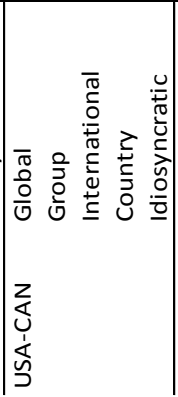 & 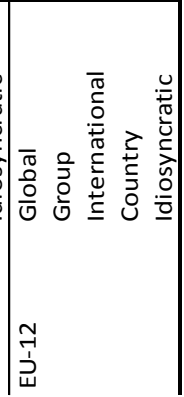 &  \\
\hline
\end{tabular}




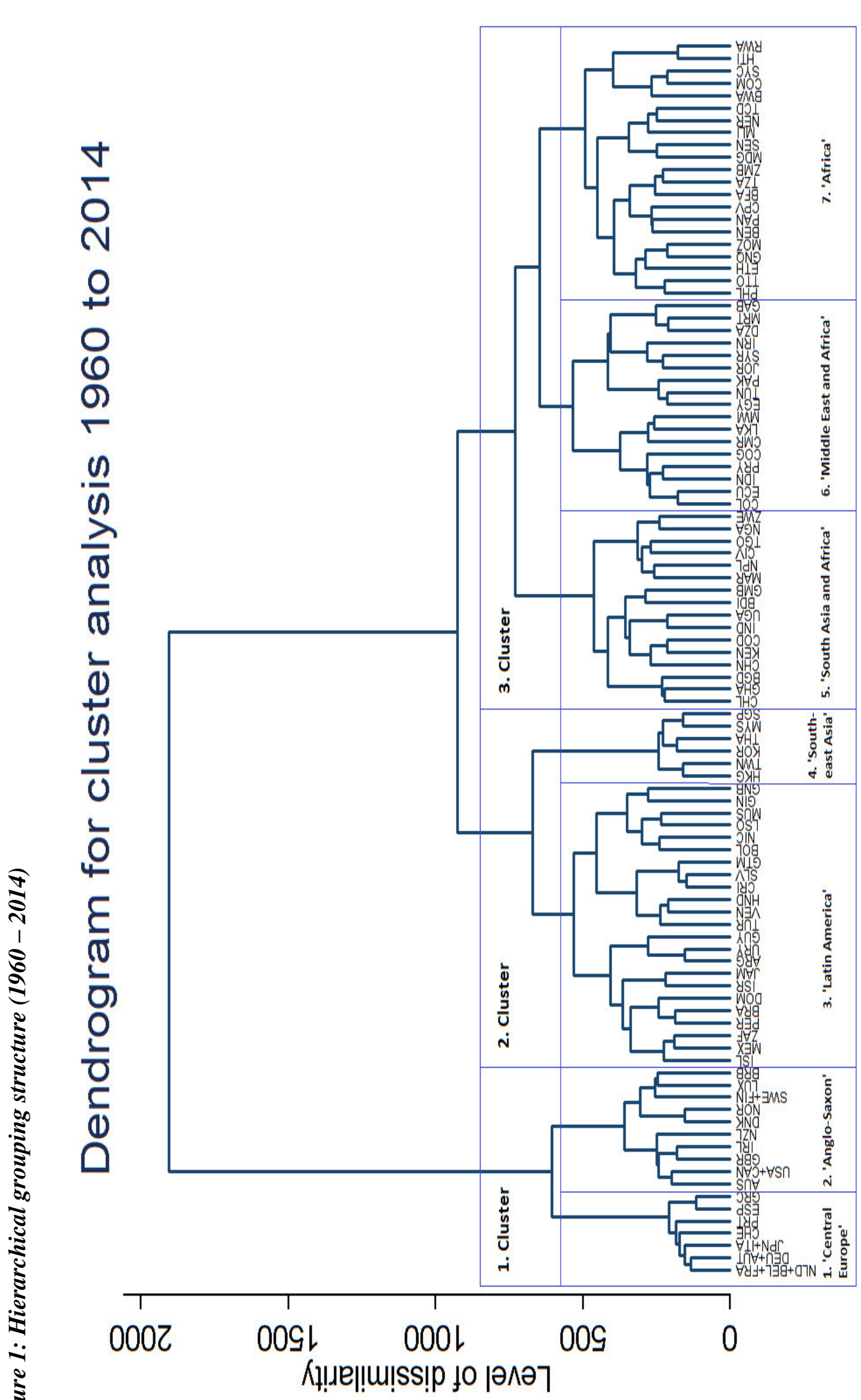

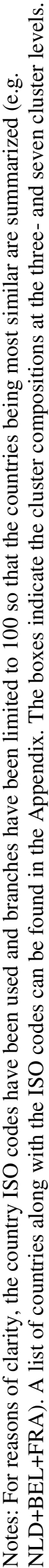



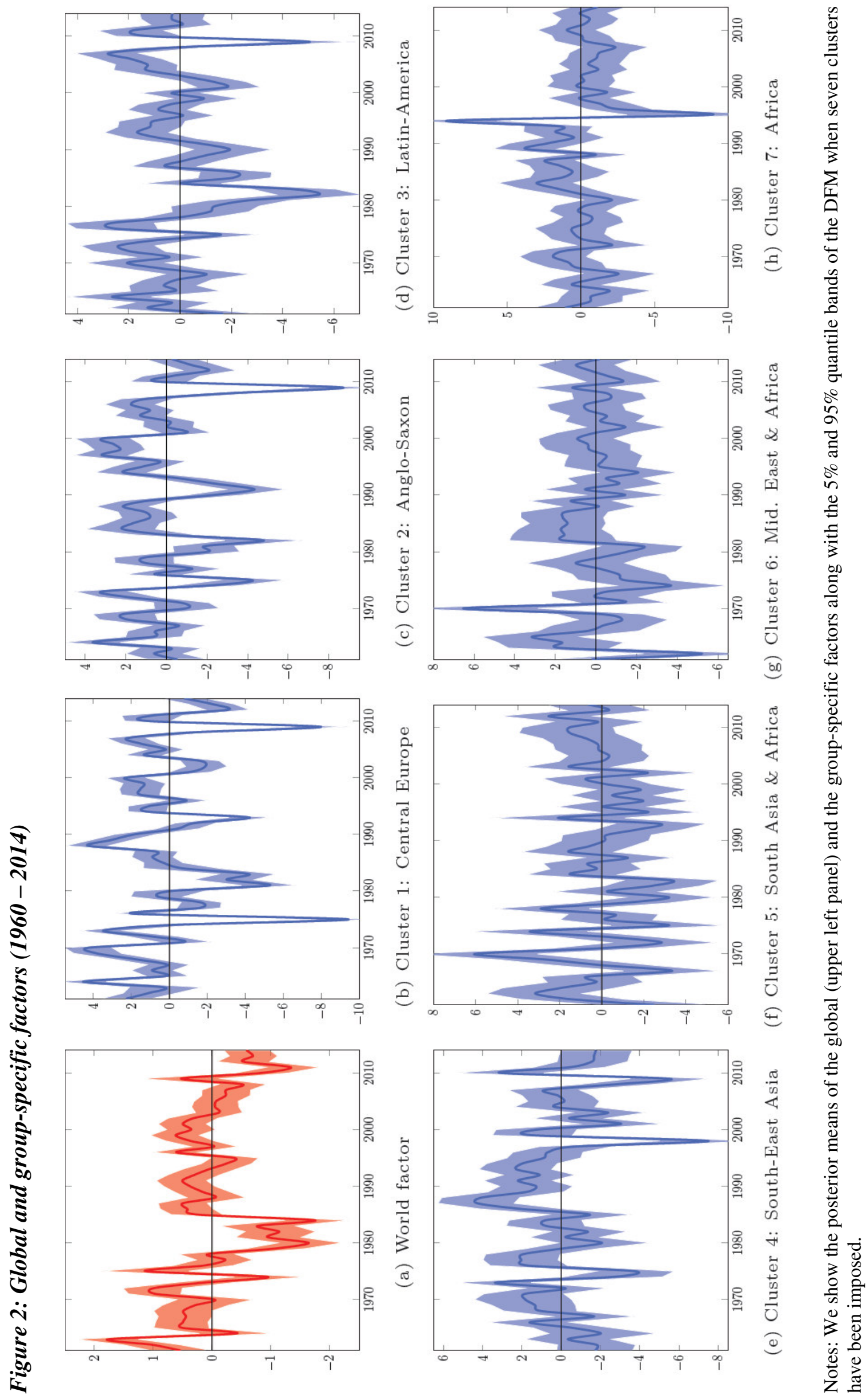




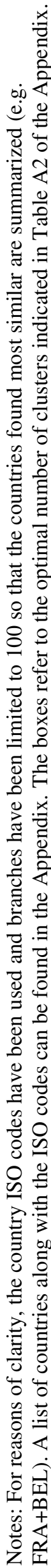




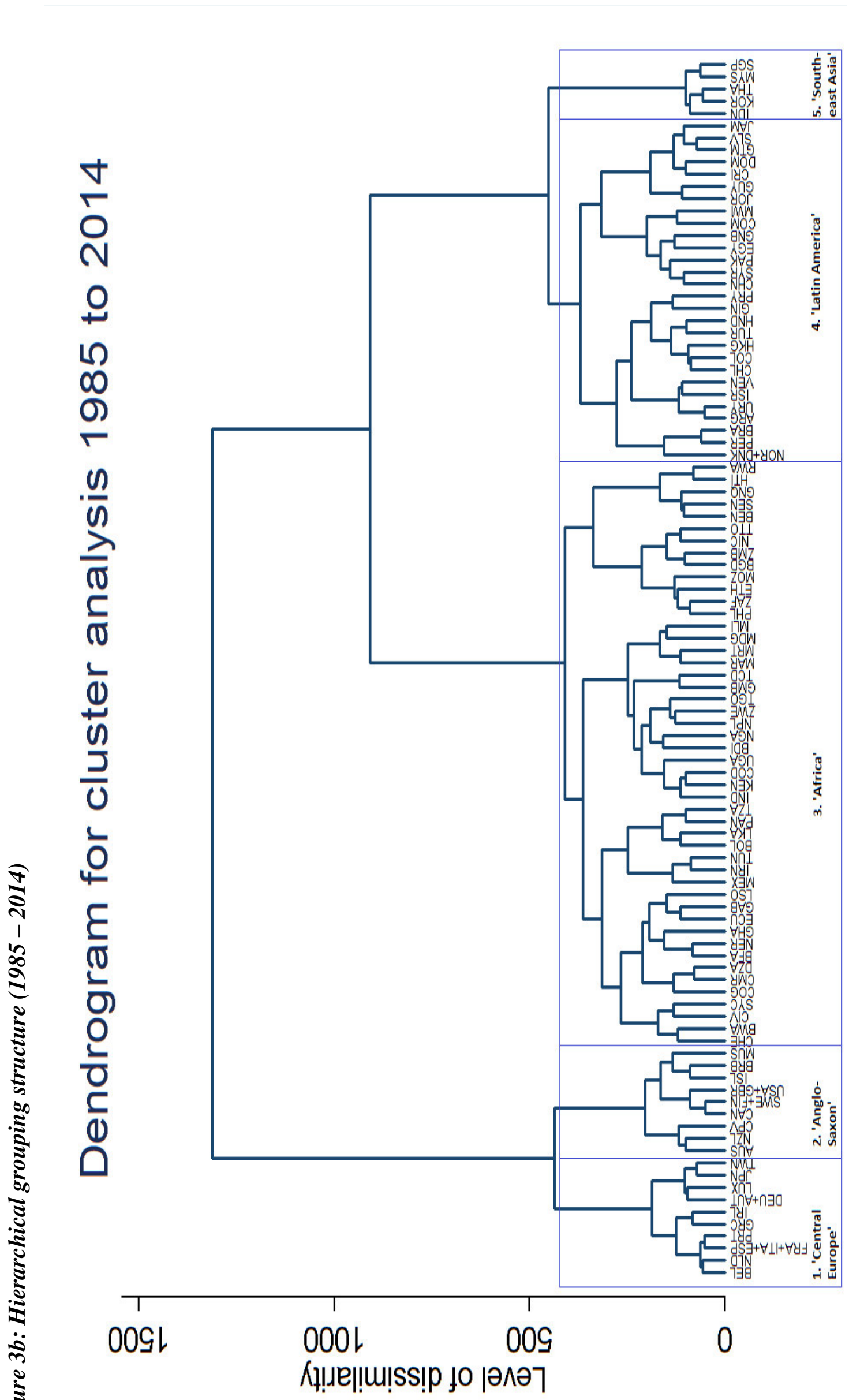

ip

e

这

寻藏

के

난

흘

.

के

롤

ठै.

胥葛

ํํㅇ

ङ

플

욤

8

응

힐

眑

ญี ญ

0

I

\&

를

하

콬

윰

它

จี

.

I

s

80

요

롤

ठ요

음

$\mathscr{0}$

高 


\section{Appendix}

\section{Table A1: List of countries and attribution to groups}

\begin{tabular}{|c|c|c|c|c|c|c|c|c|c|}
\hline No. & Country & ISO code & Development level & World Region & No. & Country & ISO code & Development level & World Region \\
\hline 1 & Algeria & DZA & Developing Economy & MENA & 54 & Jamaica & JAM & Developing Economy & LAC \\
\hline 2 & Argentina & ARG & Emerging Market & LAC & 55 & Japan & JPN & Industrialized Economy & Asia \\
\hline 3 & Australia & AUS & Industrialized Economy & Oceania & 56 & Jordan & JOR & Emerging Market & MENA \\
\hline 4 & Austria & AUT & Industrialized Economy & Europe & 57 & Kenya & KEN & Developing Economy & SSA \\
\hline 5 & Bangladesh & BGD & Developing Economy & Asia & 58 & Lesotho & LSO & Developing Economy & SSA \\
\hline 6 & Barbados & BRB & Developing Economy & LAC & 59 & Luxembourg & LUX & Industrialized Economy & Europe \\
\hline 7 & Belgium & BEL & Industrialized Economy & Europe & 60 & Madagascar & MDG & Developing Economy & SSA \\
\hline 8 & Benin & BEN & Developing Economy & SSA & 61 & Malawi & MWI & Developing Economy & SSA \\
\hline 9 & Bolivia & $\mathrm{BOL}$ & Developing Economy & LAC & 62 & Malaysia & MYS & Emerging Market & Asia \\
\hline 10 & Botswana & BWA & Developing Economy & SSA & 63 & Mali & MLI & Developing Economy & SSA \\
\hline 11 & Brazil & BRA & Emerging Market & LAC & 64 & Mauritania & MRT & Developing Economy & SSA \\
\hline 12 & Burkina Faso & BFA & Developing Economy & SSA & 65 & Mauritius & MUS & Developing Economy & SSA \\
\hline 13 & Burundi & $\mathrm{BDI}$ & Developing Economy & SSA & 66 & Mexico & MEX & Emerging Market & NA \\
\hline 14 & Cameroon & CMR & Developing Economy & SSA & 67 & Morocco & MAR & Emerging Market & MENA \\
\hline 15 & Canada & CAN & Industrialized Economy & NA & 68 & Mozambique & MOZ & Developing Economy & SSA \\
\hline 16 & Cape Verde & CPV & Developing Economy & SSA & 69 & Nepal & NPL & Developing Economy & Asia \\
\hline 17 & Chad & TCD & Developing Economy & SSA & 70 & Netherlands & NLD & Industrialized Economy & Europe \\
\hline 18 & Chile & $\mathrm{CHL}$ & Emerging Market & LAC & 71 & New Zealand & NZL & Industrialized Economy & Oceania \\
\hline 19 & China & $\mathrm{CHN}$ & Emerging Market & Asia & 72 & Nicaragua & NIC & Developing Economy & LAC \\
\hline 20 & Colombia & COL & Emerging Market & LAC & 73 & Niger & NER & Developing Economy & SSA \\
\hline 21 & Comoros & COM & Developing Economy & SSA & 74 & Nigeria & NGA & Developing Economy & SSA \\
\hline 22 & Congo - Brazzaville & COG & Developing Economy & SSA & 75 & Norway & NOR & Industrialized Economy & Europe \\
\hline 23 & Congo - Kinshasa & COD & Developing Economy & SSA & 76 & Pakistan & PAK & Emerging Market & Asia \\
\hline 24 & Costa Rica & CRI & Developing Economy & LAC & 77 & Panama & PAN & Developing Economy & LAC \\
\hline 25 & Denmark & DNK & Industrialized Economy & Europe & 78 & Paraguay & PRY & Developing Economy & LAC \\
\hline 26 & Dominican Republic & DOM & Developing Economy & LAC & 79 & Peru & PER & Emerging Market & LAC \\
\hline 27 & Ecuador & ECU & Developing Economy & LAC & 80 & Philippines & PHL & Emerging Market & Asia \\
\hline 28 & Egypt & EGY & Emerging Market & MENA & 81 & Portugal & PRT & Industrialized Economy & Europe \\
\hline 29 & El Salvador & SLV & Developing Economy & LAC & 82 & Rwanda & RWA & Developing Economy & SSA \\
\hline 30 & Equatorial Guinea & GNQ & Developing Economy & SSA & 83 & Senegal & SEN & Developing Economy & SSA \\
\hline 31 & Ethiopia & ETH & Developing Economy & SSA & 84 & Seychelles & SYC & Developing Economy & SSA \\
\hline 32 & Finland & FIN & Industrialized Economy & Europe & 85 & Singapore & SGP & Emerging Market & Asia \\
\hline 33 & France & FRA & Industrialized Economy & Europe & 86 & South Africa & ZAF & Emerging Market & SSA \\
\hline 34 & Gabon & GAB & Developing Economy & SSA & 87 & South Korea & KOR & Emerging Market & Asia \\
\hline 35 & Gambia & GMB & Developing Economy & SSA & 88 & Spain & ESP & Industrialized Economy & Europe \\
\hline 36 & Germany & DEU & Industrialized Economy & Europe & 89 & Sri Lanka & LKA & Developing Economy & Asia \\
\hline 37 & Ghana & GHA & Developing Economy & SSA & 90 & Sweden & SWE & Industrialized Economy & Europe \\
\hline 38 & Greece & GRC & Industrialized Economy & Europe & 91 & Switzerland & $\mathrm{CHE}$ & Industrialized Economy & Europe \\
\hline 39 & Guatemala & GTM & Developing Economy & LAC & 92 & Syria & SYR & Developing Economy & MENA \\
\hline 40 & Guinea & GIN & Developing Economy & SSA & 93 & Taiwan & TWN & Emerging Market & Asia \\
\hline 41 & Guinea-Bissau & GNB & Developing Economy & SSA & 94 & Tanzania & TZA & Developing Economy & SSA \\
\hline 42 & Guyana & GUY & Developing Economy & LAC & 95 & Thailand & THA & Emerging Market & Asia \\
\hline 43 & Haiti & HTI & Developing Economy & LAC & 96 & Togo & TGO & Developing Economy & SSA \\
\hline 44 & Honduras & HND & Developing Economy & LAC & 97 & Trinidad and Tobago & тто & Developing Economy & LAC \\
\hline 45 & Hong Kong & HKG & Emerging Market & Asia & 98 & Tunisia & TUN & Developing Economy & MENA \\
\hline 46 & Iceland & ISL & Industrialized Economy & Europe & 99 & Turkey & TUR & Emerging Market & Europe \\
\hline 47 & India & IND & Emerging Market & Asia & 100 & Uganda & UGA & Developing Economy & SSA \\
\hline 48 & Indonesia & IDN & Emerging Market & Asia & 101 & United Kingdom & GBR & Industrialized Economy & Europe \\
\hline 49 & Iran & IRN & Developing Economy & MENA & 102 & United States & USA & Industrialized Economy & NA \\
\hline 50 & Ireland & IRL & Industrialized Economy & Europe & 103 & Uruguay & URY & Developing Economy & LAC \\
\hline 51 & Israel & ISR & Emerging Market & MENA & 104 & Venezuela & VEN & Emerging Market & LAC \\
\hline 52 & Italy & ITA & Industrialized Economy & Europe & 105 & Zambia & $\mathrm{ZMB}$ & Developing Economy & SSA \\
\hline 53 & Ivory Coast & $\mathrm{CIV}$ & Developing Economy & SSA & 106 & Zimbabwe & ZWE & Developing Economy & SSA \\
\hline
\end{tabular}




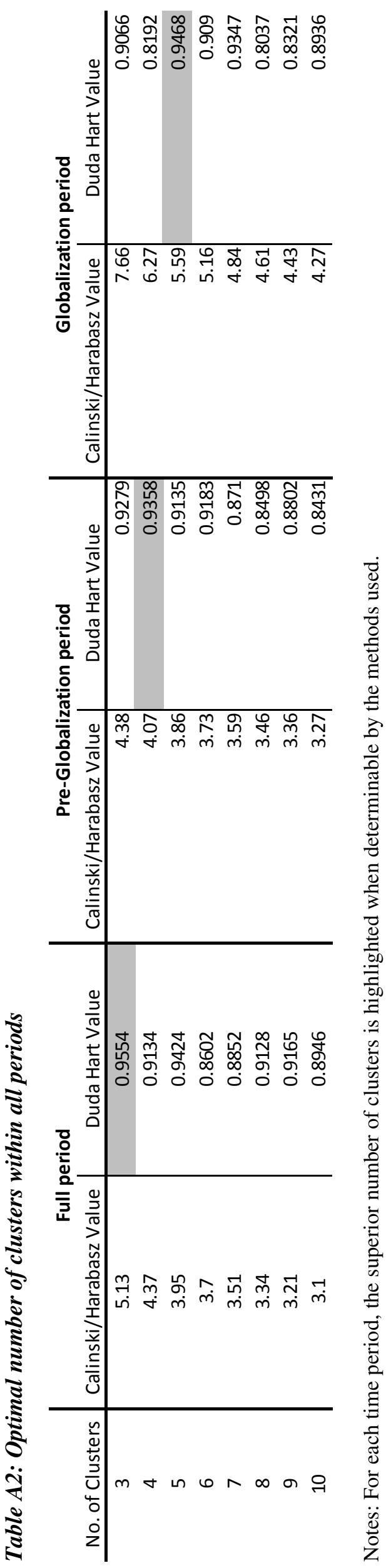




\section{Chapter 5}

\section{Conclusion}

Over the past decade, the European economies have witnessed unprecedented economic and financial turmoil deeply connected with the setup of EMU. Following the inception of the Euro in 1999, the former weak currency countries in Europe's southern periphery attracted large capital inflows that fostered domestic growth and employment, but also led to substantial debt accumulation, real appreciation, and current account deficits. These developments had thus been accompanied by a loss of competitiveness relative to the Central European core countries, which could no longer be adjusted with an exchange rate mechanism. When the global financial and economic crisis hit Europe in 2008/09, the deficit countries were confronted with drastic internal and external demand compressions followed by a sudden stop in capital inflows. Hence, the rapidly increasing recapitalization costs and public deficits, the troubled private sectors and a poor economic outlook all together provoked fears of contagious sovereign bankruptcies that required immediate policy action from both the EU and the ECB. But as Europe was largely unprepared and, above all, unwilling to reverse the Euro project, the GIIPS countries were supposed to undergo the painful path of structural change, internal devaluation, and austerity in exchange for massive financial assistance. As a consequence, the southern periphery suffered from prolonged economic hardship, while the faster recovering core countries struggled with the implications of their solidarity. This antagonism of the 'euro crisis' well reflects an uncomfortable truth shaking the foundations of an ever-closer European integration: The introduction of a common currency in differently developed and suitable sets of countries has not yet resulted in an automatic overall convergence towards an OCA, but rather enabled the emergence and persistence of macroeconomic imbalances in and between such country groups.

On the other hand, the Eastern European periphery did experience a quite similar development over the Euro's first decade, but most of the CEECs have maintained individual currencies throughout the crisis of 2008/09 and partly until today. In fact, the length and depth of the recessions varied substantially across the CEECs but did evolve very differently from the southern periphery. However, as no country resigned from the Euro, but conversely, all remaining EU member states are still obliged to enter the EA sooner or later, the persistence of 
the core-periphery pattern of macroeconomic developments will most likely continue to impair the smooth functioning of EMU.

The present dissertation aimed at highlighting such group-dynamic con- and divergences among European economies based on macroeconomic parameters in order to enable groupspecific and national policy advice. To this end, the research articles of Chapters 2 to 4 use diverse statistical and econometric methods as well as variables suitable for assessing the functioning of a monetary union. Chapter 2 follows a multivariate framework using the MIP scoreboard of indicators to cluster European economies in terms of external balances, competitiveness, indebtedness, and economic performance. The country group pattern of European business cycles based on univariate output gap series is assessed in Chapter 3. And, finally, Chapter 4 looks at multivariate European business cycles in a worldwide country sample that allows for disentangling the European co-movements from those at a global level.

While each of the articles thereby provides a distinct contribution to the economic literature, the three approaches are related in a sense that they all address a limitation of empirical assessments, namely the arbitrary ex-ante definition of country groups. For example, the vast literature assessing the relation of the European core and periphery typically either assigns each country to these groups beforehand or affiliates the member states according to their synchronicities with an ex-ante chosen reference group or country. Similarly, the literature on international business cycles applies large-scale dynamic factor models, in which the groupspecific factors are common to a set of ex-ante classified countries that do not necessarily exhibit commonalities in their time series. Nonetheless, providing empirical evidence of the country groups present in the data should be the basis, when deriving conclusions about groupspecific developments. By doing so, Chapters 2 to 4 show that there indeed exist deviations between the data-based group compositions and those that have been previously assumed. Hence, the research contributions are meant to enhance our understanding of the con- and divergences of individual countries and whole groups.

The main findings can be summarized as follows. Overall, macroeconomic developments within Europe are subject to several group-dynamic homogeneities roughly referring to a Central European core, a Southern European periphery, an Eastern European periphery, and eventually a Northern European periphery, depending on the indicators used. These borders are, however, neither static nor clear-cut. On the one hand, many of the countries should not be seen as absolute members of any singular country group, but rather exhibiting a relative degree of 
similarity with all clusters. By applying fuzzy clustering approaches, some countries indeed cluster together very closely, whereas others fall right between the groups. On the other hand, as the characteristic macroeconomic features change with time, so does the relative assignment of individual countries and the composition of groups. While parts of the southern periphery, for instance, followed a distinct path already before the crisis of 2008/09 and even more so thereafter, parts of the eastern periphery began to converge towards the relatively persistent core cluster. As a consequence, in some specifications, countries like Italy or particular CEECs cannot be attributed clearly to their geographic groups but rather show a relatively high degree of belongingness to both groups, if not approaching the core cluster. Moreover, by using different business cycle data and including a global set of countries, the fourth Chapter suggests the existence of an 'Anglo-Saxon' business cycle cluster comprising countries at the geographic Northern European periphery as opposed to the remaining Southern and Central European economies.

What can be concluded from these group dynamics? The highlighted heterogeneity or even divergence of core and peripheral countries certainly is an explosive charge for the future EMU, which may be hard or, as some say, impossible to defuse without (re)establishing individual or group-specific European currencies. This is because the economic needs of a particular subgroup cannot be addressed by a common monetary policy so that a high degree of homogeneity among all Euro countries remains a prerequisite for a 'one size fits all' monetary union. Similarly, if the participating countries' private and public indebtedness and the way that credits are spent (e.g., in housing markets) substantially differ between the groups, this can induce problems of financial stability. One possible solution to the diverse macroeconomic developments the analysis has shown is the introduction of several currency areas corresponding to the identified country clusters. Within each of the peripheral groups and the core, a separate monetary policy would be able to affect all countries equally well. For example, while the southern periphery may indeed require low interest rates and a weaker currency, the opposite would suite many core countries. However, as the group assignments are to some degree dynamic and the switching costs supposedly immense, this appears not to be a feasible way either politically or economically.

If, on the other hand, all countries are to stay committed to the Euro, achieving macroeconomic homogeneity over the medium and long-run will come at high economic costs and imply transitory divergence of many relevant parameters, at least for the southern peripheral Euro countries. Because, in that case, the GIIPS countries have to mitigate the discrepancies in 
competitiveness and indebtedness by internal devaluation of prices and wages, deleveraging from the high debt burden, and structural change of the economy and institutions. These adjustments, however, have so far been accompanied by sharp output compression and high unemployment rates, resulting in the observed diverging pattern after the crisis of 2008/09. Moreover, real exchange rates would have to evolve in the opposite direction in the core and southern periphery for quite some time, as the latter group would have to reverse its significant real appreciation over the Euro's first decade. If, for instance, inflation rates should thereby remain positive and average at the envisaged two percent, this would require the core countries to inflate more and the periphery to inflate less than that. Obviously, such a scenario is not what the core countries would appreciate, but nonetheless point to the need of enhancing economic policy coordination within EMU. Many of the reforms undertaken in this direction, however, imply a highly controversial closer political integration and even a 'transfer union,' which might over the long run bring along greater economic homogeneity, but at the cost of general agreement with the EU. Ultimately, it is thus not only the economic convergence but also the European social and political cohesion that will determine the future of EMU.

Some conclusions can be drawn for individual countries, too. Despite the widespread negative attitude towards supra-national politics that came to light in the recent Italian elections, the country exhibits a high degree of similarly with the core countries, at least with regard to cyclical factors and compared to the other GIIPS. This would not speak in favor of leaving the EA or even the EU for supposedly inappropriate polices. In line with the literature, on the side of the CEECs, Hungary is the closest to the core group both in terms of the MIP indicators as well as business cycle synchronization, suggesting that membership in the EA would be less costly than for other CEECs. The same is true for the EA-outs or EU-outs Denmark, Sweden, the UK, and Switzerland, which would generally fit well into the Euro-suitable core group of countries, even though there is certainly more involved in the membership decision. That said, it is remarkable, on the other hand, that these countries have so far been the most skeptical against the Euro or the EU. As such negative attitudes have resulted in the apparently irreversible 'Brexit' decision, in fact, none of these countries appear ready to review their reluctance in the near future. Interestingly, this is somehow supported by the third Chapter finding a northern periphery in terms of business cycle fluctuations, which appears quite contrary to the first articles but based on different indicators and a much longer time horizon. For Ireland, having been a member of both the GIIPS and the Anglo-Saxon business cycle 
cluster, but recently experiencing an impressive idiosyncratic growth performance, implies problems with the appropriateness of the ECB monetary policy.

Overall, the dissertation has shown that the EU is far from what may be judged as a homogenous European economy needed for a single currency. It remains to be seen whether and how the convergence of income levels among the Southern, Eastern, and Central European euro countries can be achieved without undermining the stability and efficiency of the common monetary union. Empirical research can make use of the approaches employed in this dissertation to update the progress that has been made and the adjustments to work on. 


\section{Promotionsstudiengang "Wirtschaftswissenschaften" \\ Versicherung bei Zulassung zur Promotionsprüfung}

Ich versichere,

1. dass ich die eingereichte Dissertation "Convergence or Divergence in the EMU?" selbstständig angefertigt habe und nicht die Hilfe Dritter in einer dem Prüfungsrecht und wissenschaftlicher Redlichkeit widersprechenden Weise in Anspruch genommen habe,

2. dass ich das Prüfungsrecht einschließlich der wissenschaftlichen Redlichkeit - hierzu gehört die strikte Beachtung des Zitiergebots, so dass die Übernahme fremden Gedankenguts in der Dissertation deutlich gekennzeichnet ist - beachtet habe,

3. dass beim vorliegenden Promotionsverfahren kein Vermittler gegen Entgelt eingeschaltet worden ist sowie im Zusammenhang mit dem Promotionsverfahren und seiner Vorbereitung

- $\quad$ kein Entgelt gezahlt oder entgeltgleiche Leistungen erbracht worden sind

- $\quad$ keine Dienste unentgeltlich in Anspruch genommen wurden, die dem Sinn und Zweck eines Prüfungsverfahrens widersprechen

4. dass ich eine entsprechende Promotion nicht anderweitig beantragt und hierbei die eingereichte Dissertation oder Teile daraus vorgelegt habe.

Mir ist bekannt, dass Unwahrheiten hinsichtlich der vorstehenden Versicherung die Zulassung zur Promotionsprüfung ausschließen und im Falle eines späteren Bekanntwerdens die Promotionsprüfung für ungültig erklärt werden oder der Doktorgrad aberkannt werden kann.

Datum

Unterschrift 